\title{
The Use of Ureates as Activators for Samarium Diiodide
}

\author{
Chriss E. McDonald*, Jeremy D. Ramsey, Christopher C. McAtee, Joseph R. Mauck, Erin M. Hale, and Justin A. Cumens
}

Department of Chemistry, Lycoming College, 700 College Place, Williamsport, PA 17701, United States

\section{Contents}

S2-S71 ${ }^{1} \mathrm{H}-\mathrm{NMR}$ and ${ }^{13} \mathrm{C}-\mathrm{NMR}$ Spectra of 6a-f, 7a-C, 8a,8b, 8d-I, 9a-I, 10-13 
Jin.

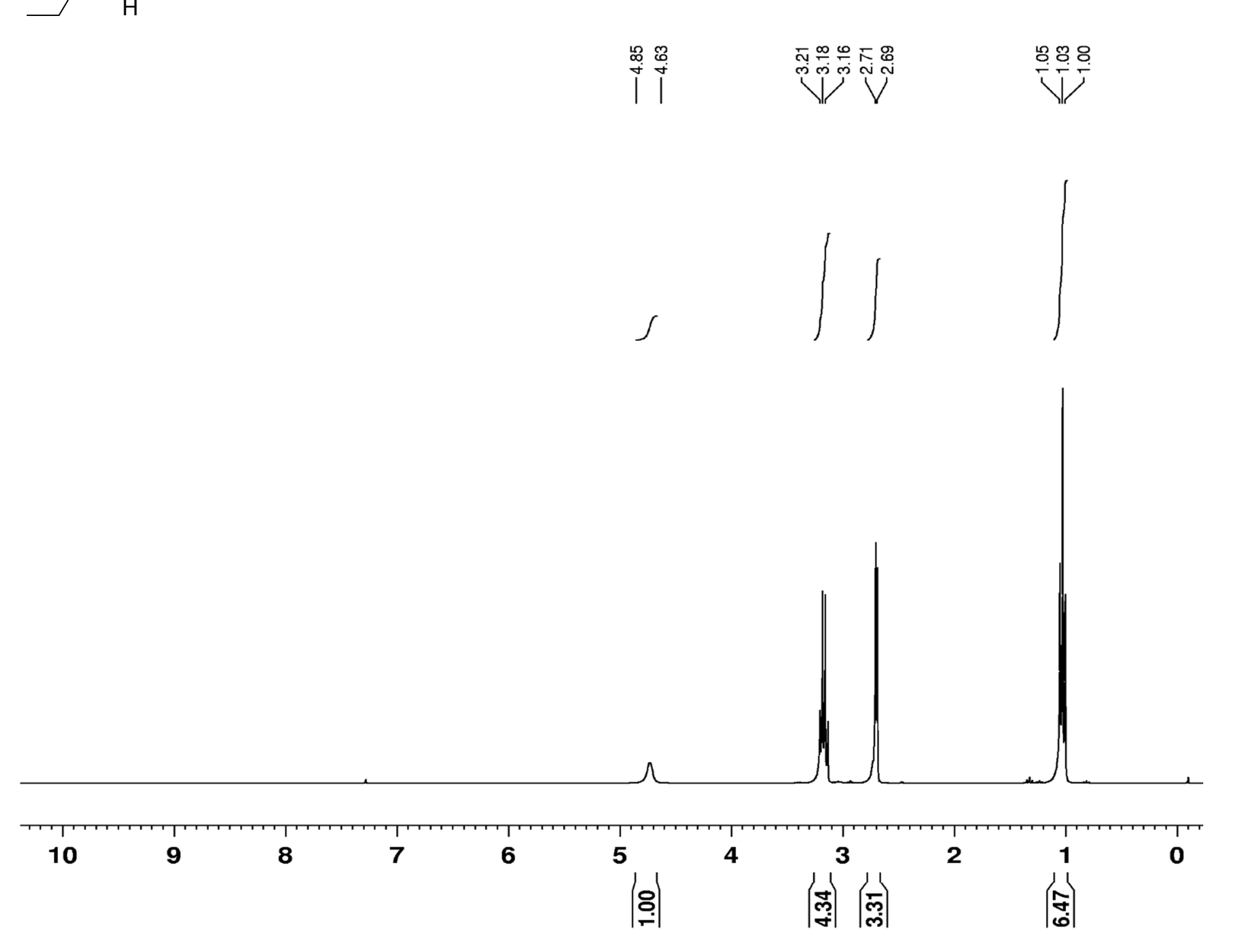


$\overbrace{\mathrm{H}}^{\mathrm{O}} \mathrm{N}_{\mathrm{H}}^{\prime} 6 \mathrm{a}$

|

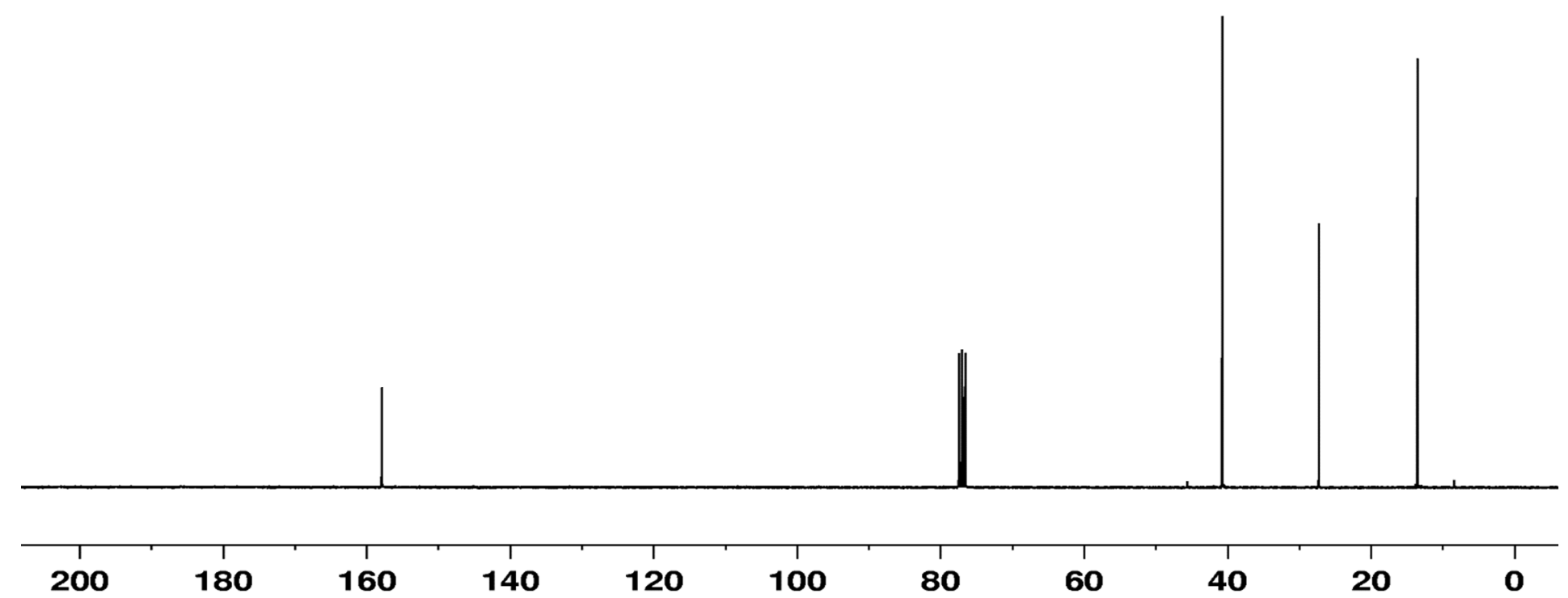


$\mathrm{C}_{\mathrm{H}}^{\mathrm{O}} \overbrace{6 b}$

|
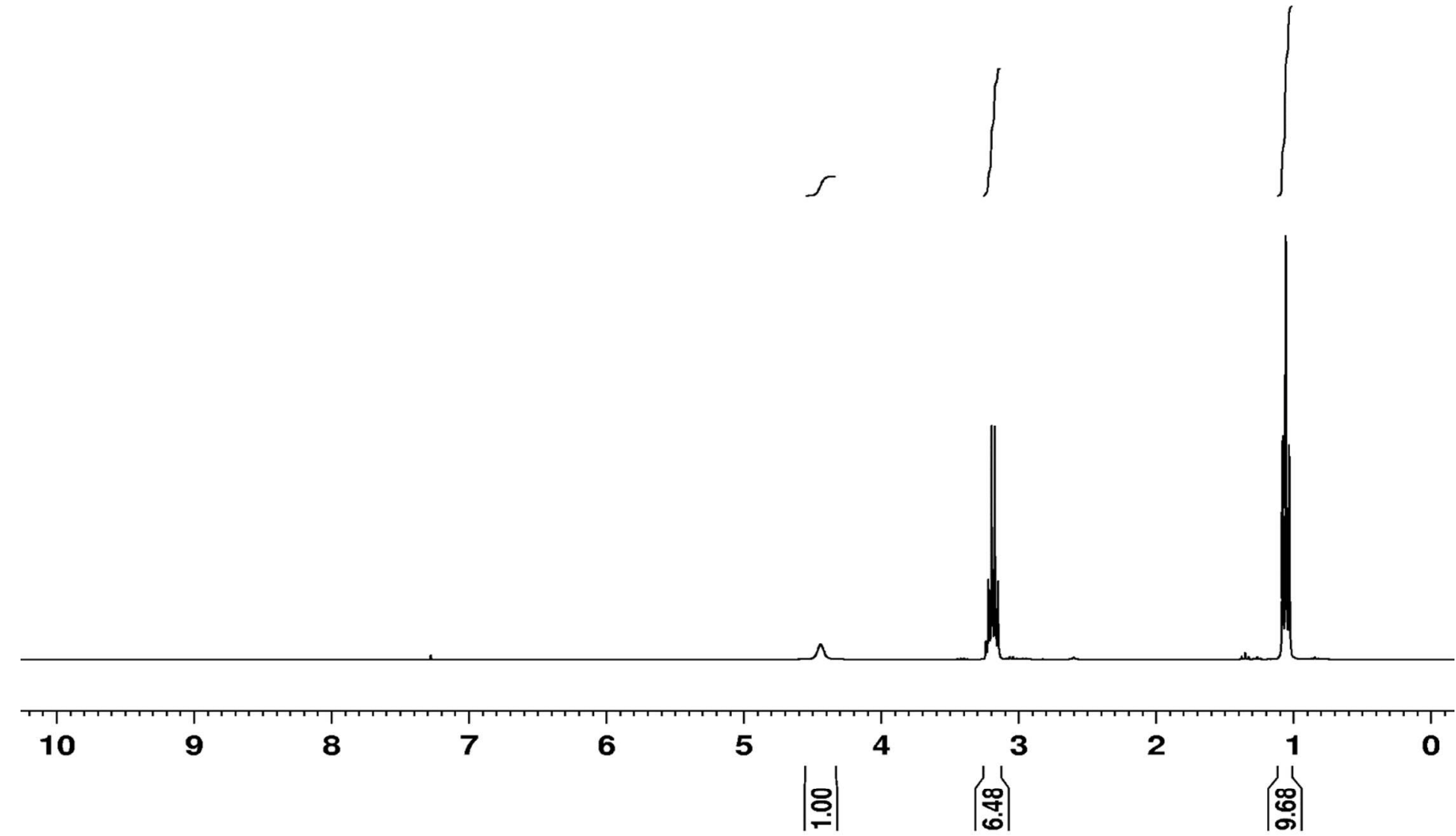
$\mathrm{N}_{\mathrm{H}}^{\mathrm{O}} \overbrace{6 b}$

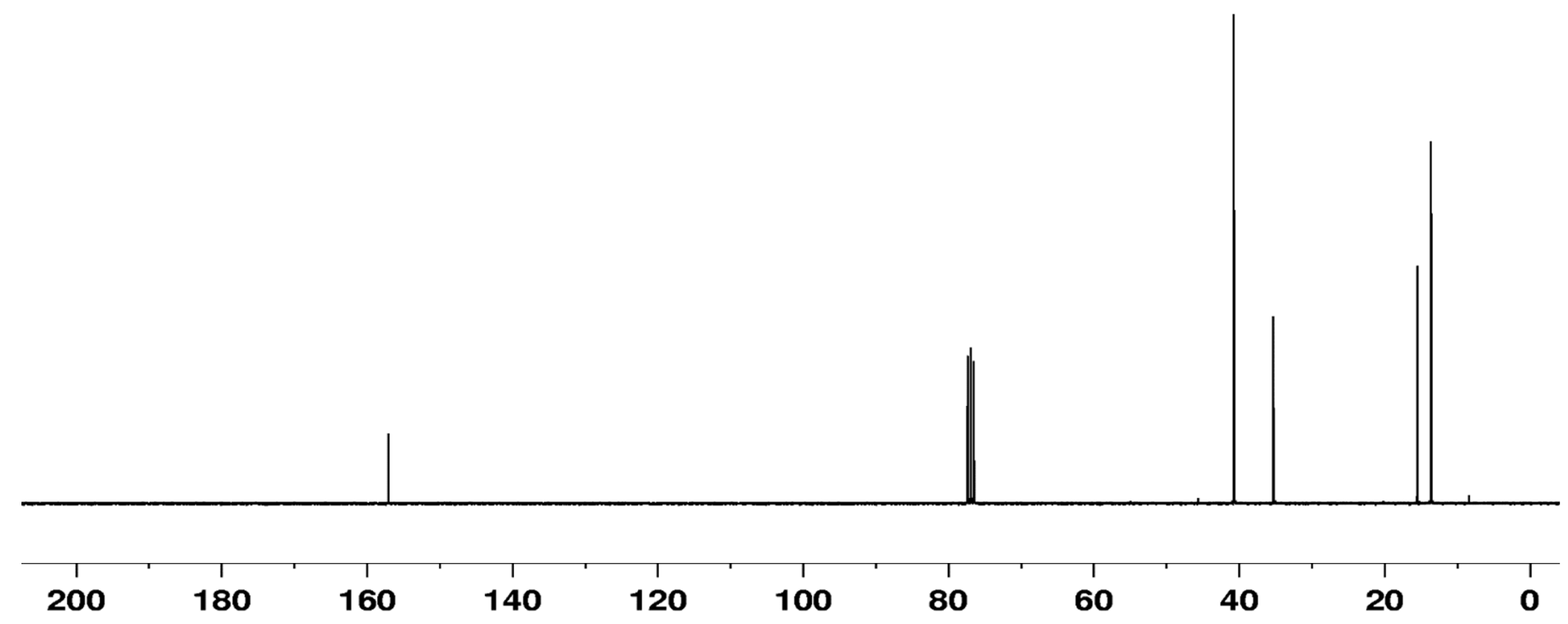




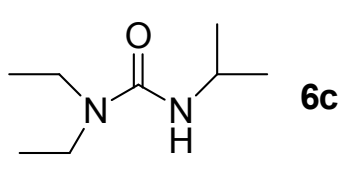

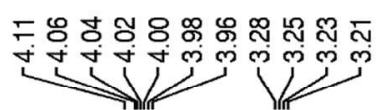

뜬 느늗

它
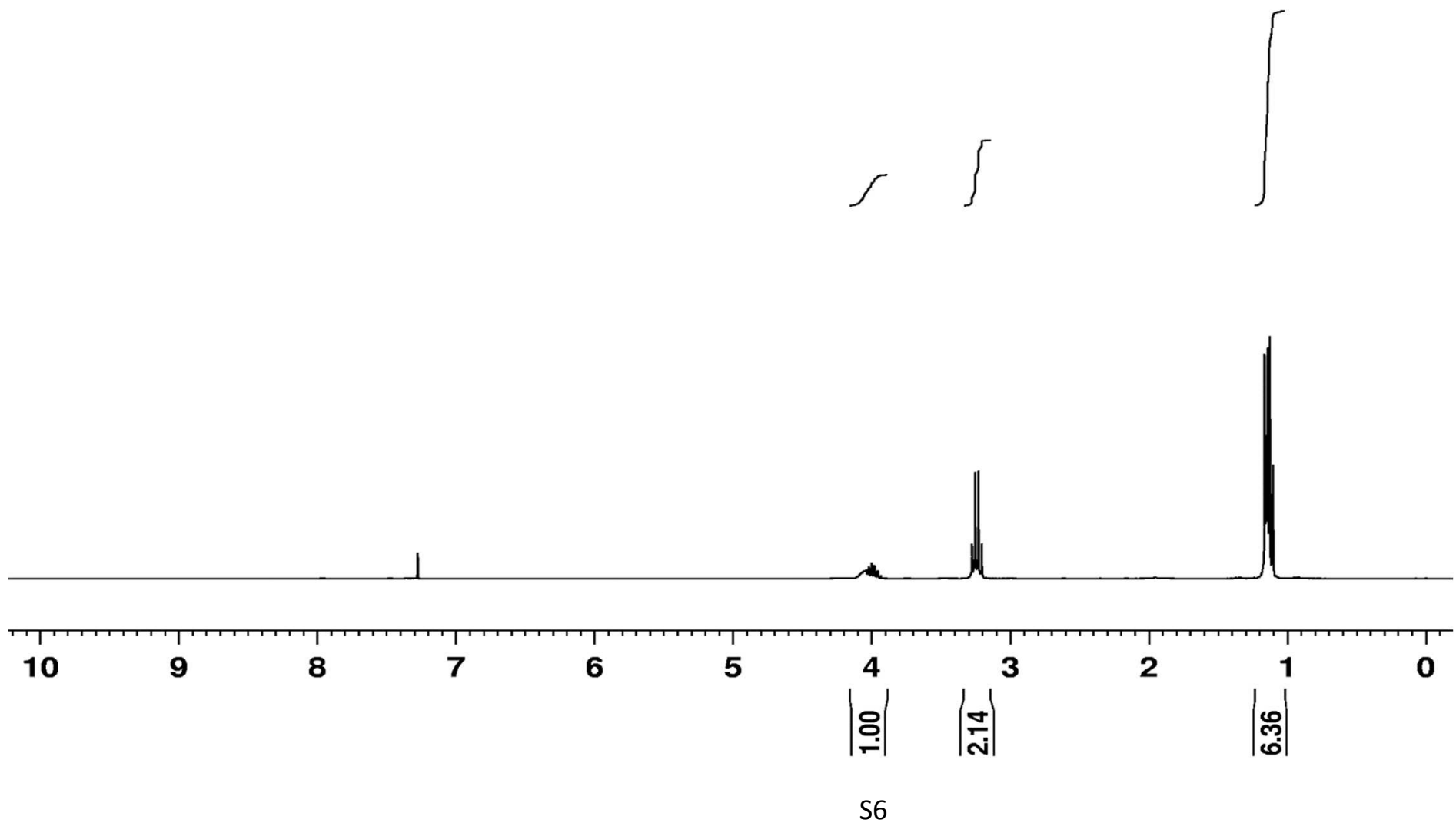
$\mathrm{N}_{\mathrm{H}} \mathrm{Nc}_{\mathrm{H}}$
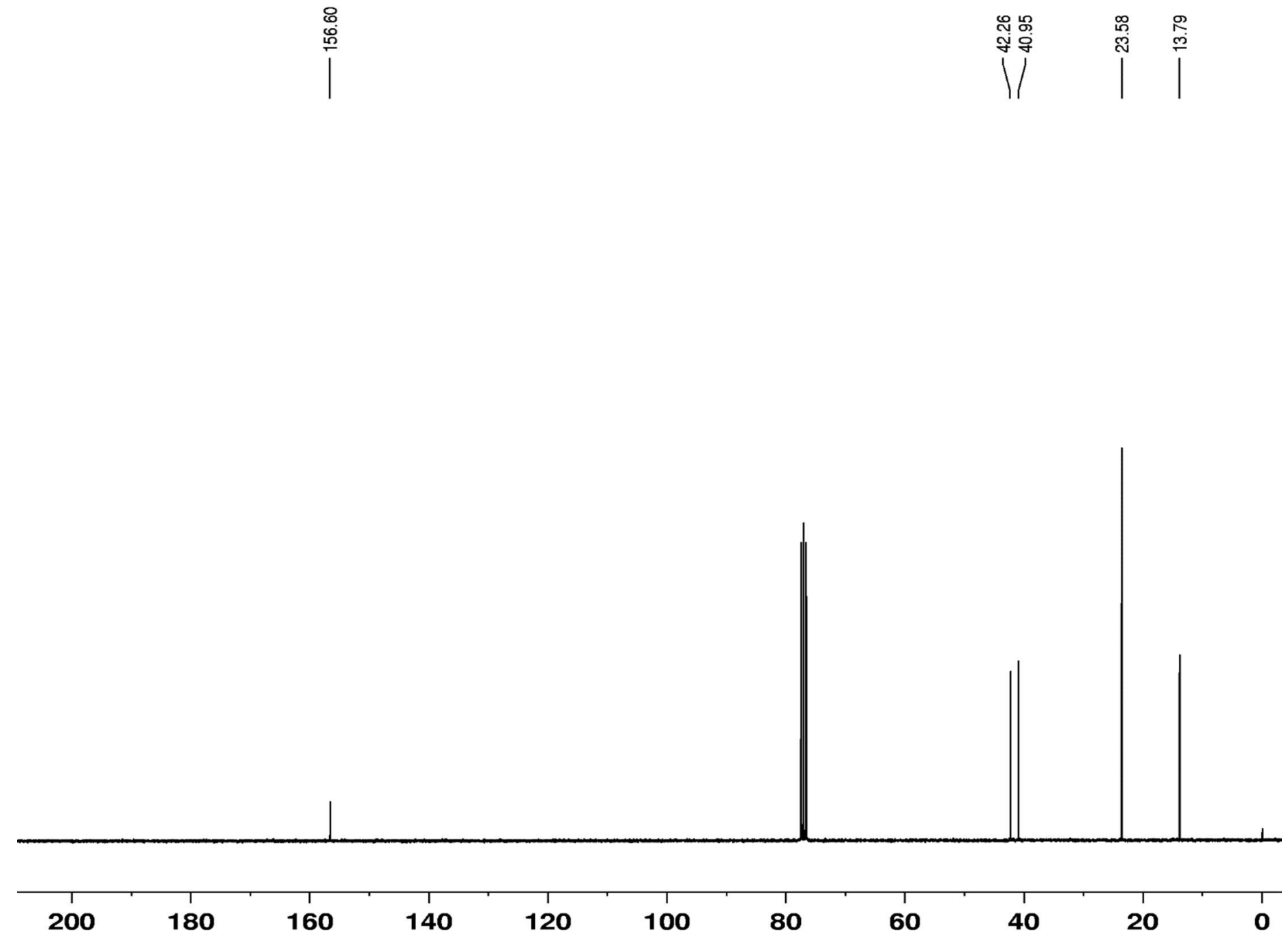


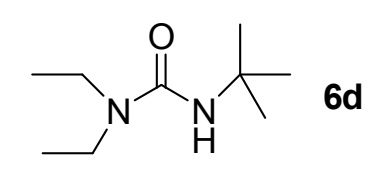

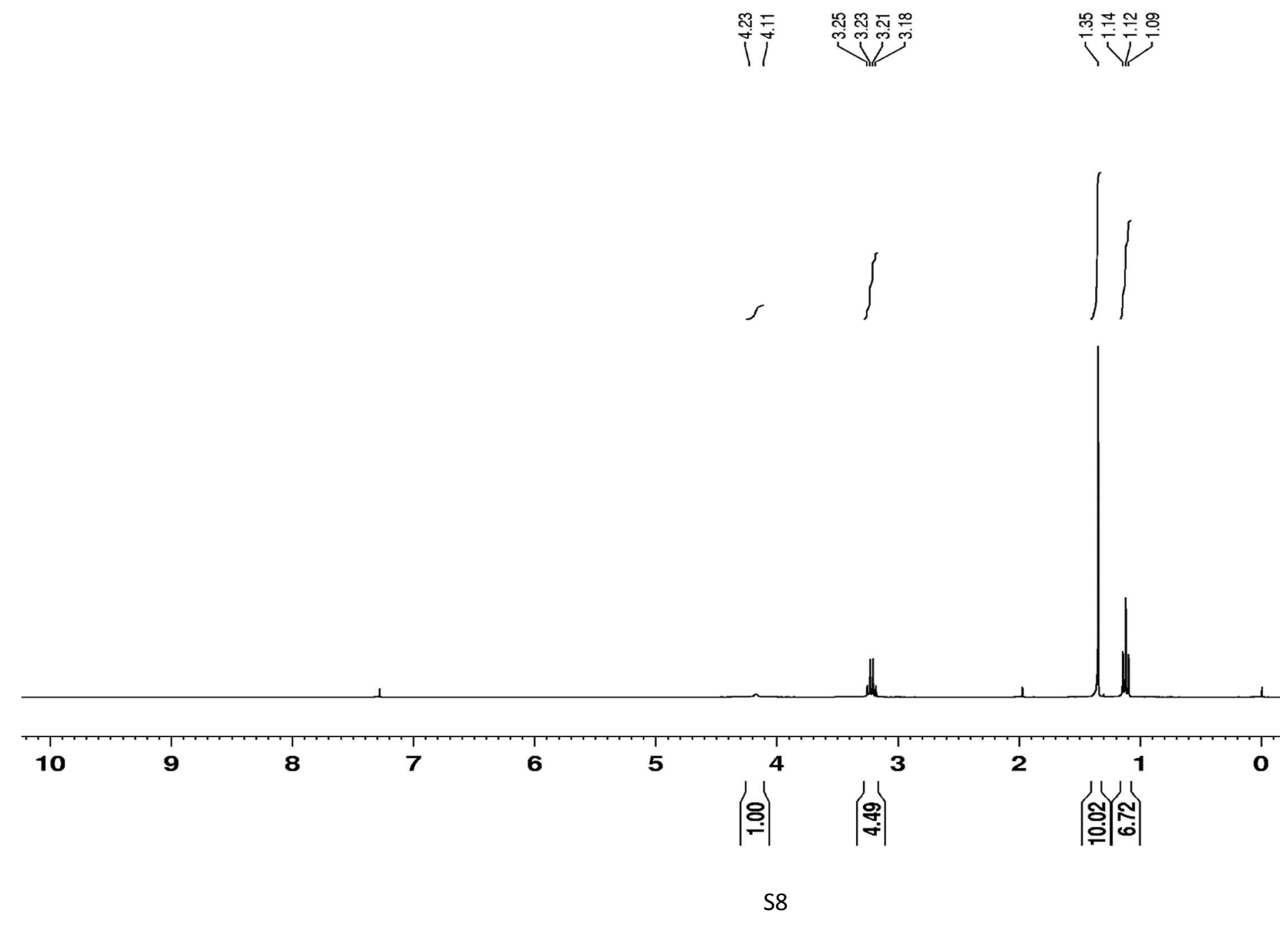


$\mathrm{C}_{\mathrm{H}} \mathrm{H}_{6 \mathrm{~d}}$

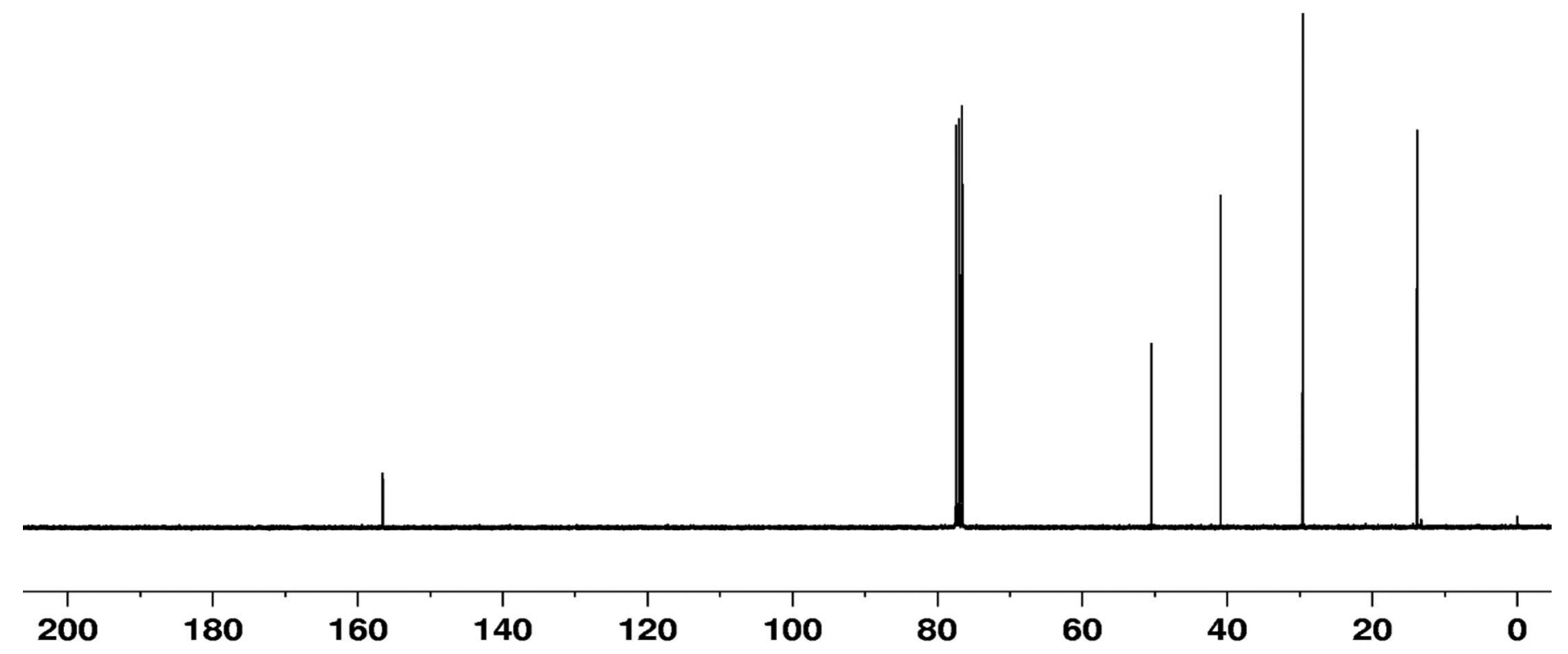




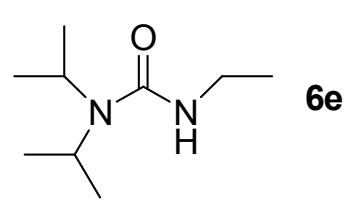

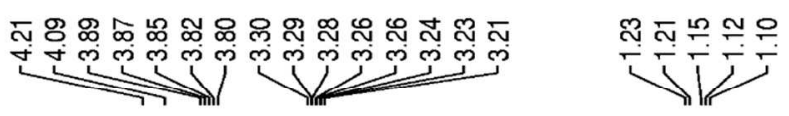
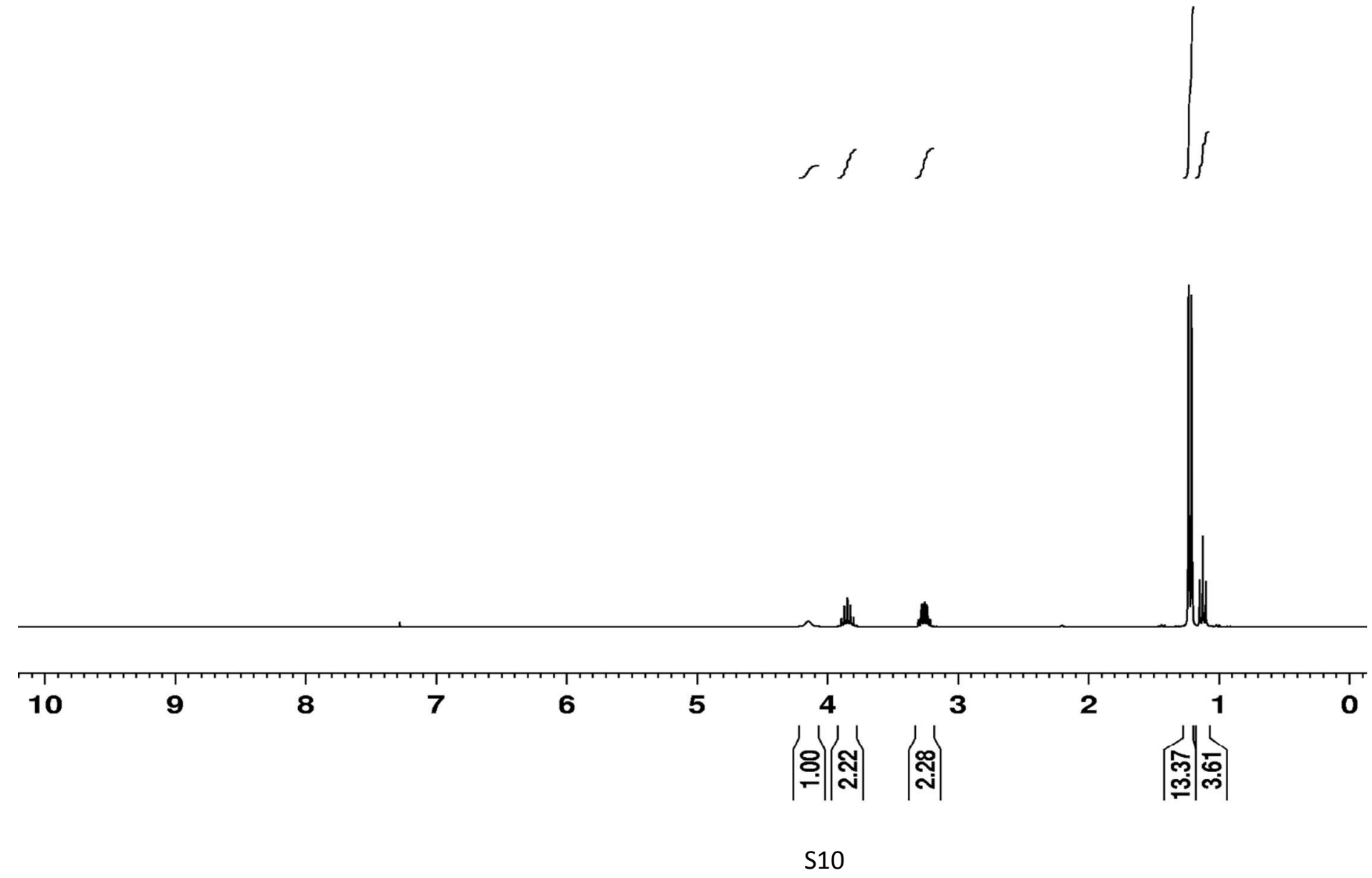

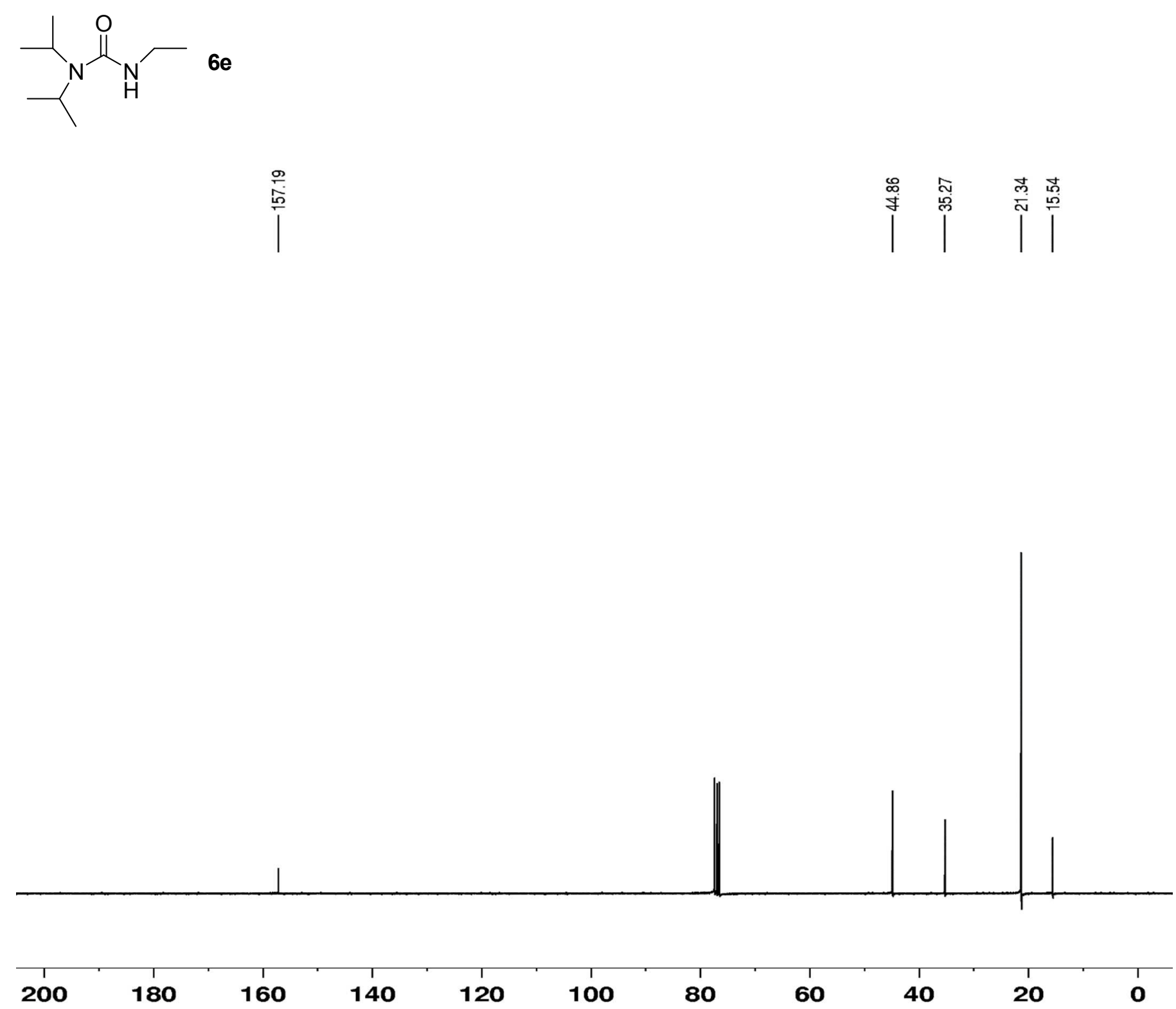
$\mathrm{C}_{\mathrm{H}}^{\mathrm{O}} \mathrm{H}^{-1}$
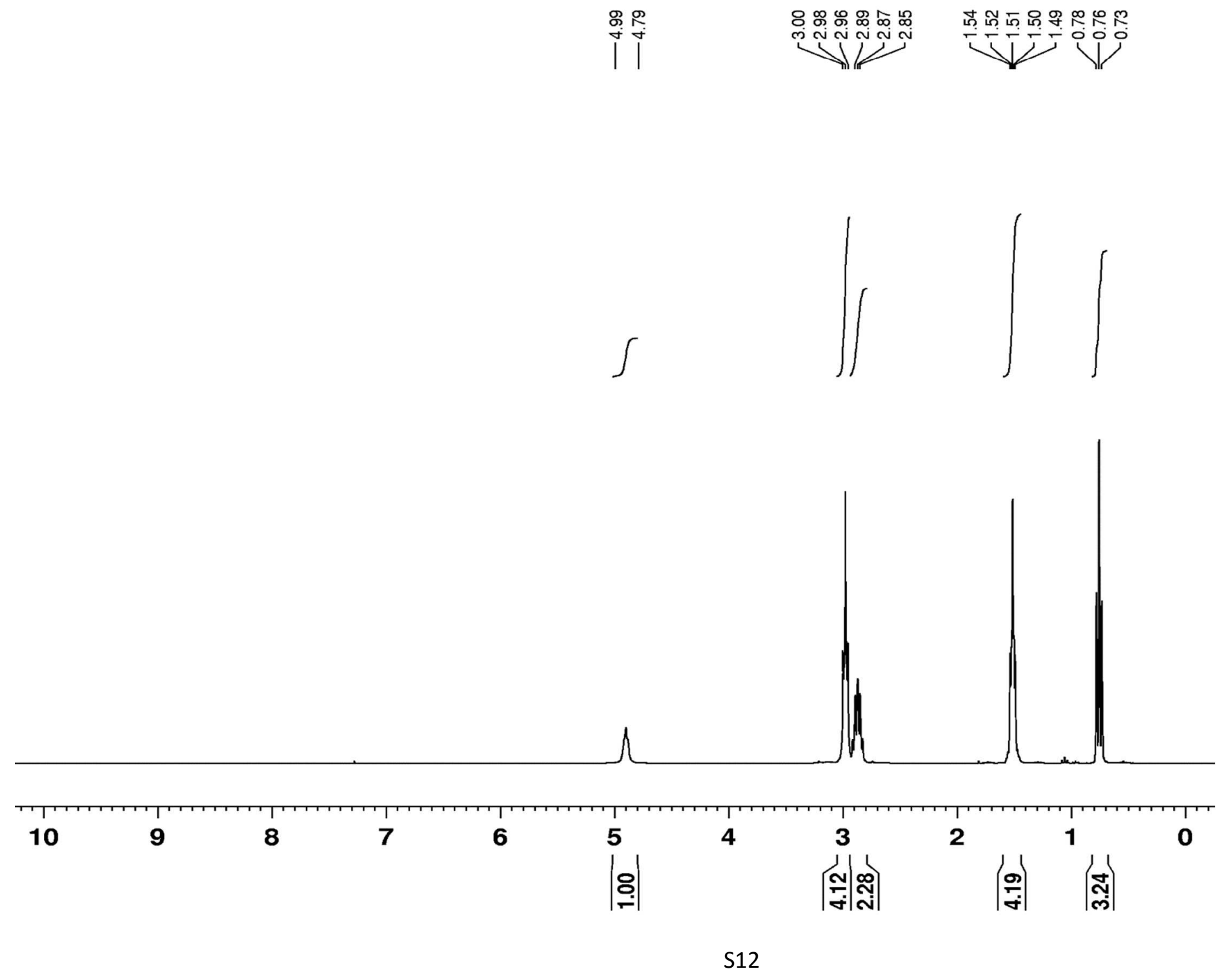
$\mathrm{C}_{\mathrm{H}}^{\mathrm{O}}{ }^{\mathrm{O}}$

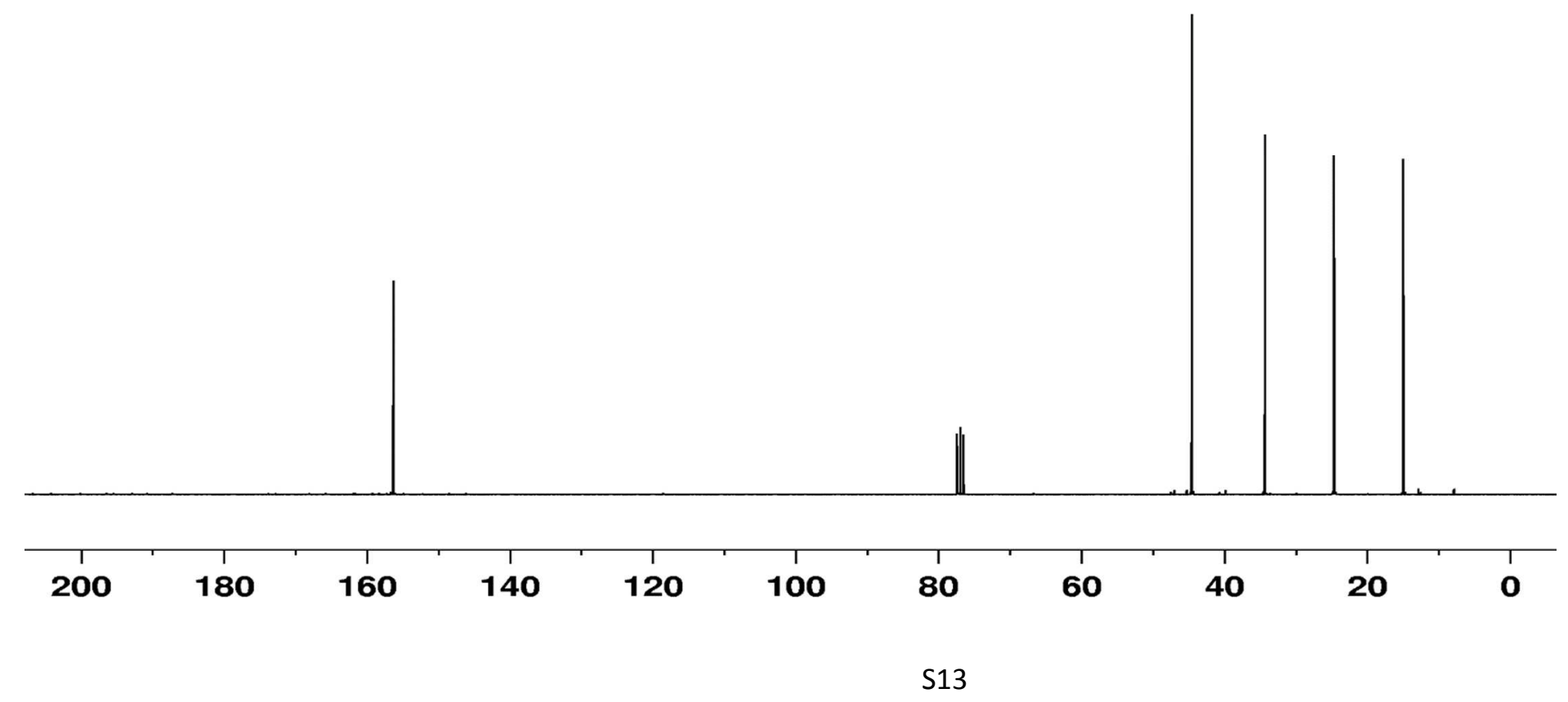



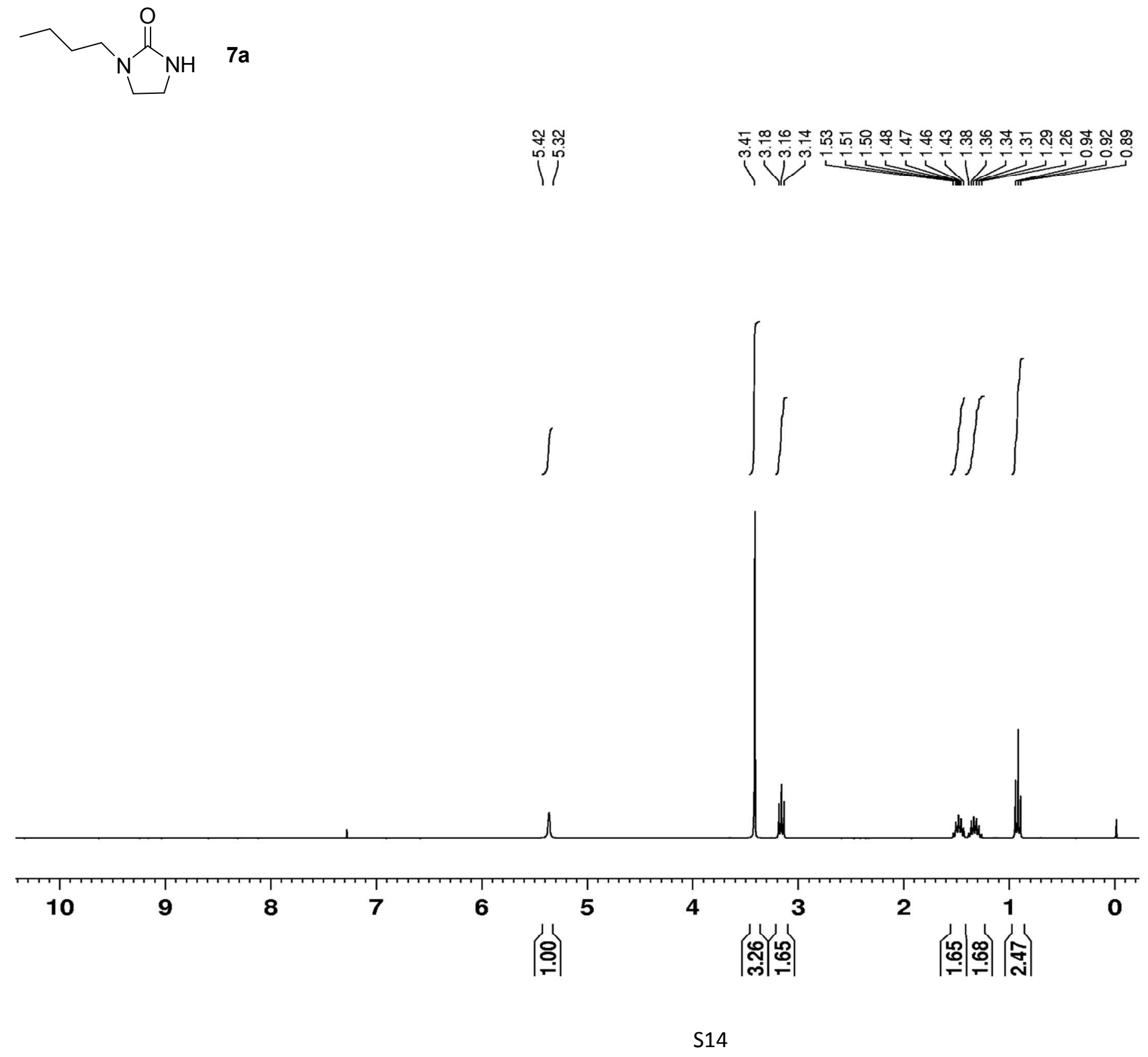
$\overbrace{\mathrm{NH}}^{\mathrm{O}} 7 \mathrm{a}$
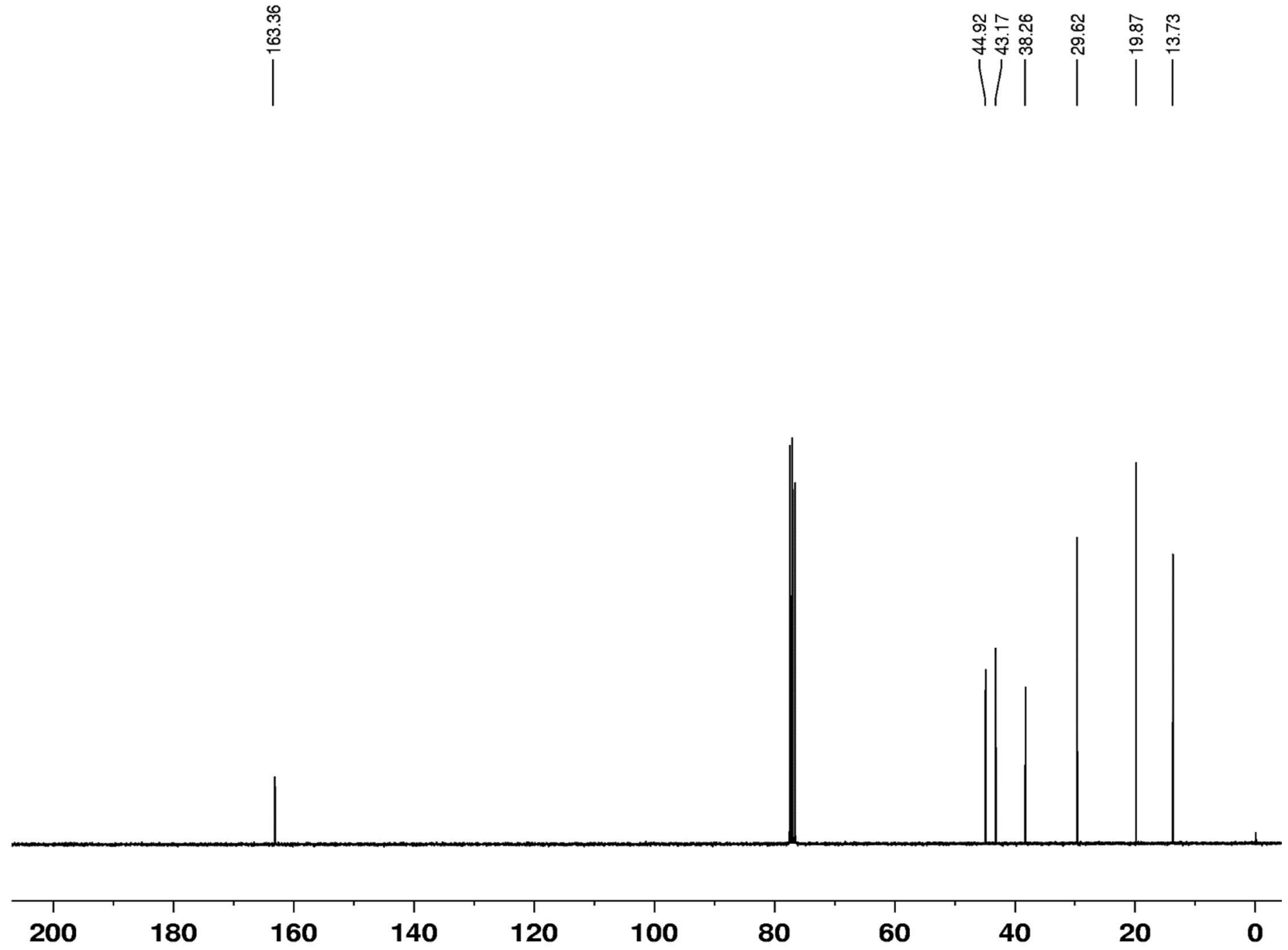


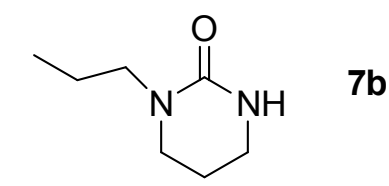

$\left.\right|^{\infty}$

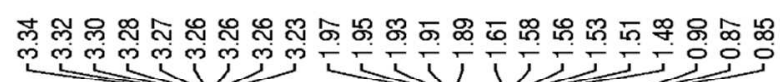
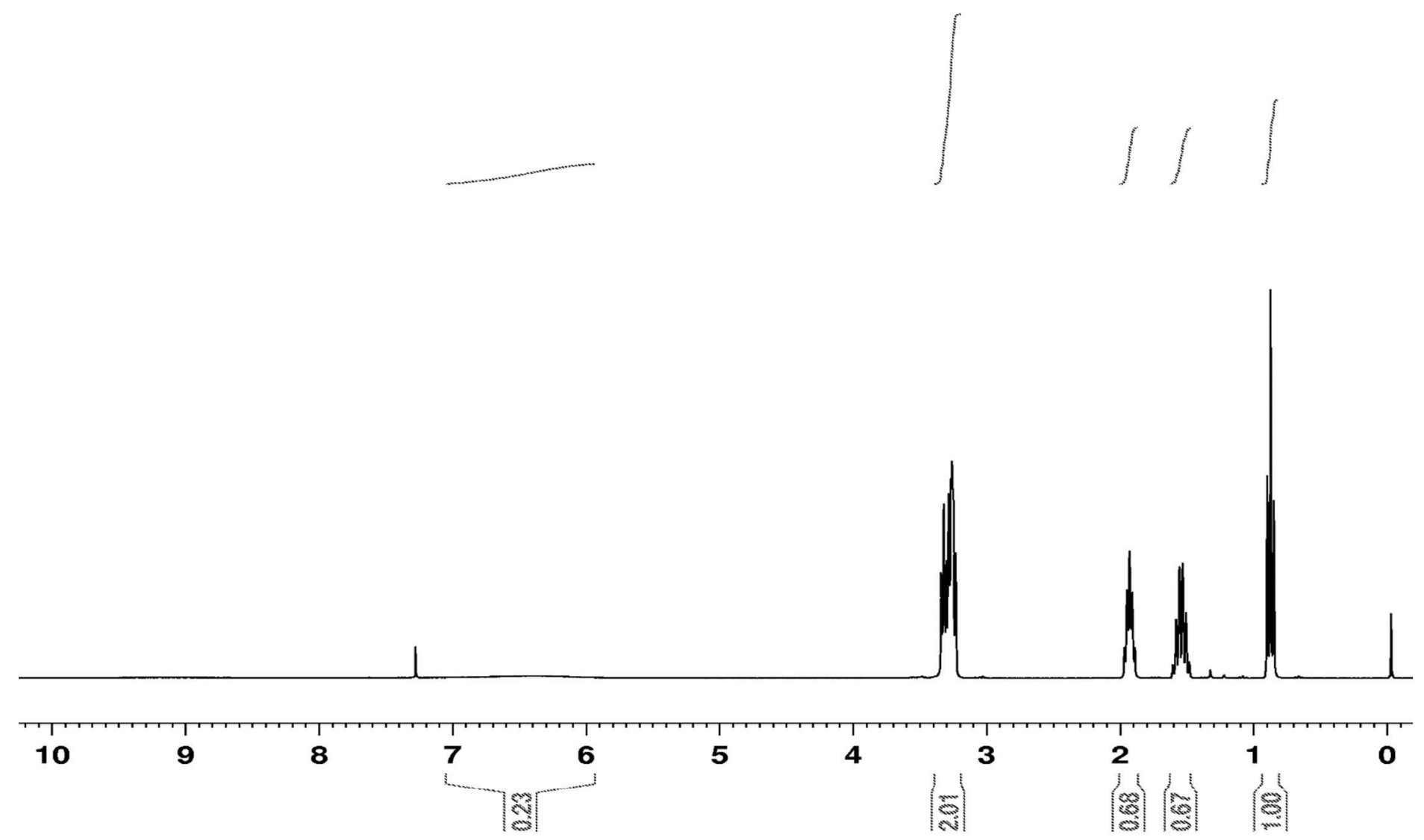
$\sim_{N}^{\mathrm{O}}{ }^{\mathrm{O}}$

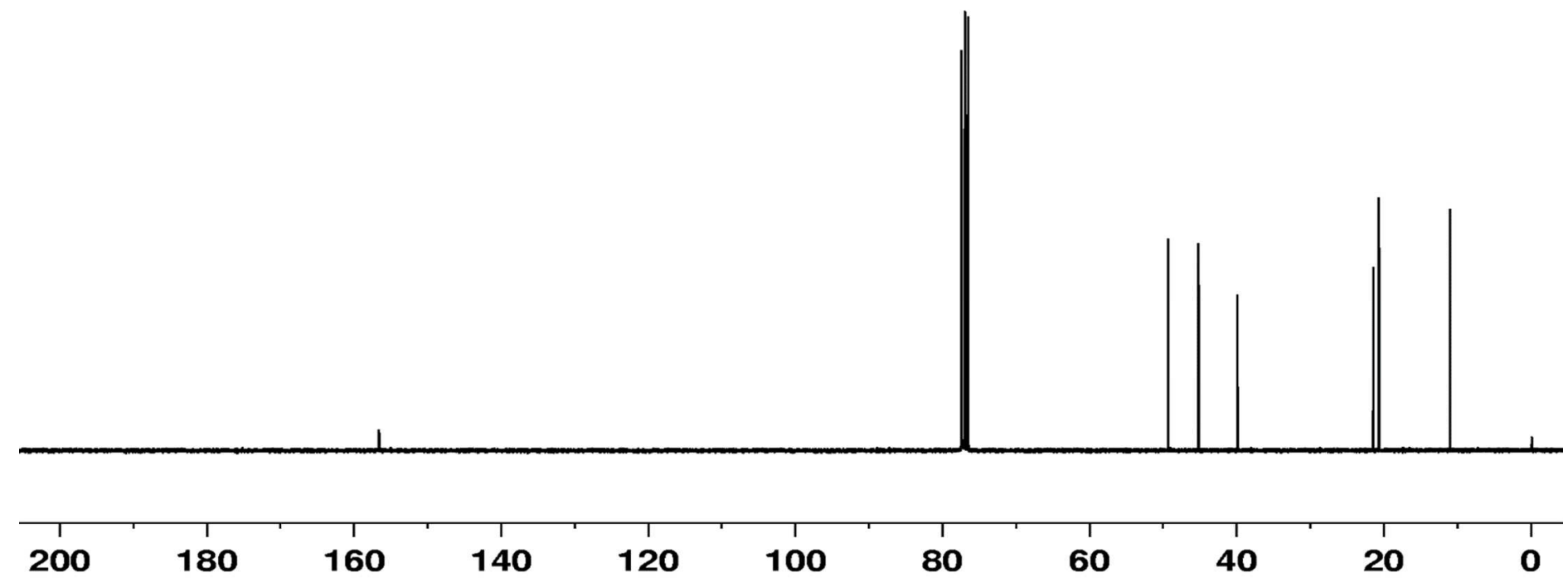


$\mathrm{C}_{\mathrm{NH}}^{\mathrm{O}} 7 \mathrm{c}$

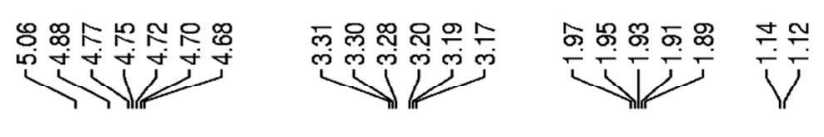

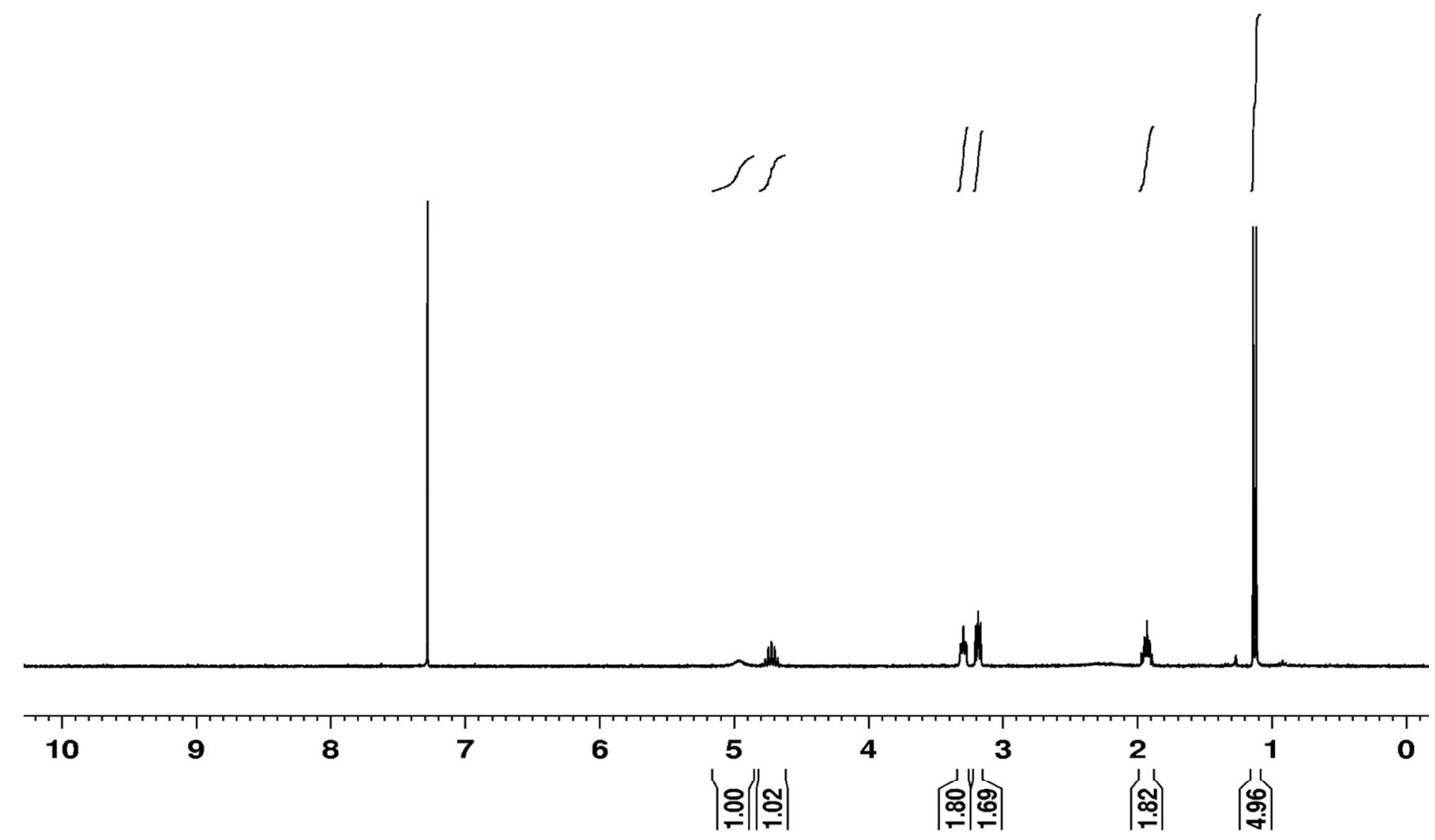




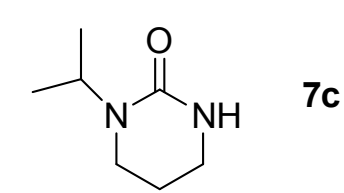

$$
\left.\right|_{\substack{5 \\ 0}} ^{\substack{0 \\ 0}}
$$

$\mid$

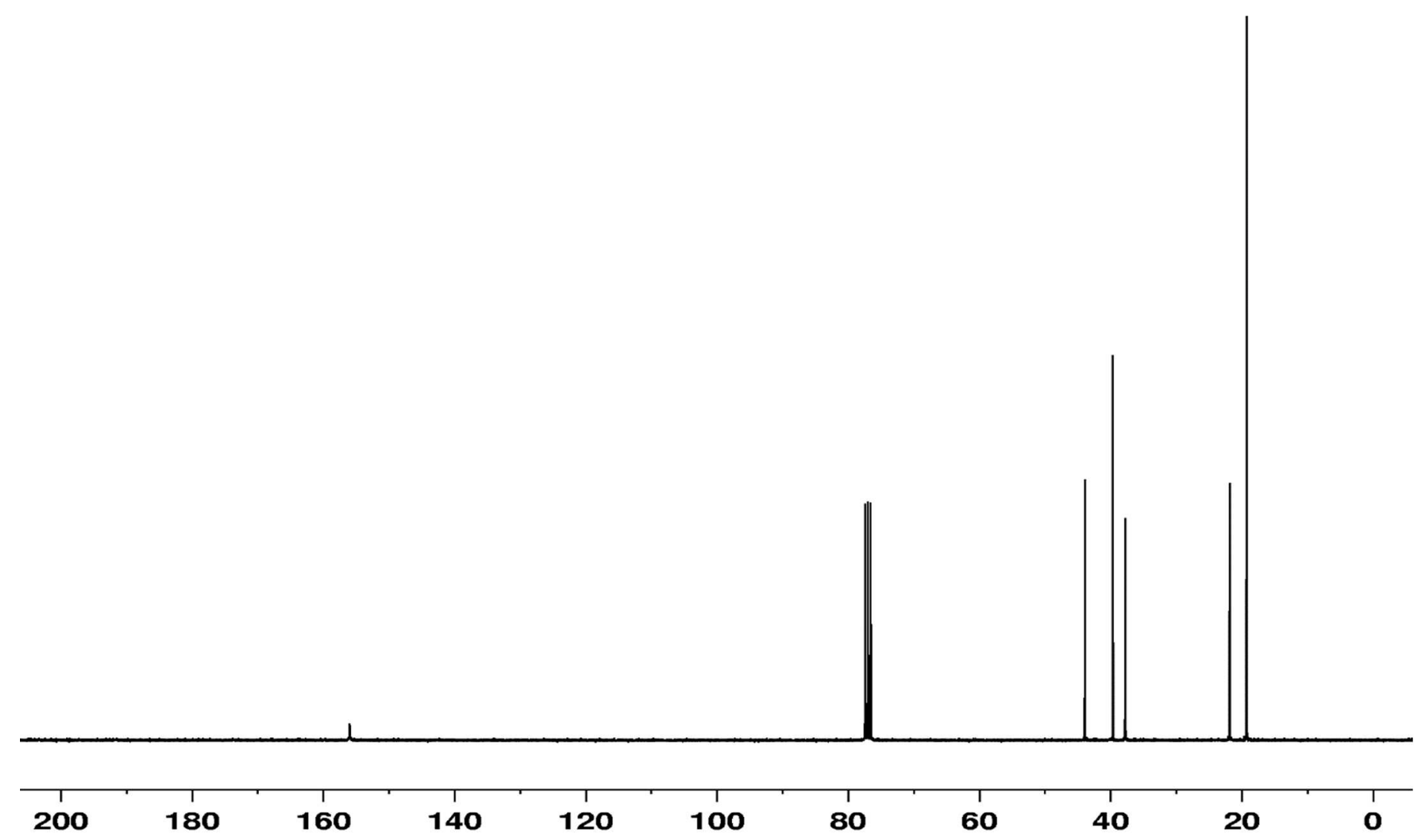




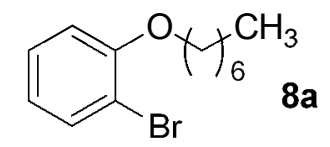

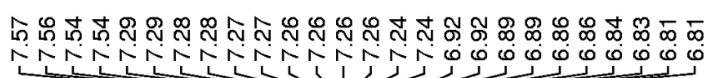

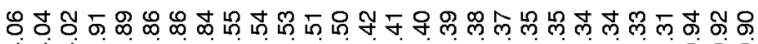
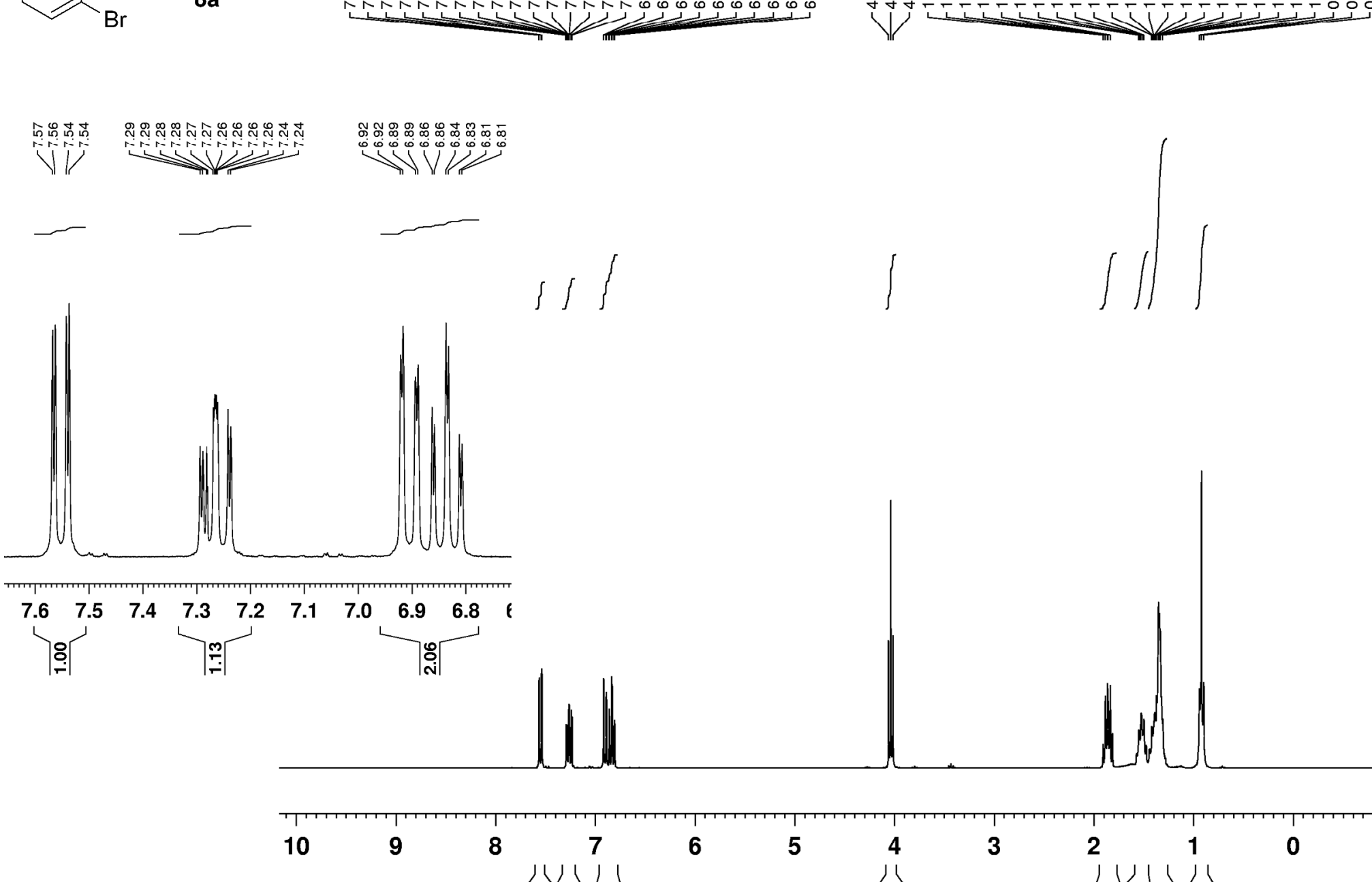

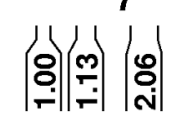
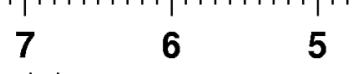

4

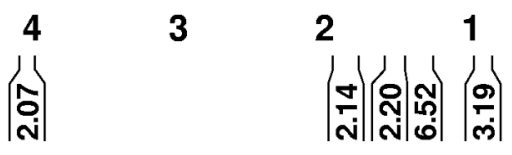


$\overbrace{\mathrm{Br}}^{\mathrm{O}_{4} \mathrm{CH}_{6} \mathrm{CH}_{3}}$
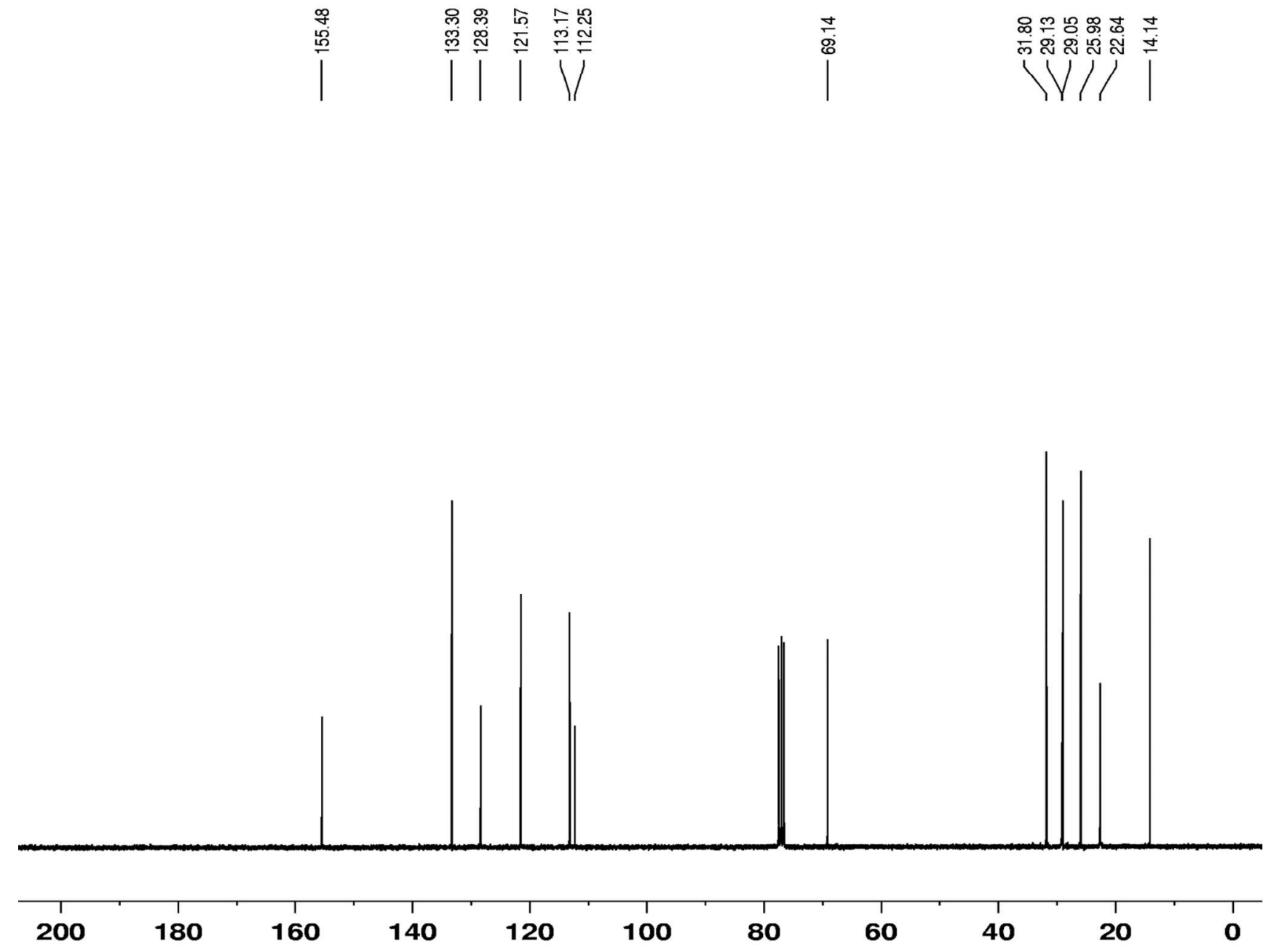
$\overbrace{\mathrm{H}}^{\mathrm{Br}}$

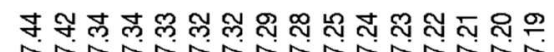

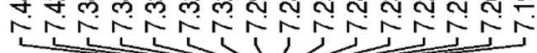

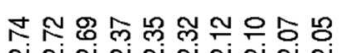

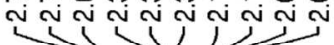

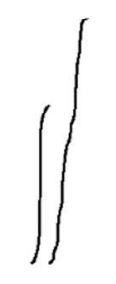

I If

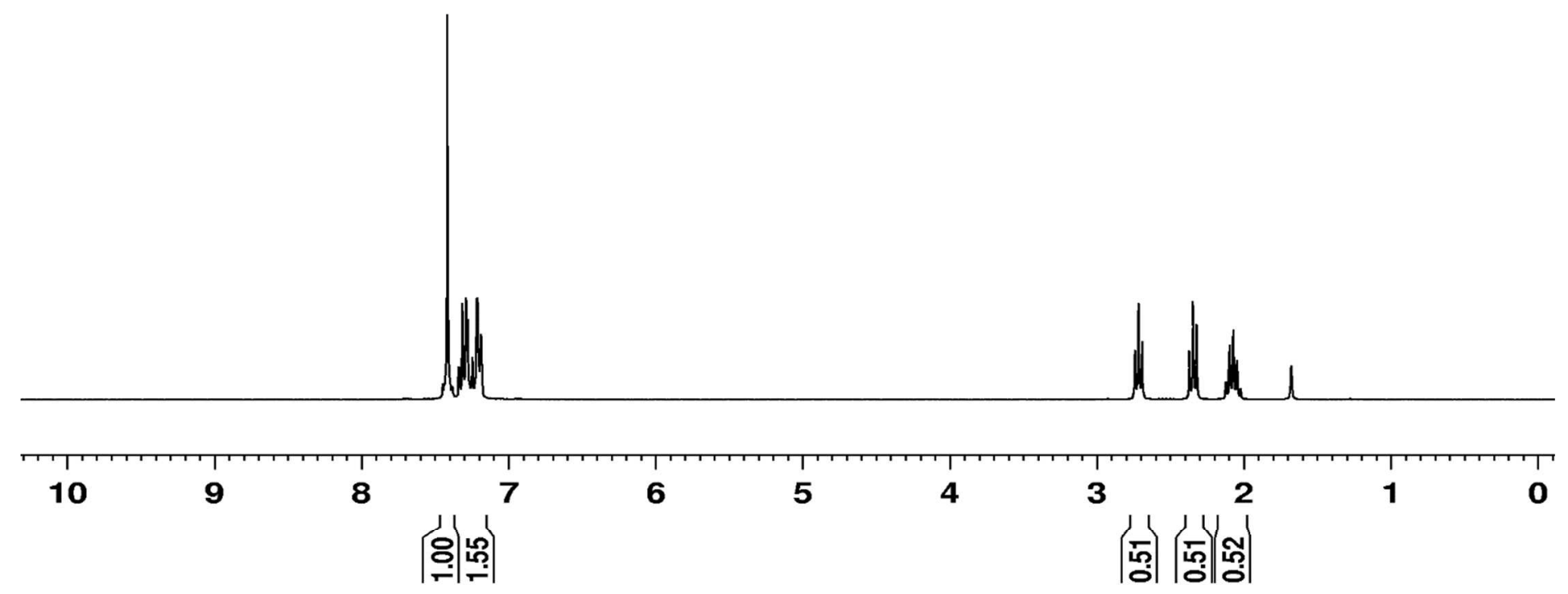


$\overbrace{\mathrm{H}}^{\mathrm{Br}}{ }_{\mathrm{H}}^{\mathrm{Ph}}{ }^{\mathrm{O}}$
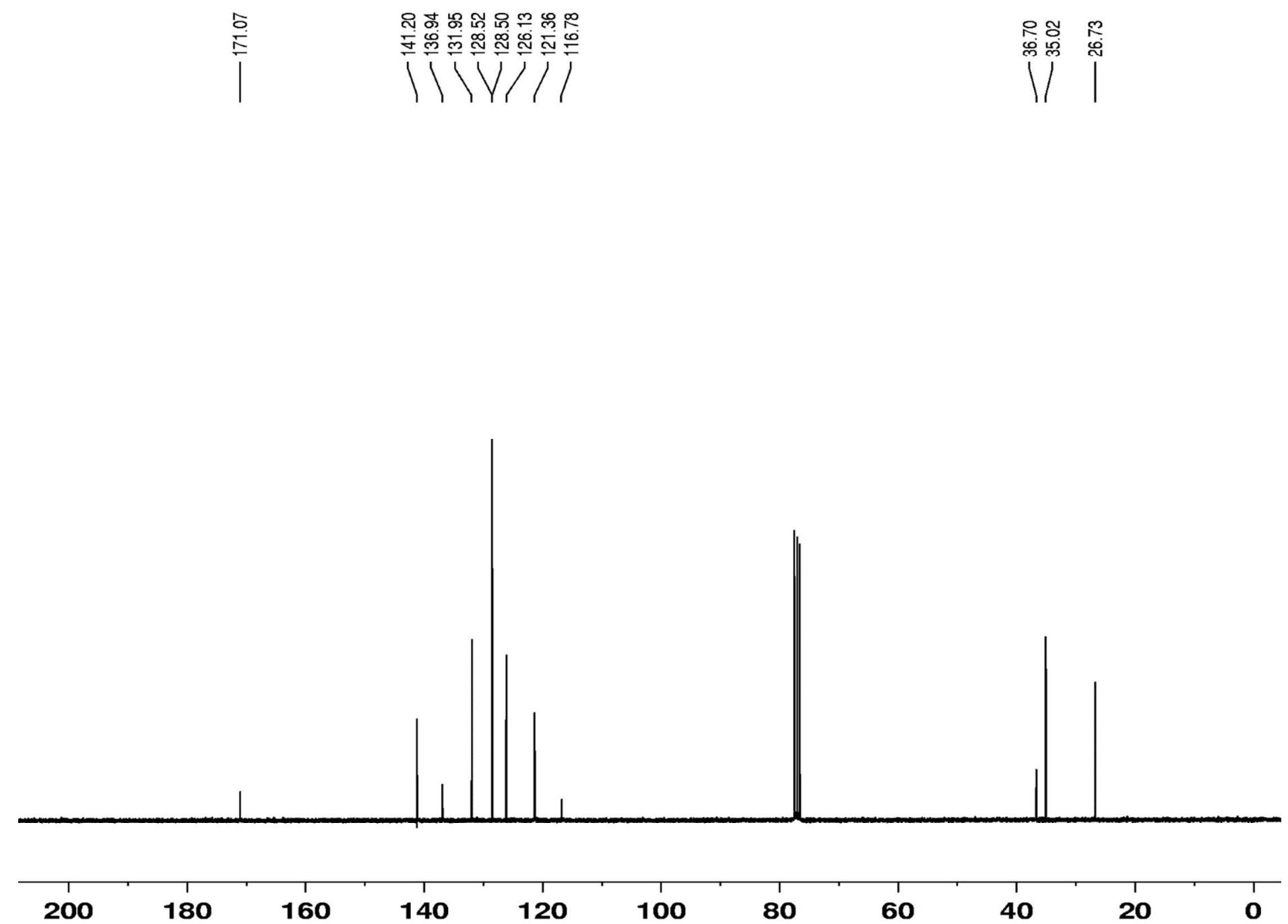


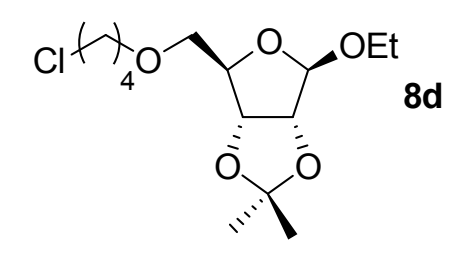

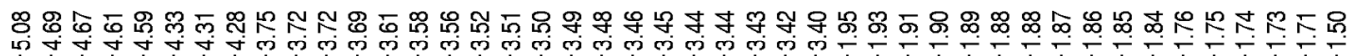

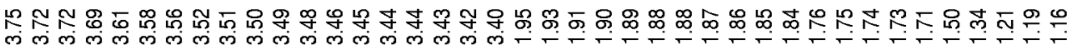

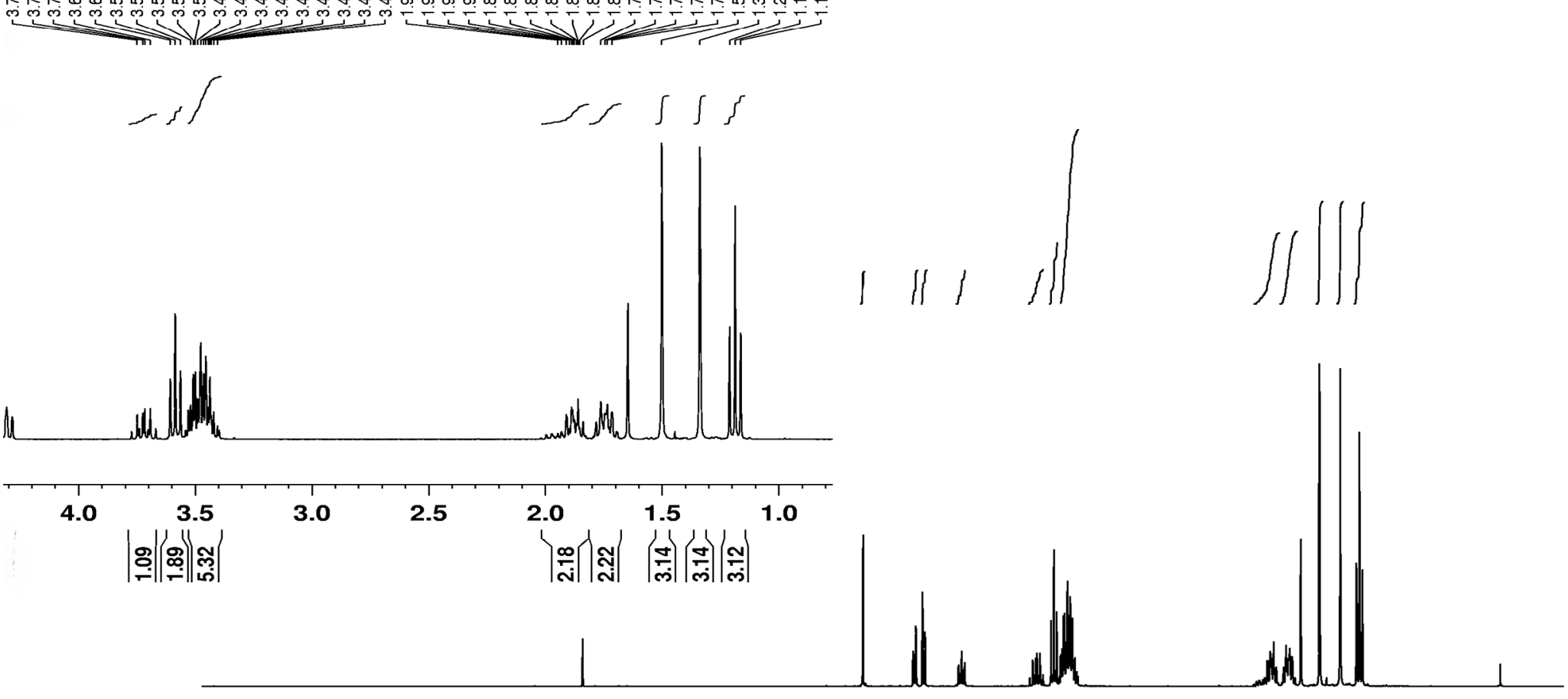

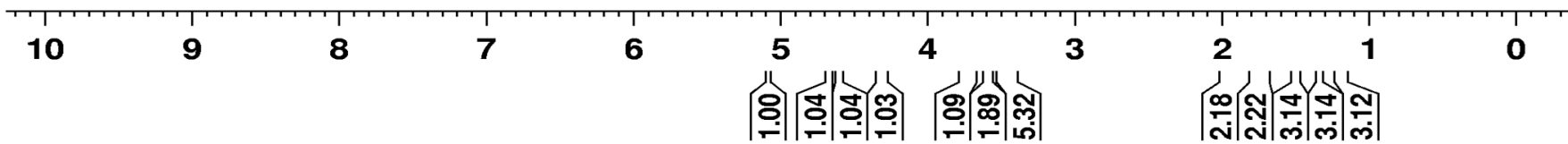



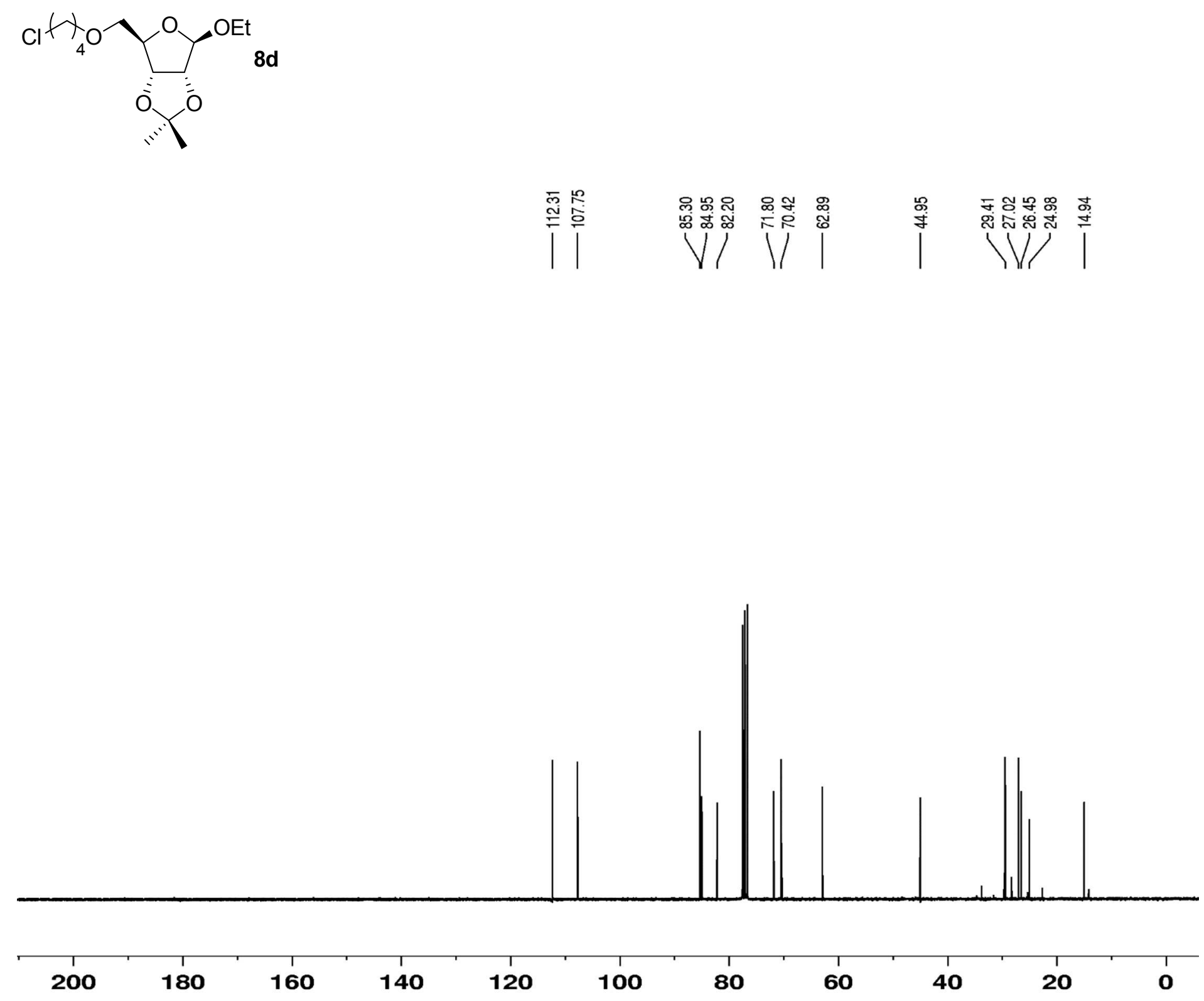
8e

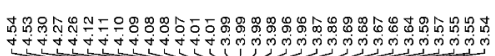

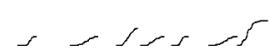

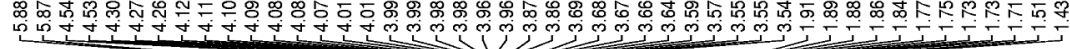

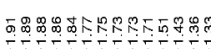

wiviti

$\cos \int^{5}$

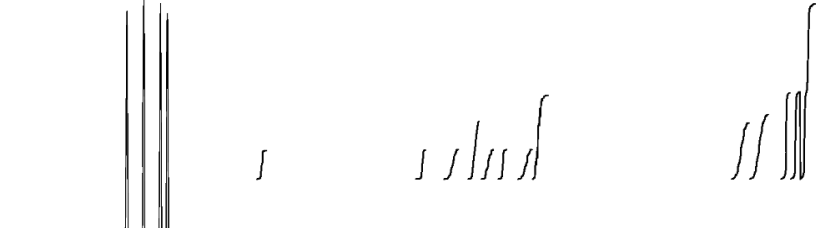

ind

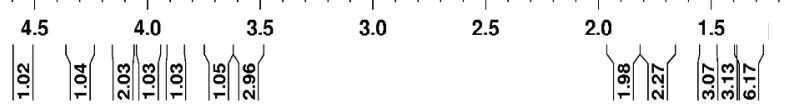

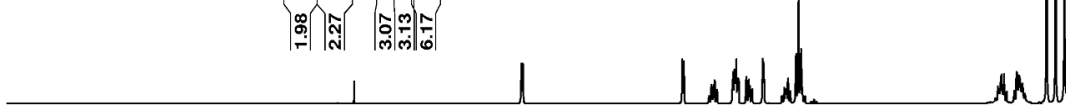

$10 \quad 9$

8

(우임

5 4

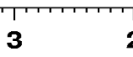

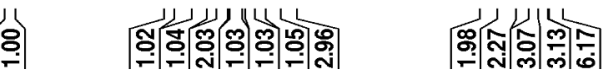




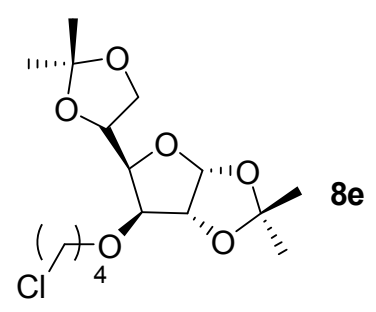

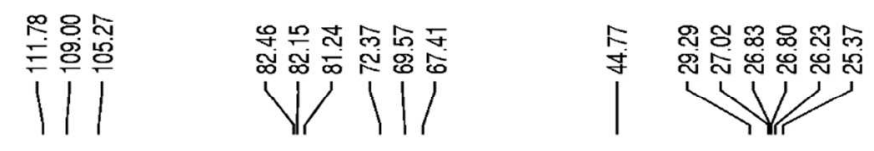

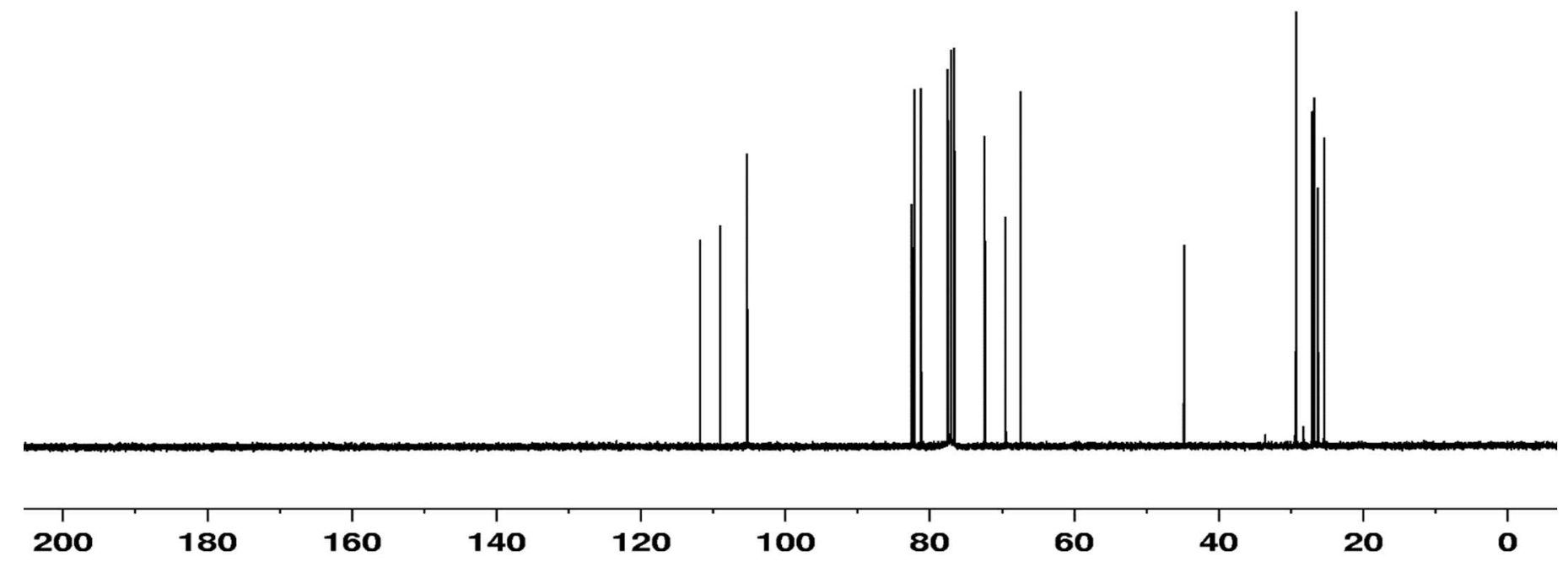




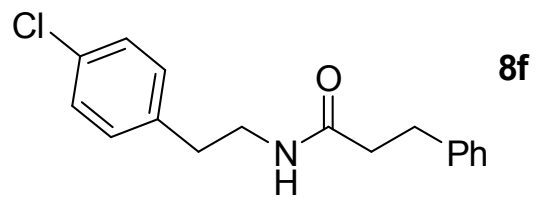

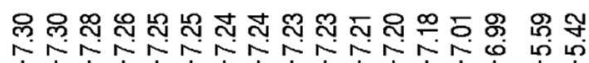

L.

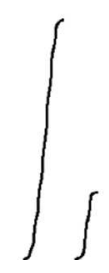

$\iiint \int$

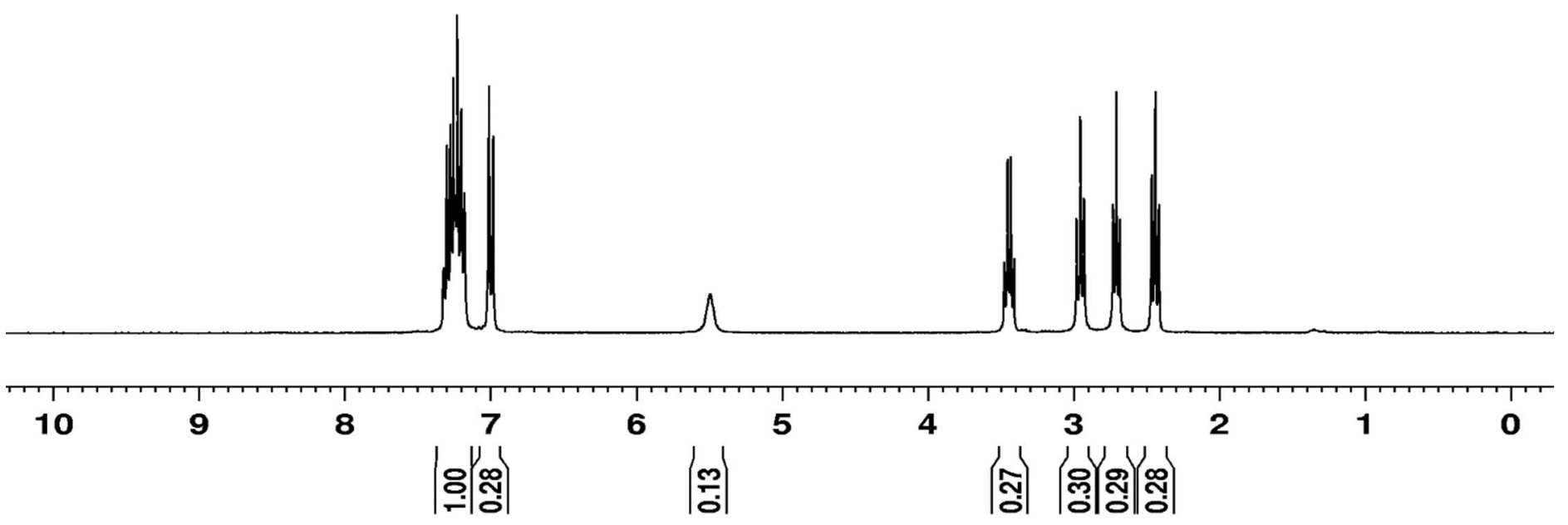



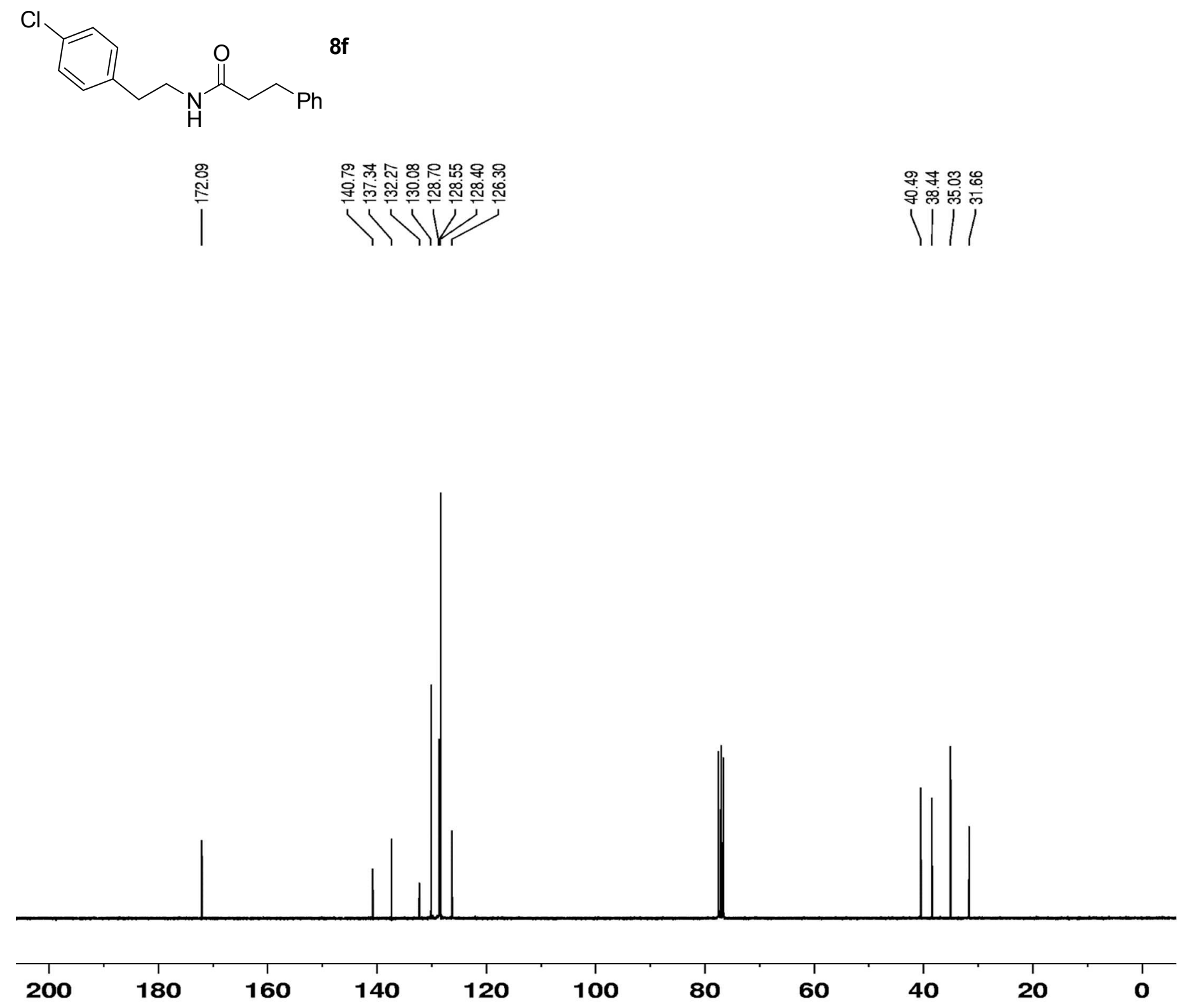


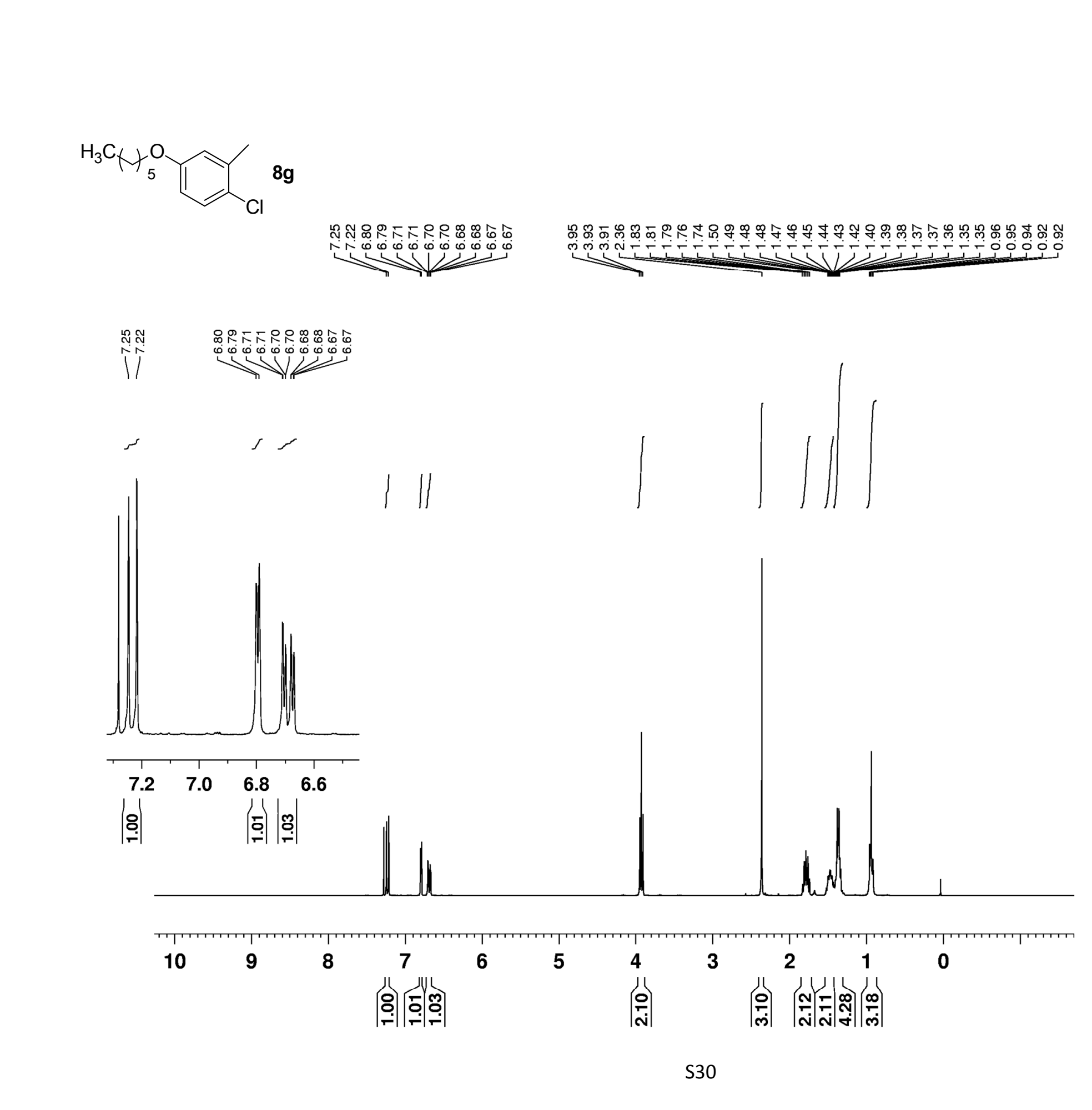




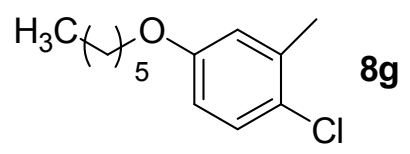

$\mid$

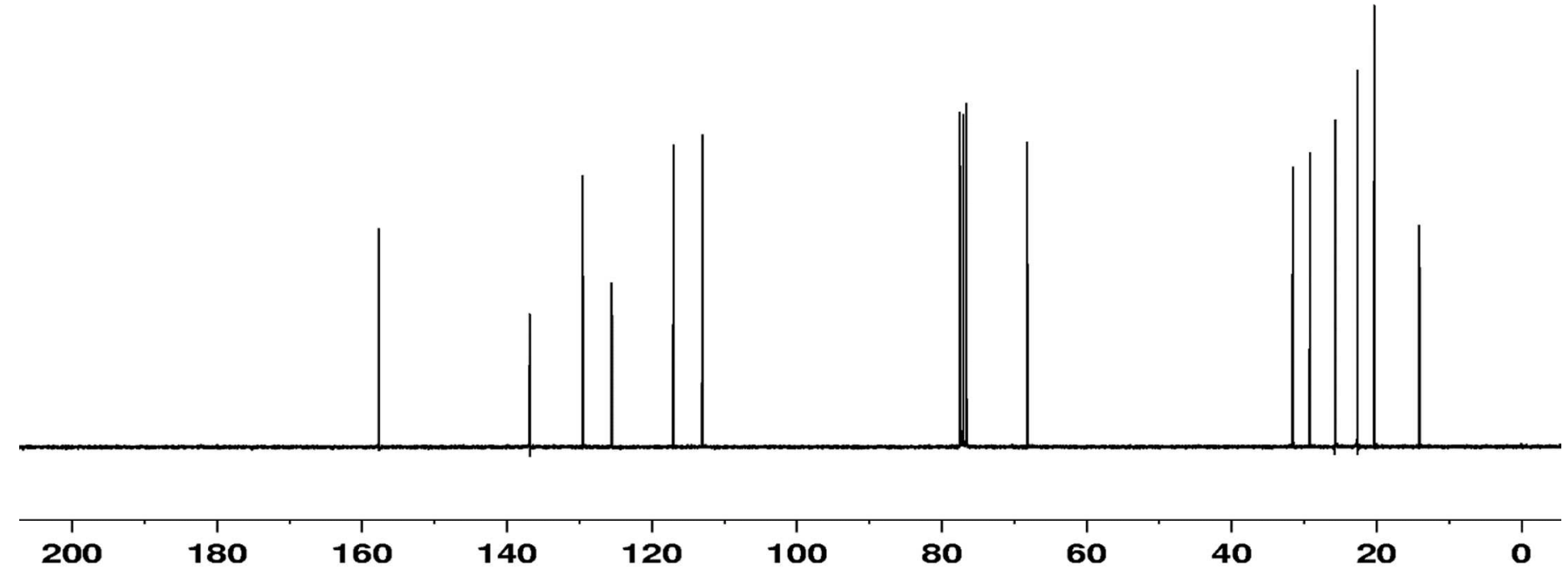


${ }_{n-\mathrm{Bu}}^{n-\mathrm{Bu}}$

年方

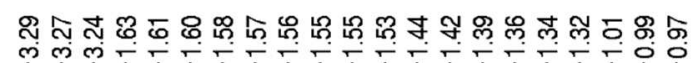

m

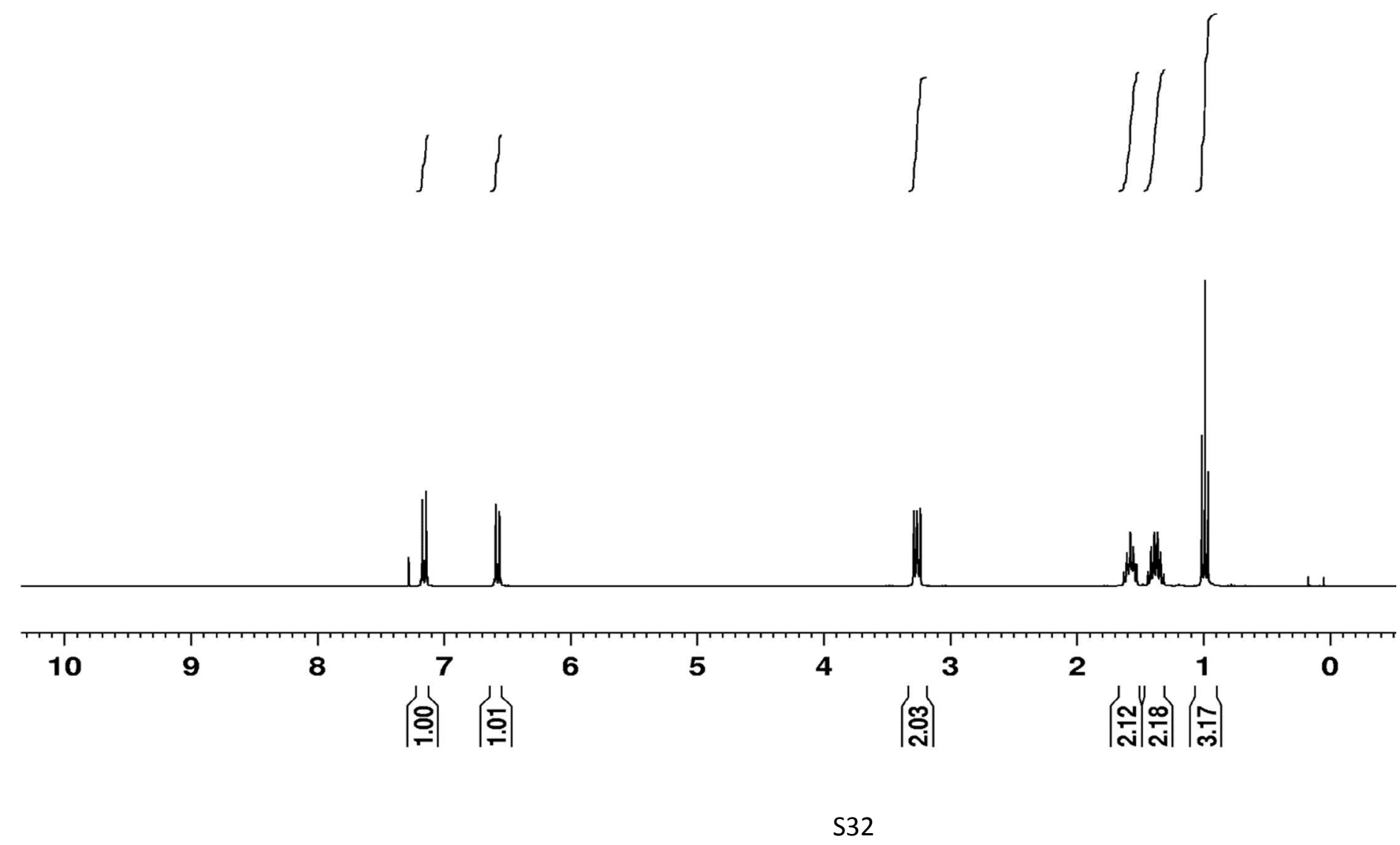


${ }_{n-\mathrm{Bu}}^{N^{\prime}-\mathrm{Bu}} 8 \mathrm{~h}$
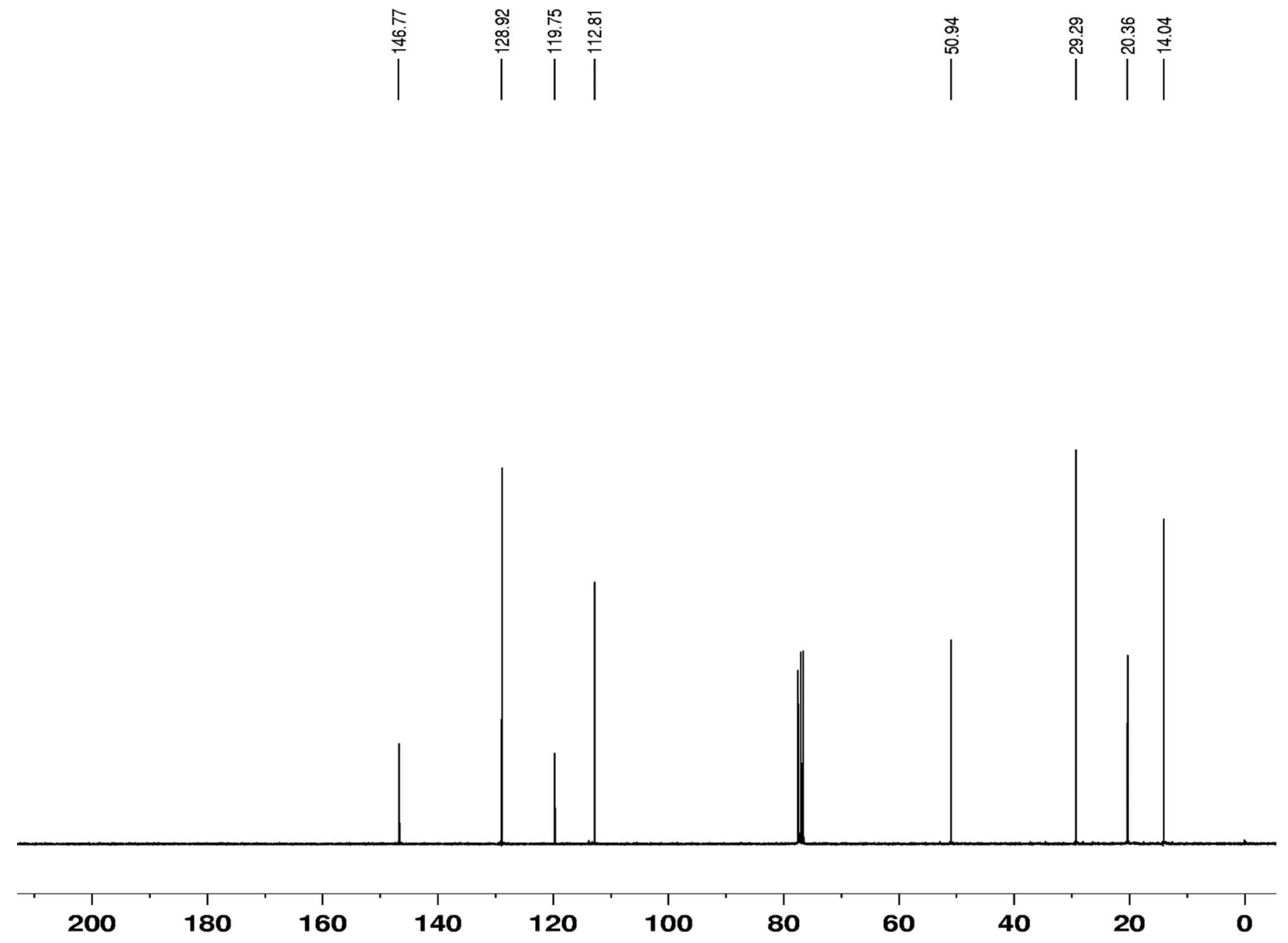


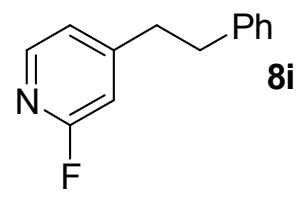

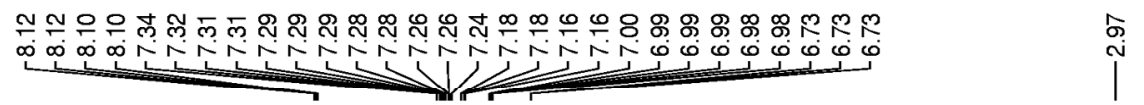

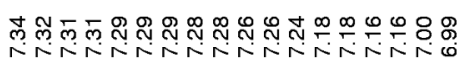

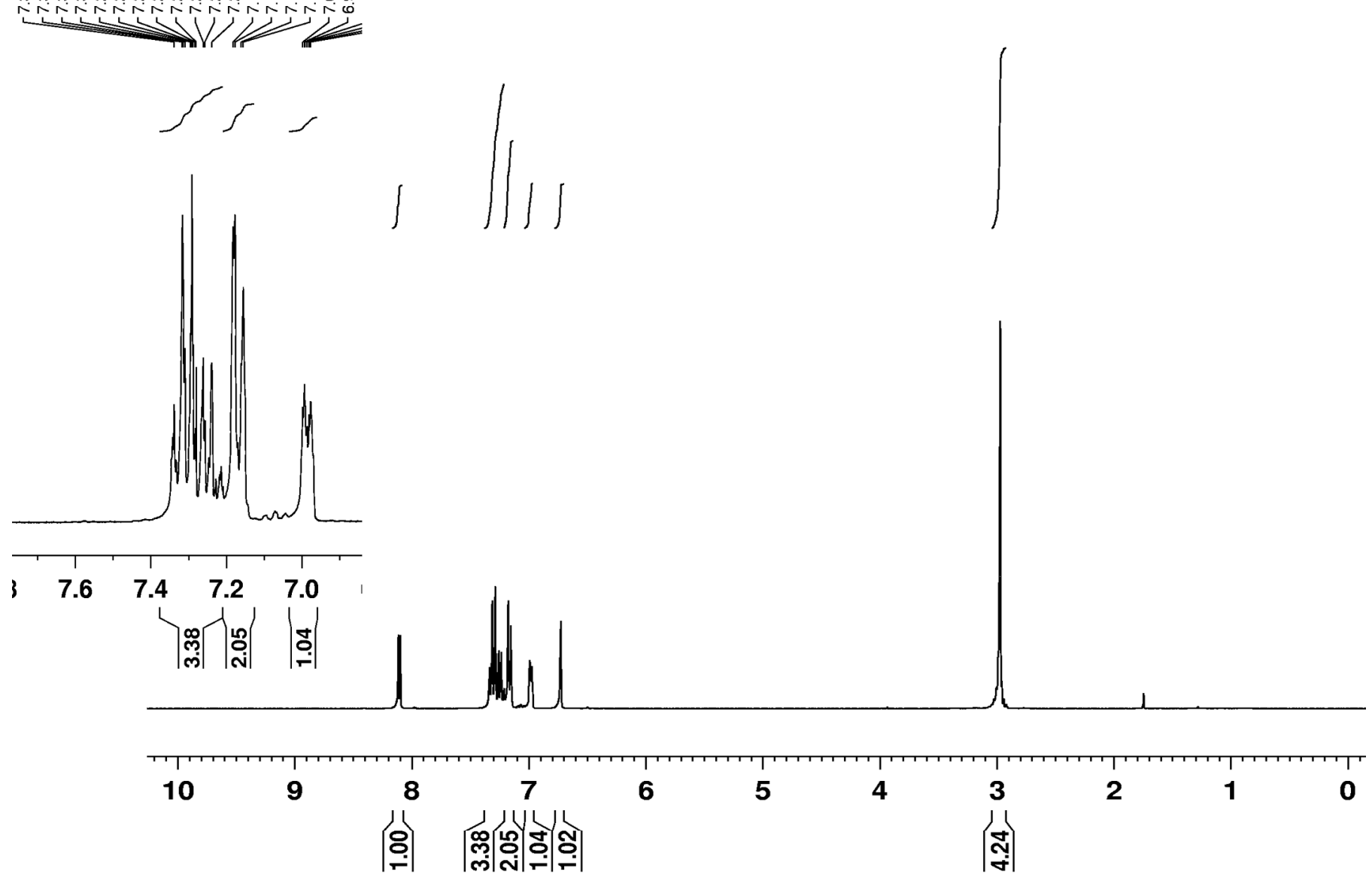




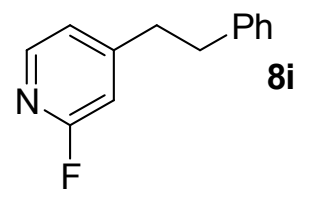

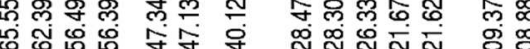

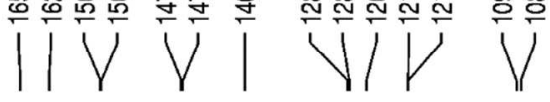

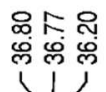

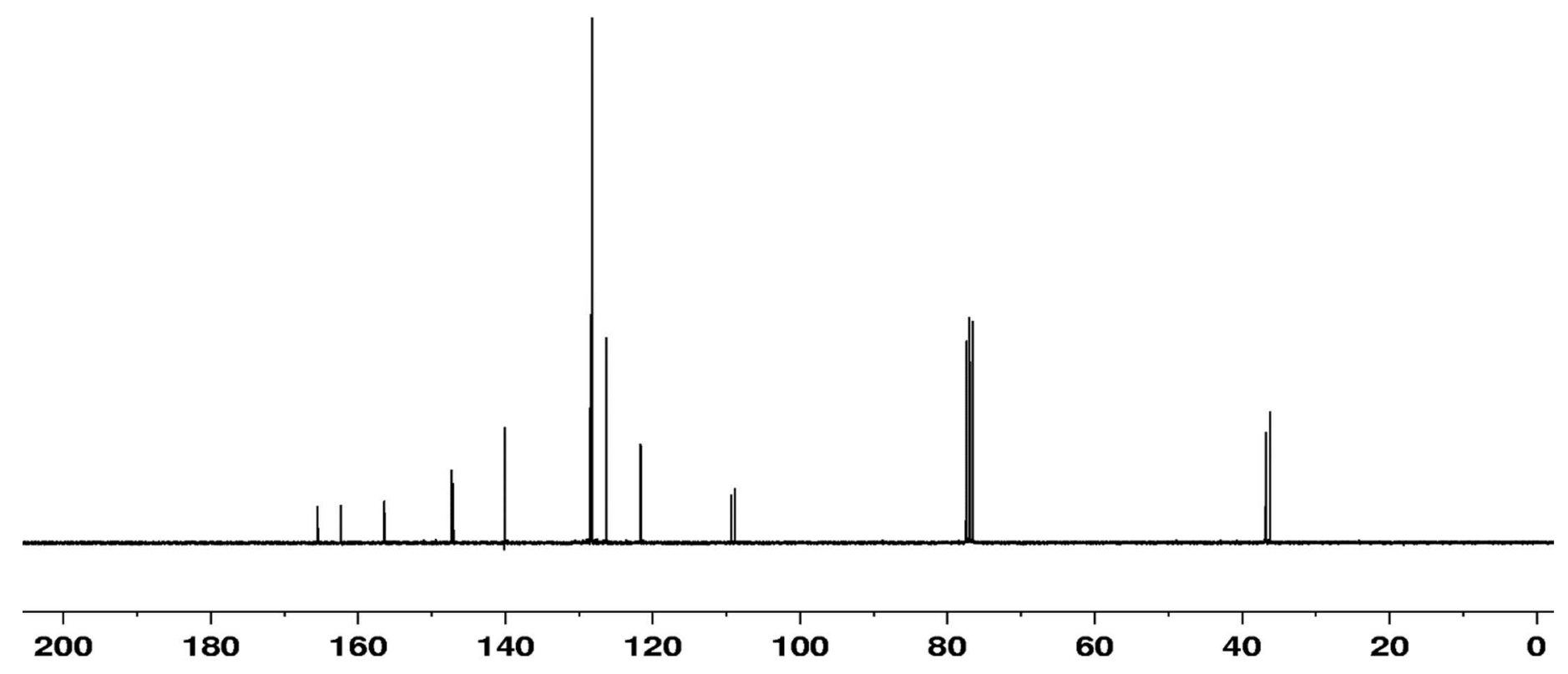


$\overbrace{\left(Y_{3} Y^{O-n-B u}\right.}{ }^{8 j}$

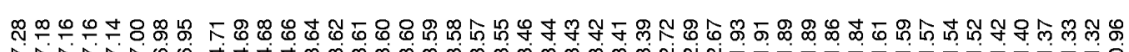
近Niu

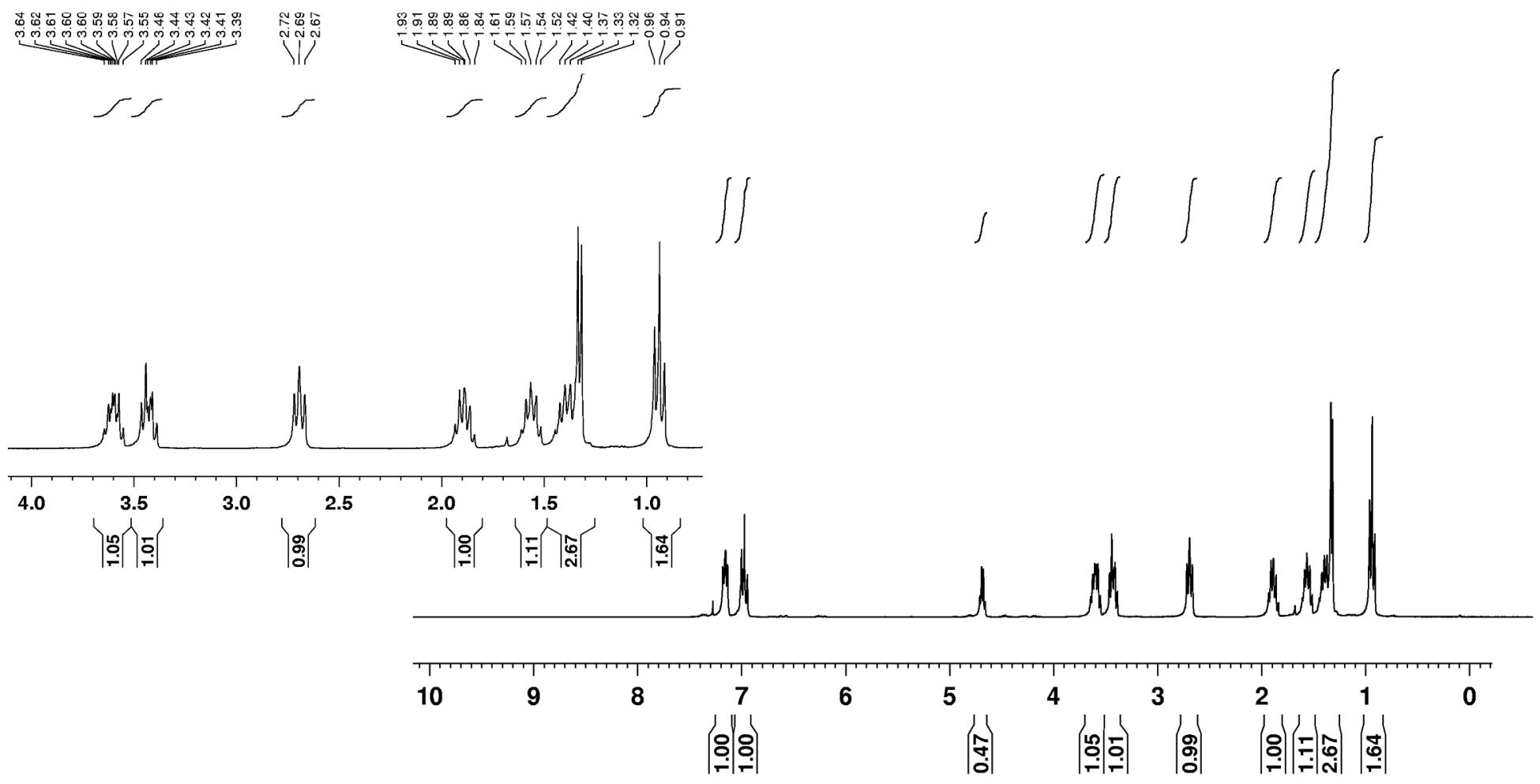




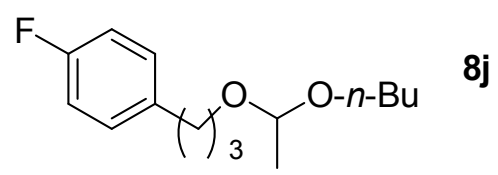
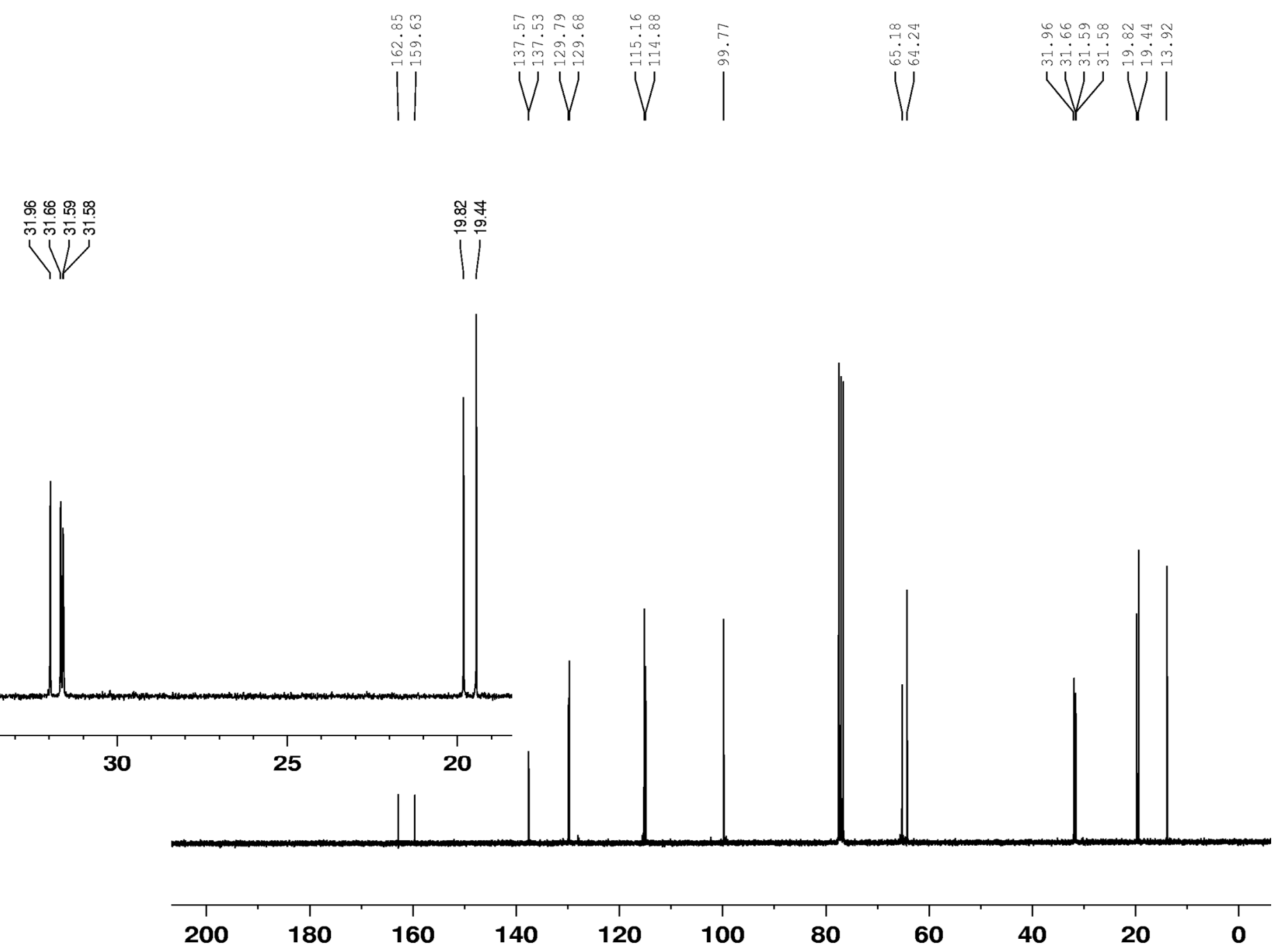


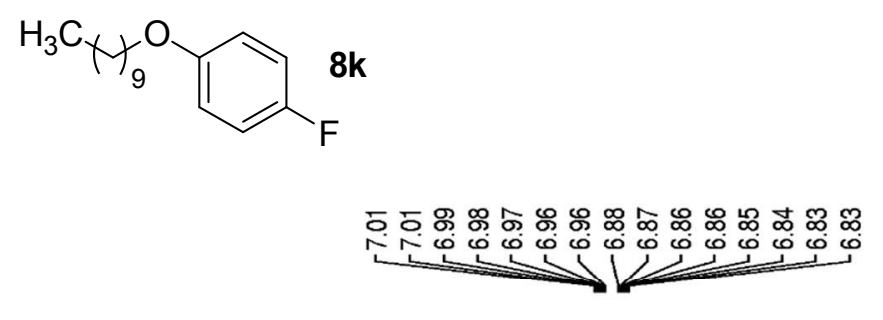

ֻ ळ

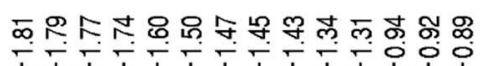

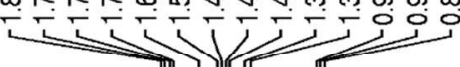

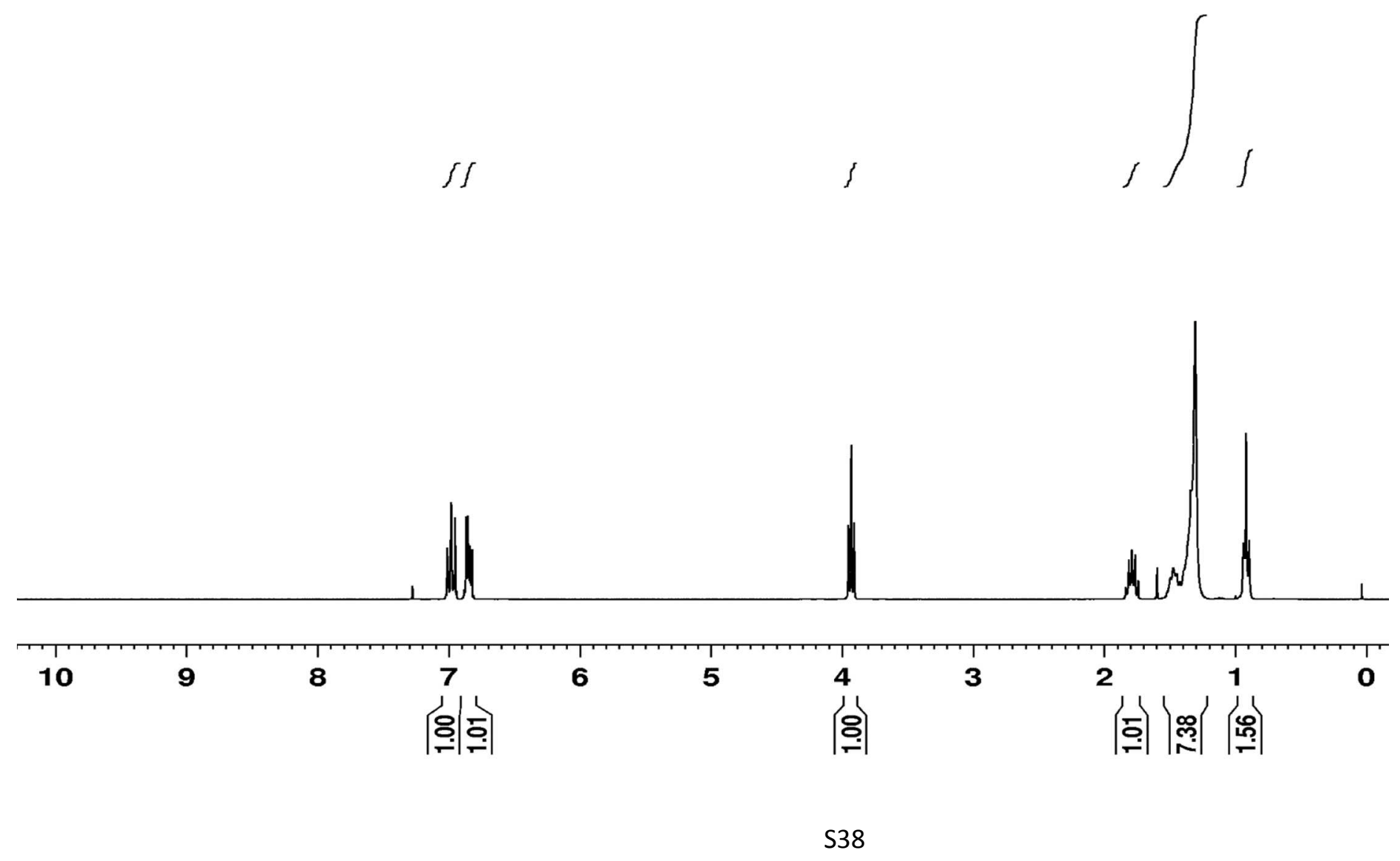


$\mathrm{H}_{3} \mathrm{C} \mathrm{H}_{\mathrm{F}}^{\mathrm{O}} \mathrm{C}_{\mathrm{k}}^{\mathrm{O}}$
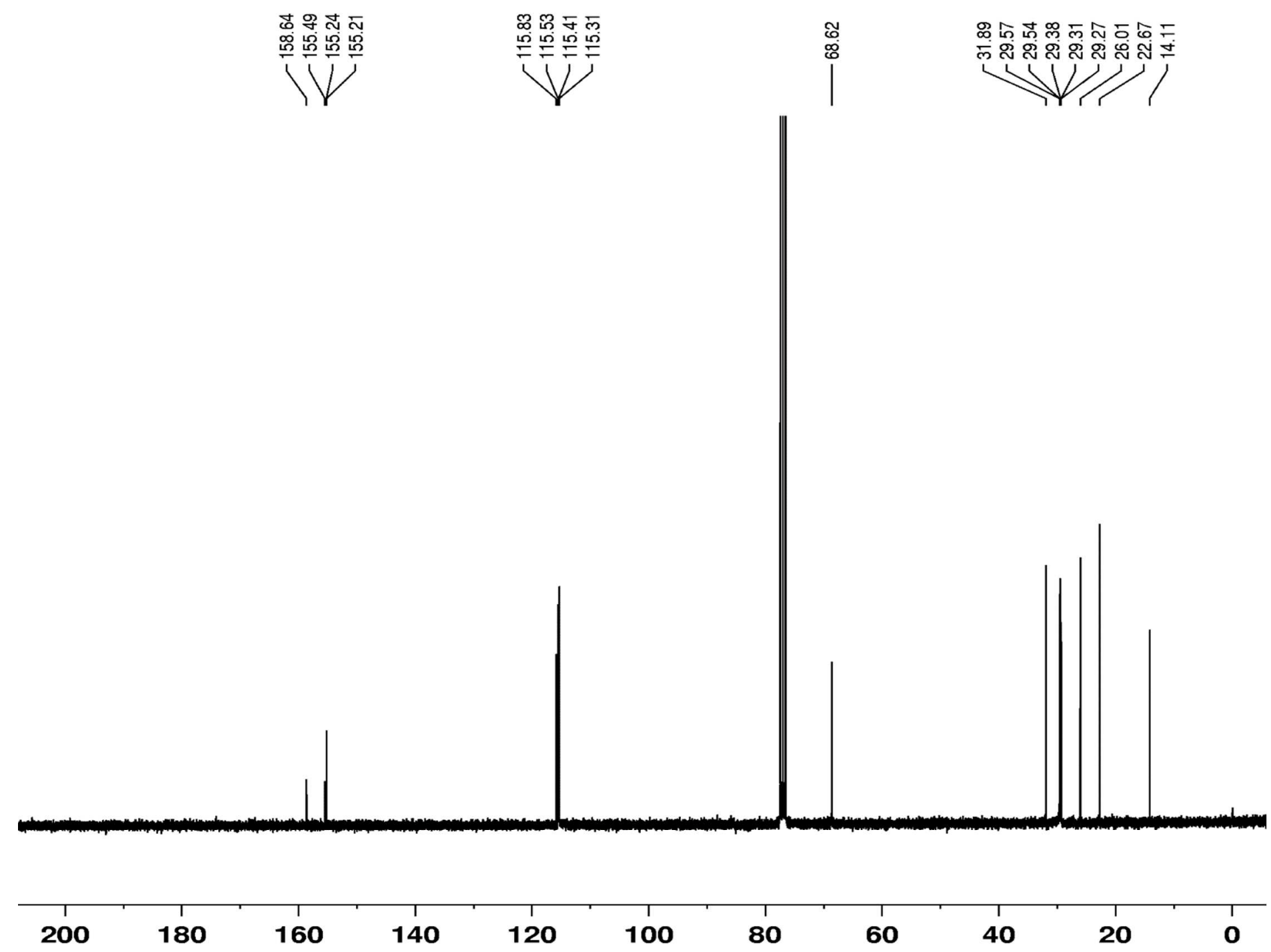

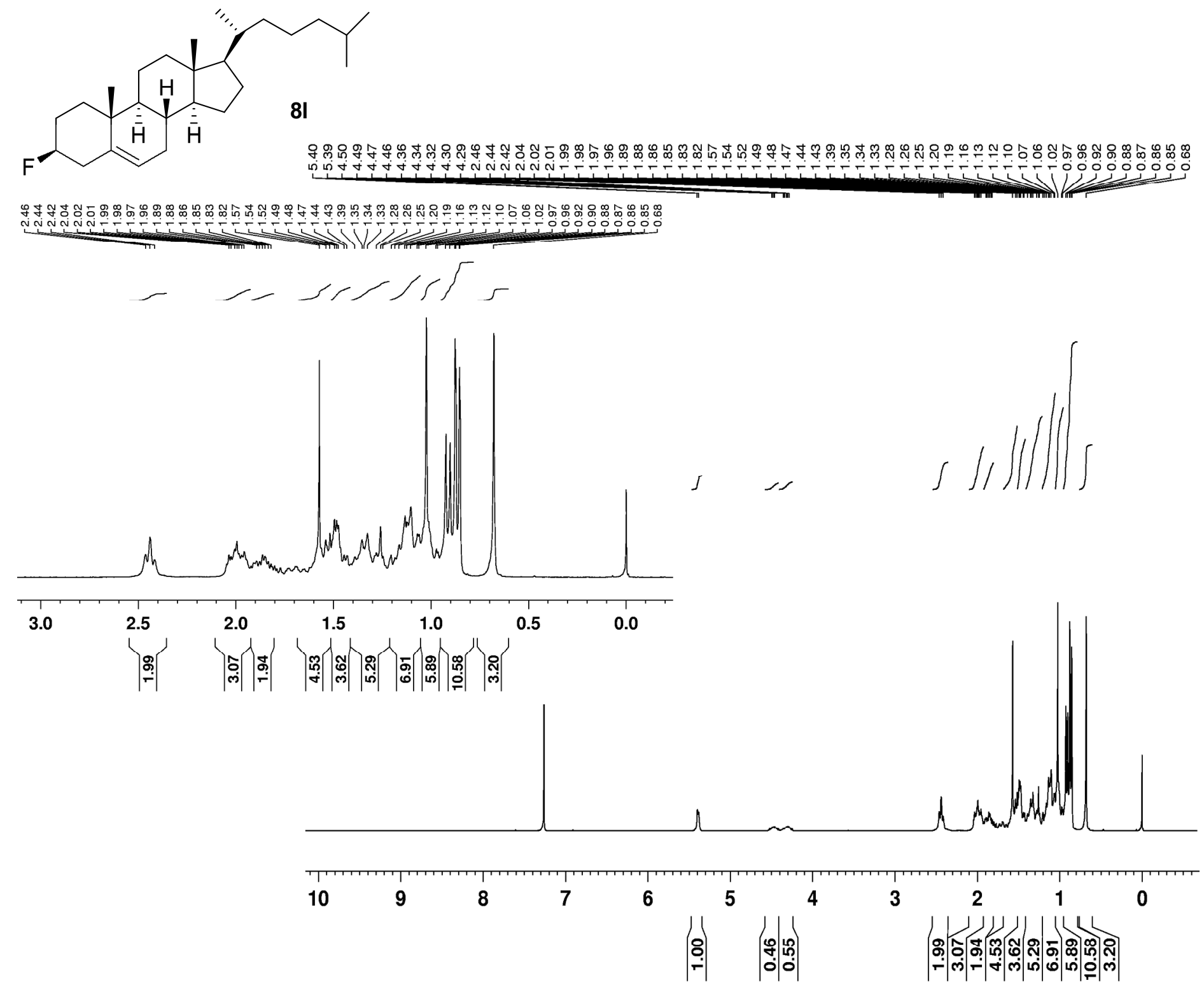


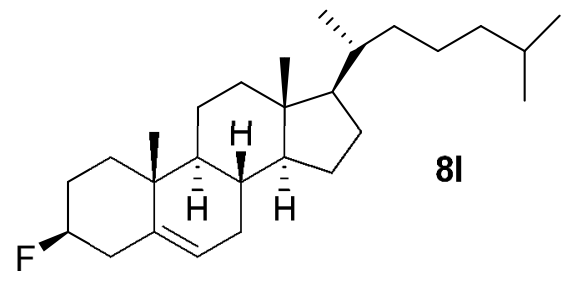

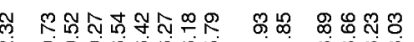

弯

VV VIV VIII

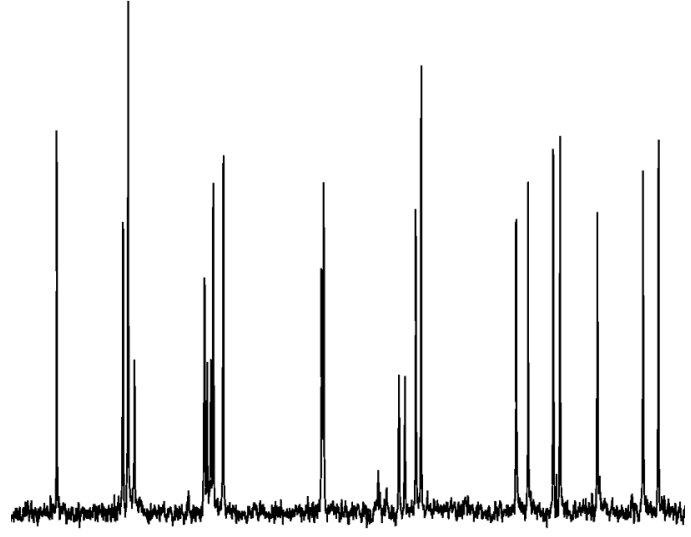

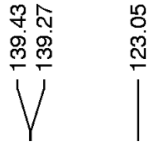

ำ 下以

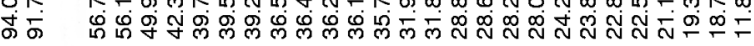

$11 / 1$

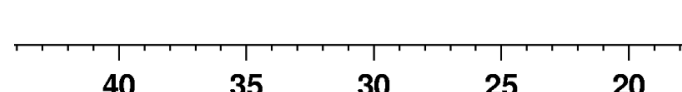 \\ 25 \\ 20}

200180

160

140

120

100

80

60

40

20 


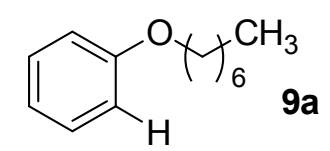

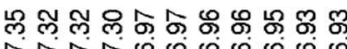

议些000000

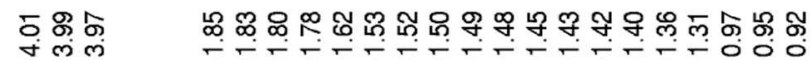

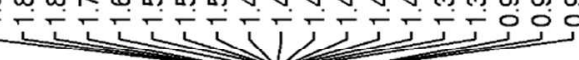
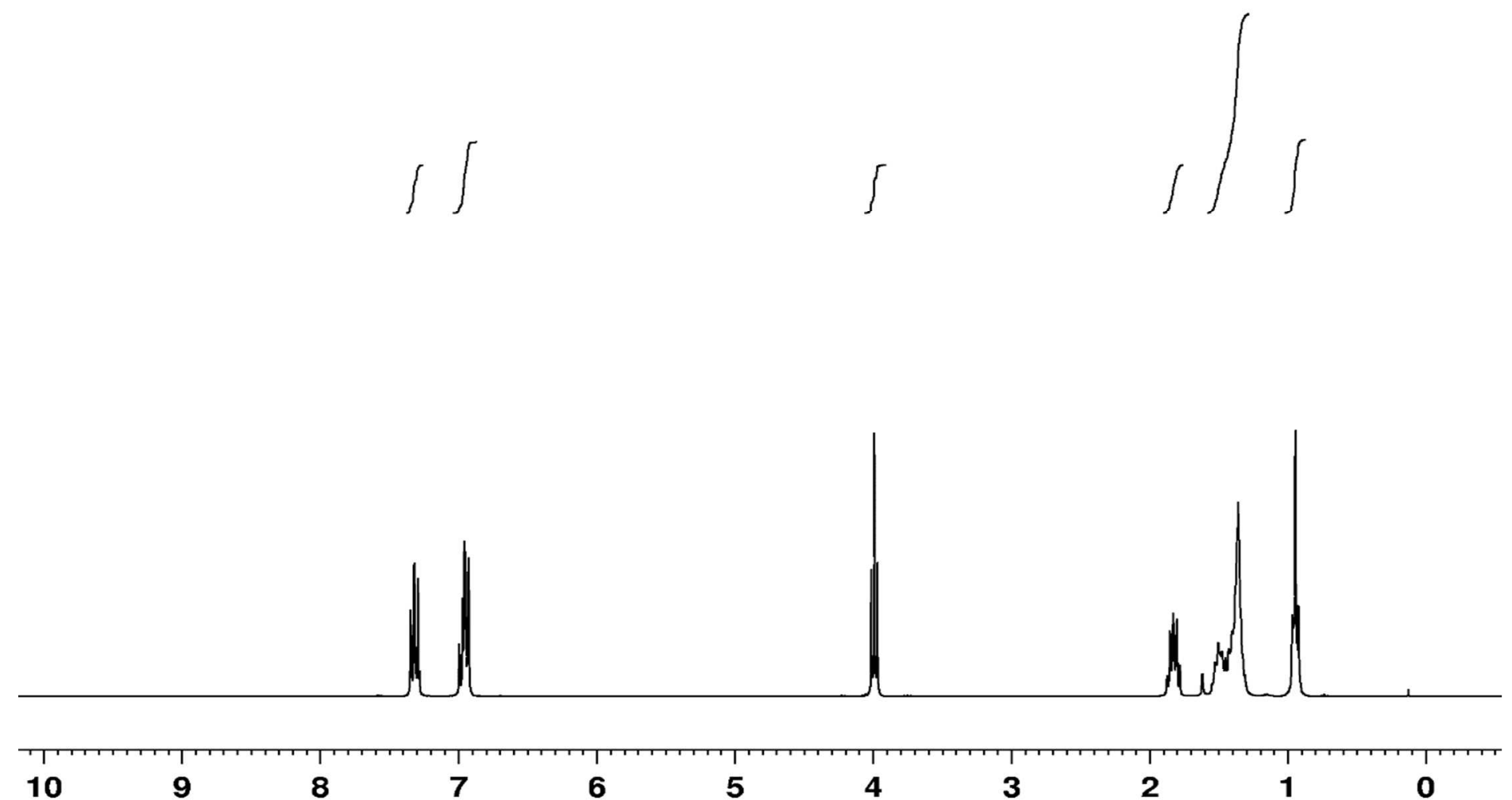

8

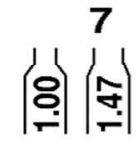

6

5

|⿱宀女:
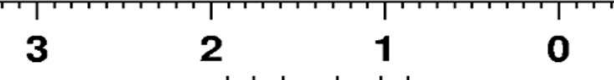

|음ำ 
$\overbrace{\mathrm{H}}^{\mathrm{O}_{4}} \mathrm{CH}^{\mathrm{CH}_{3}}$
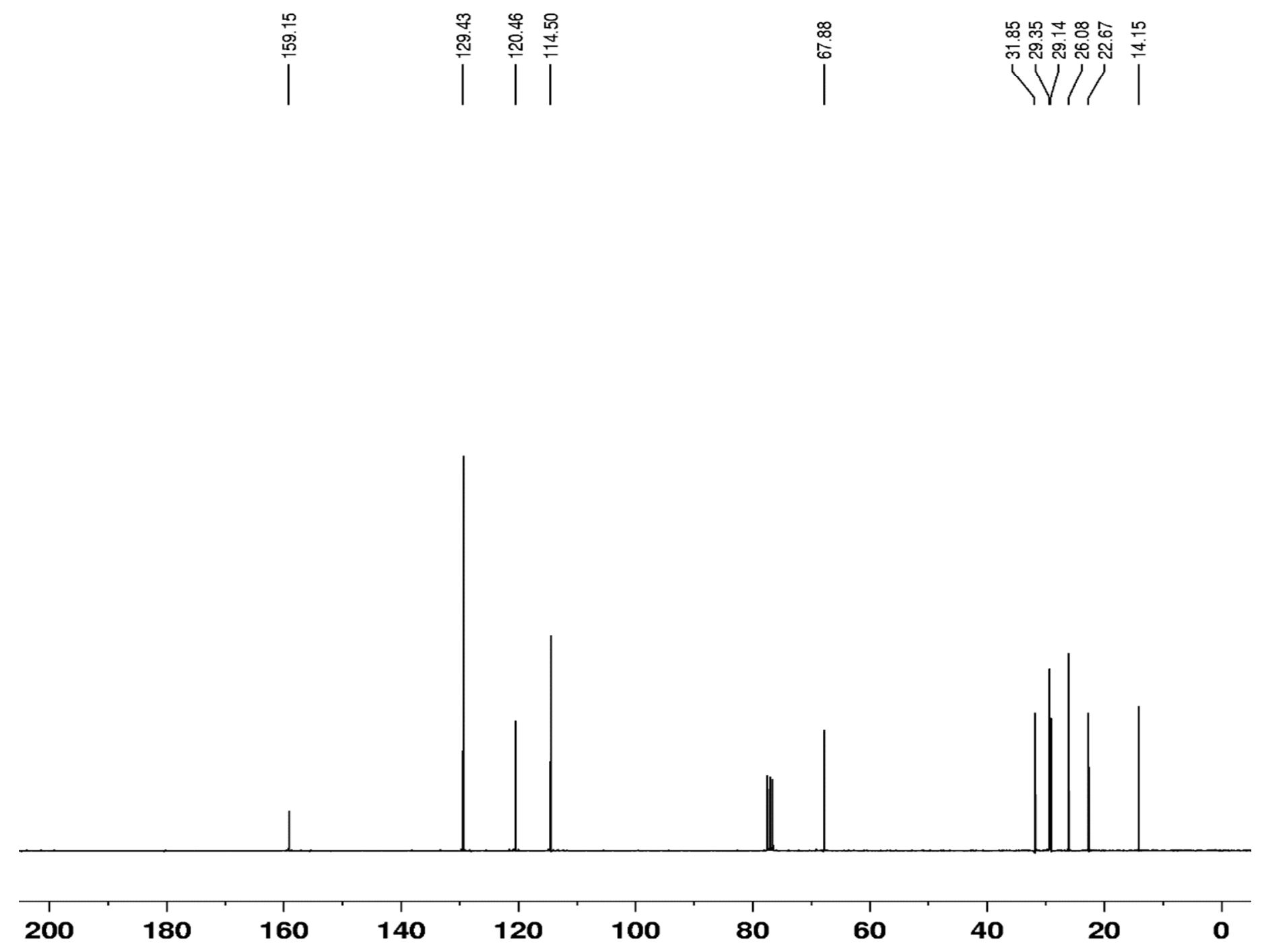
"Ton

员

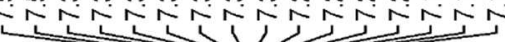

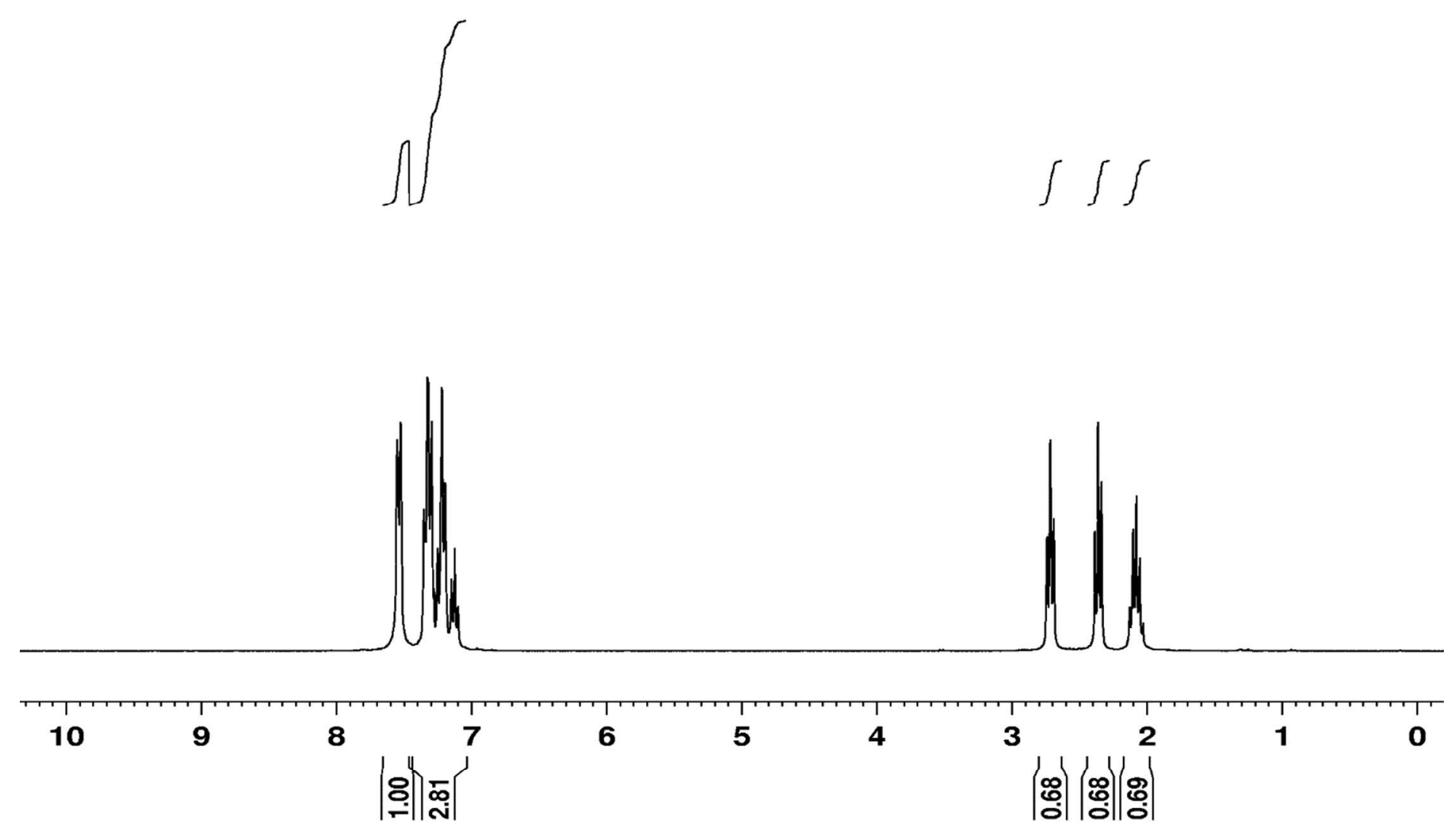

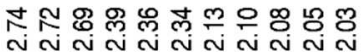

Nivin

$\iint S$

$\left|\begin{array}{l}\infty \\ 0 \\ 0\end{array}\right|\left|\begin{array}{l}\infty \\ 0 \\ 0\end{array}\right|\left|\begin{array}{l}0 \\ 0 \\ 0\end{array}\right|$ 

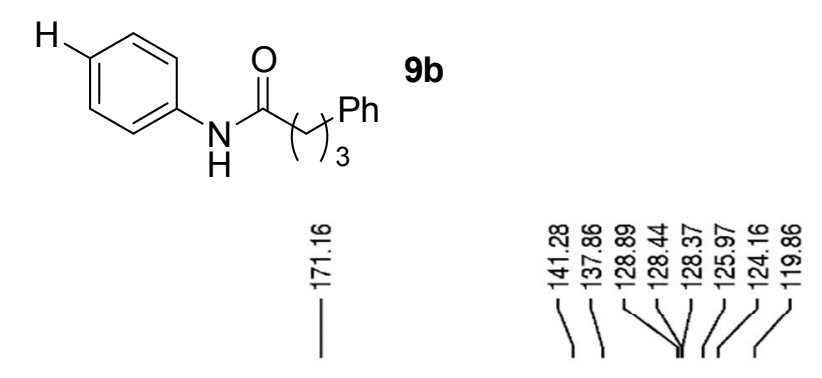

$\mid$

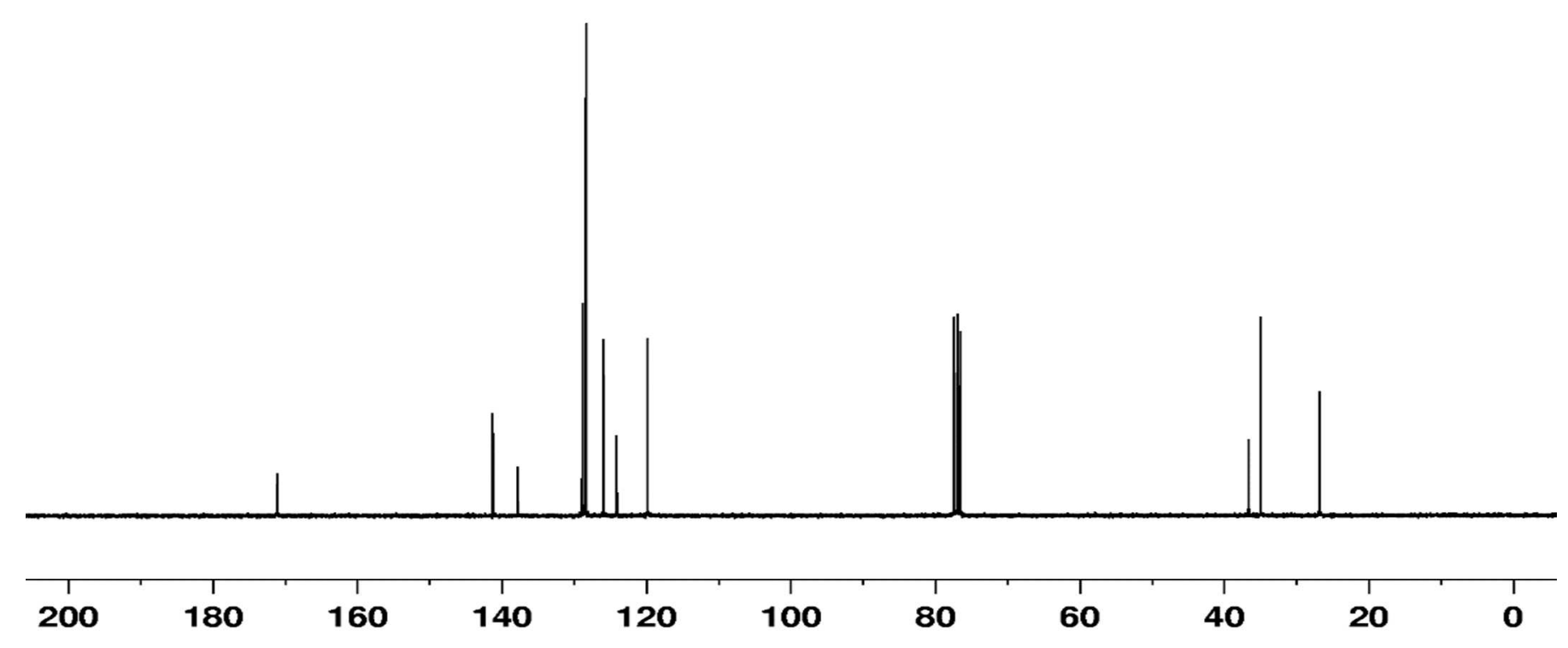



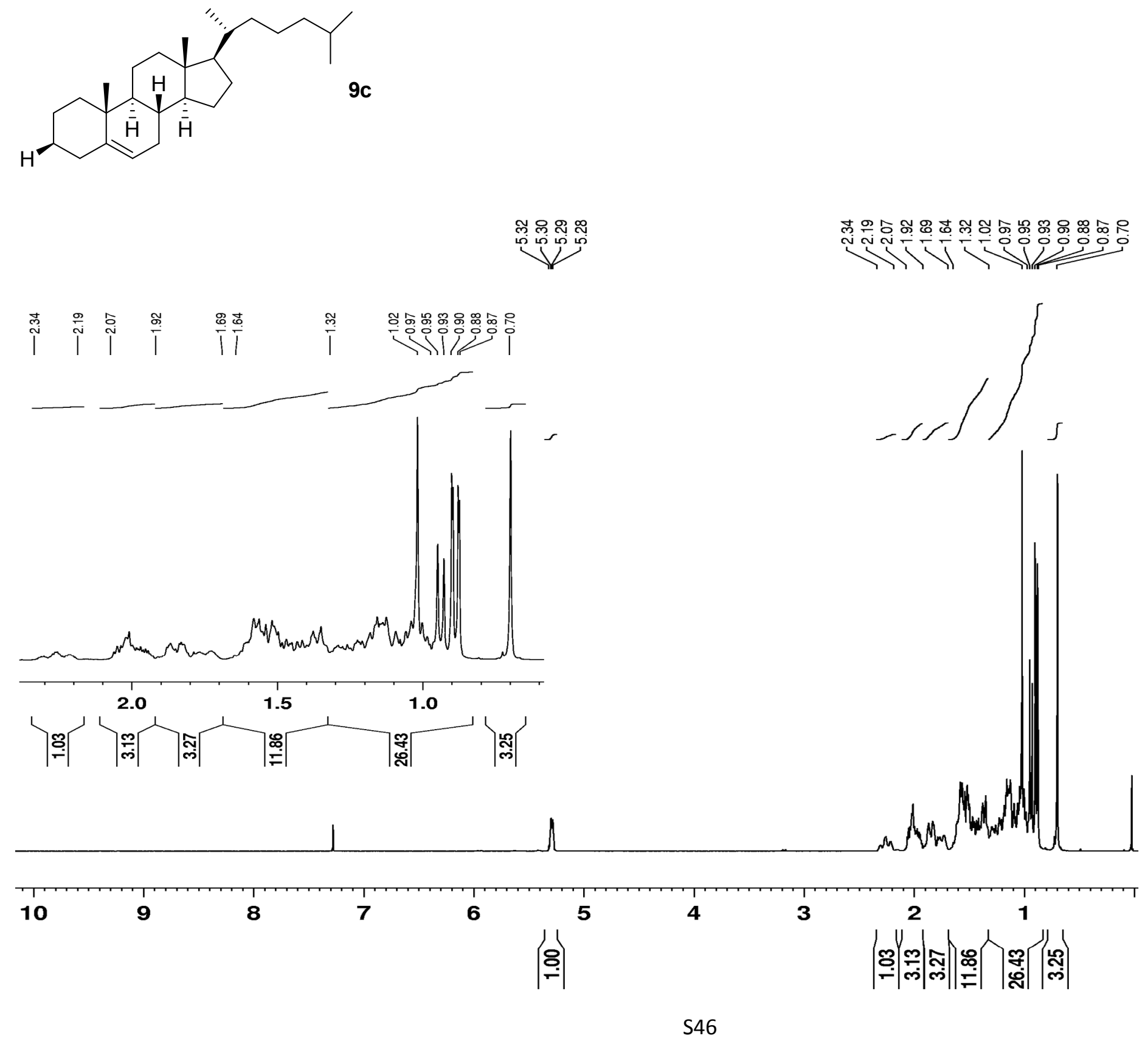


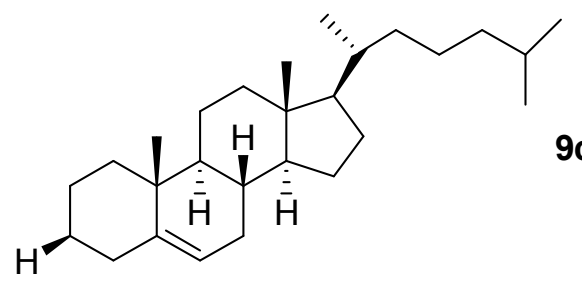

9c

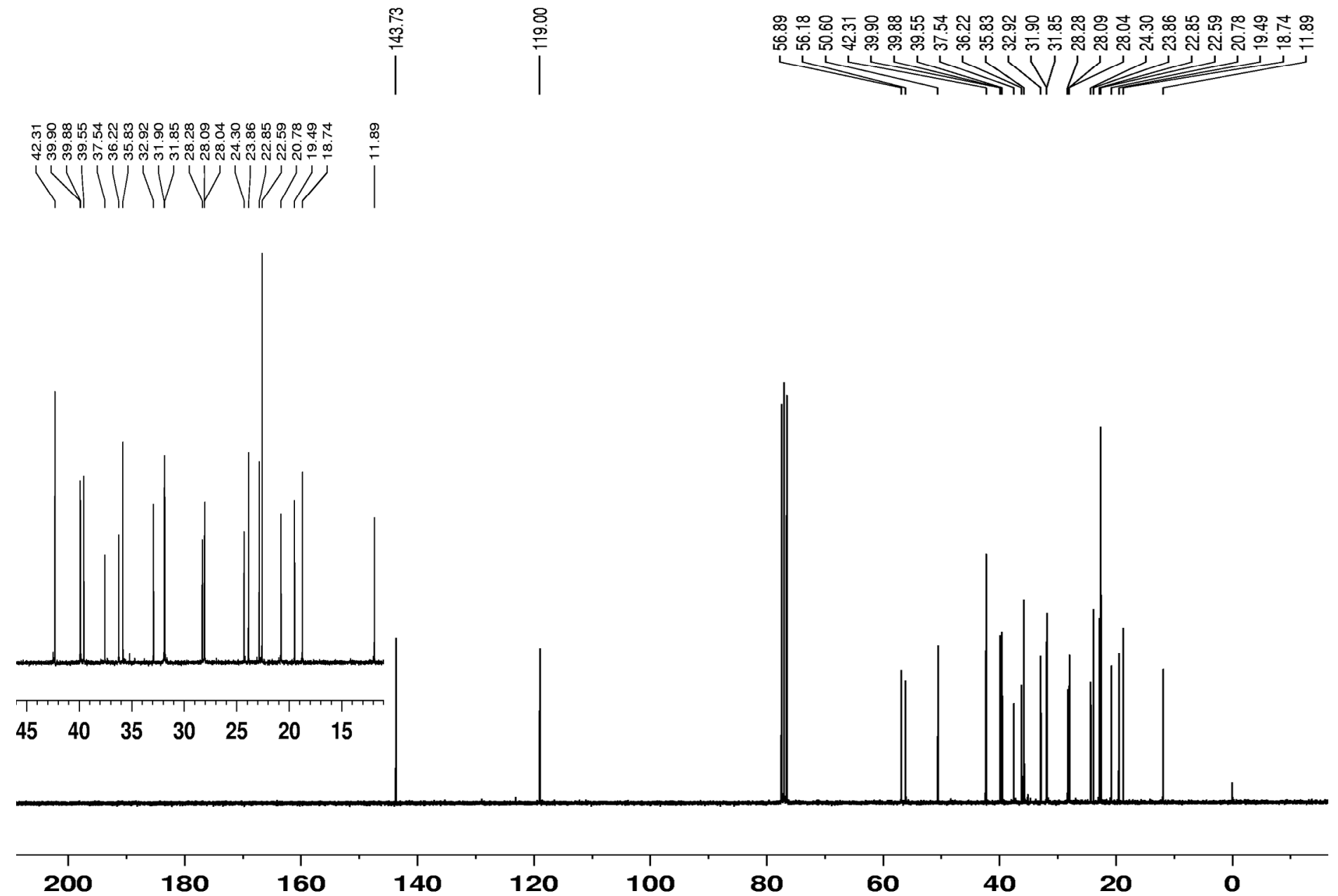




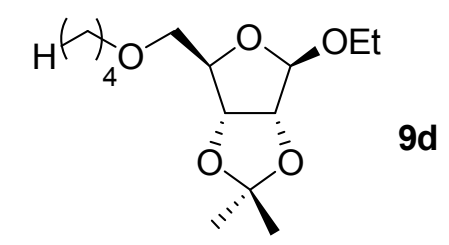

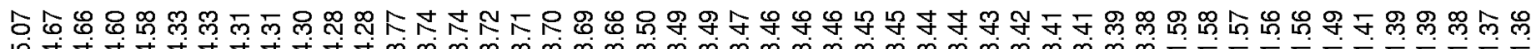

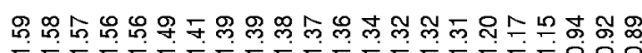

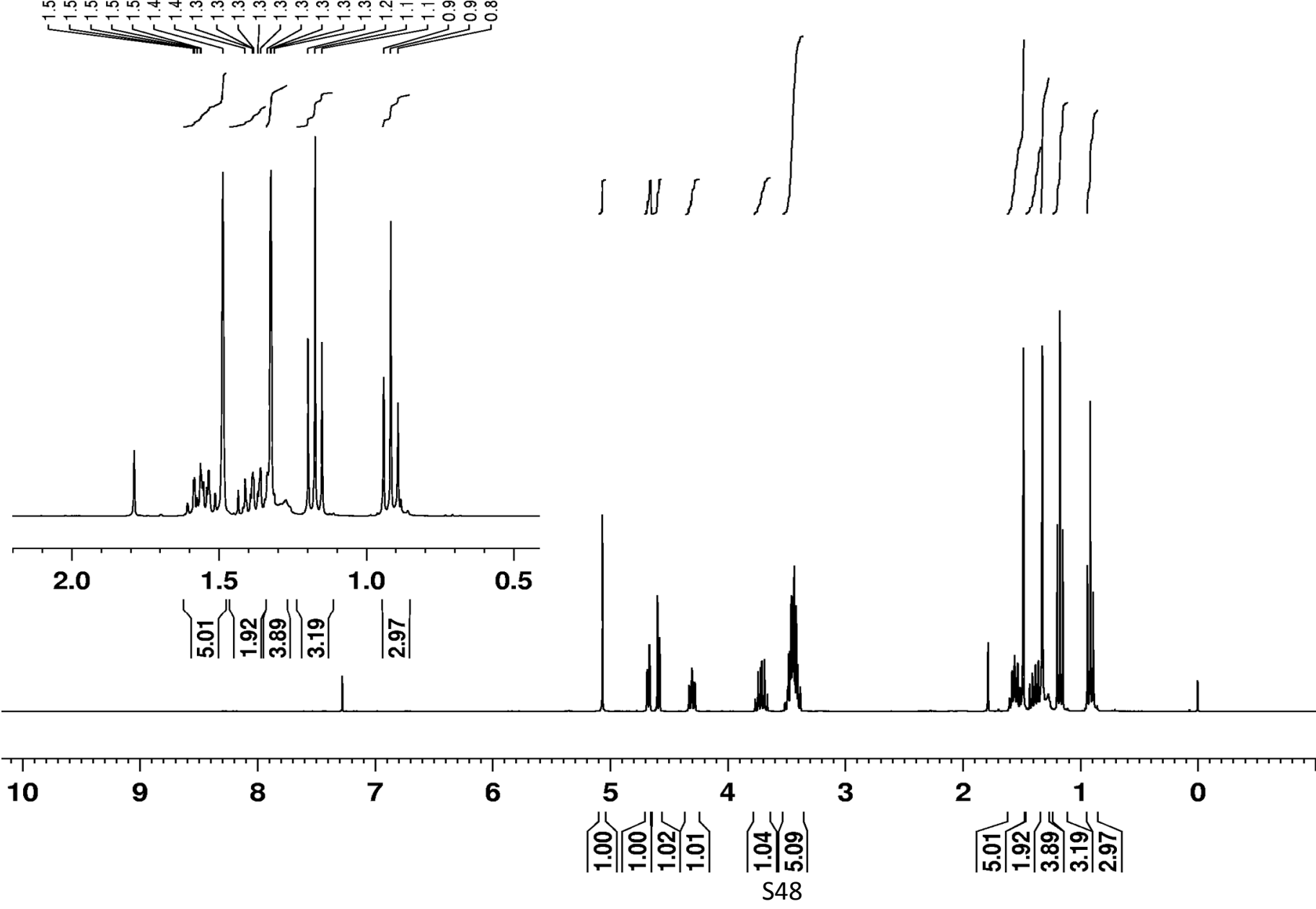


(N)

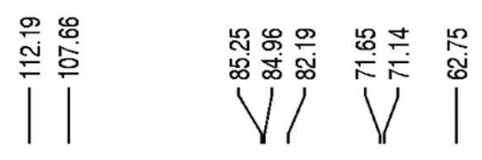

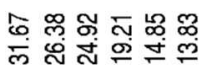

II $\mid V$

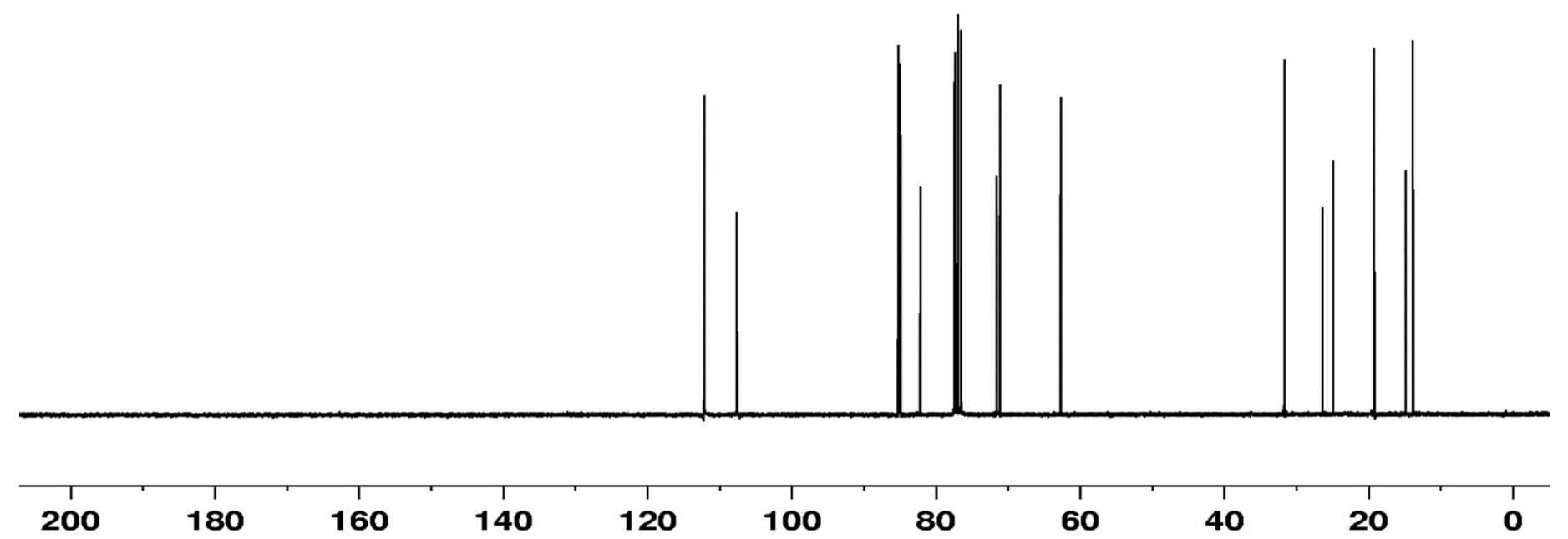




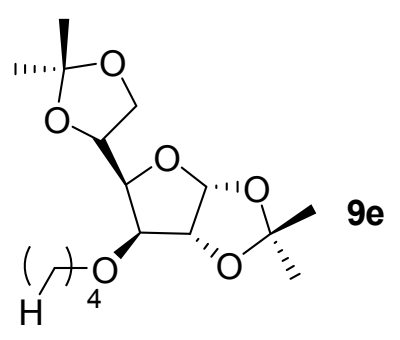

இ

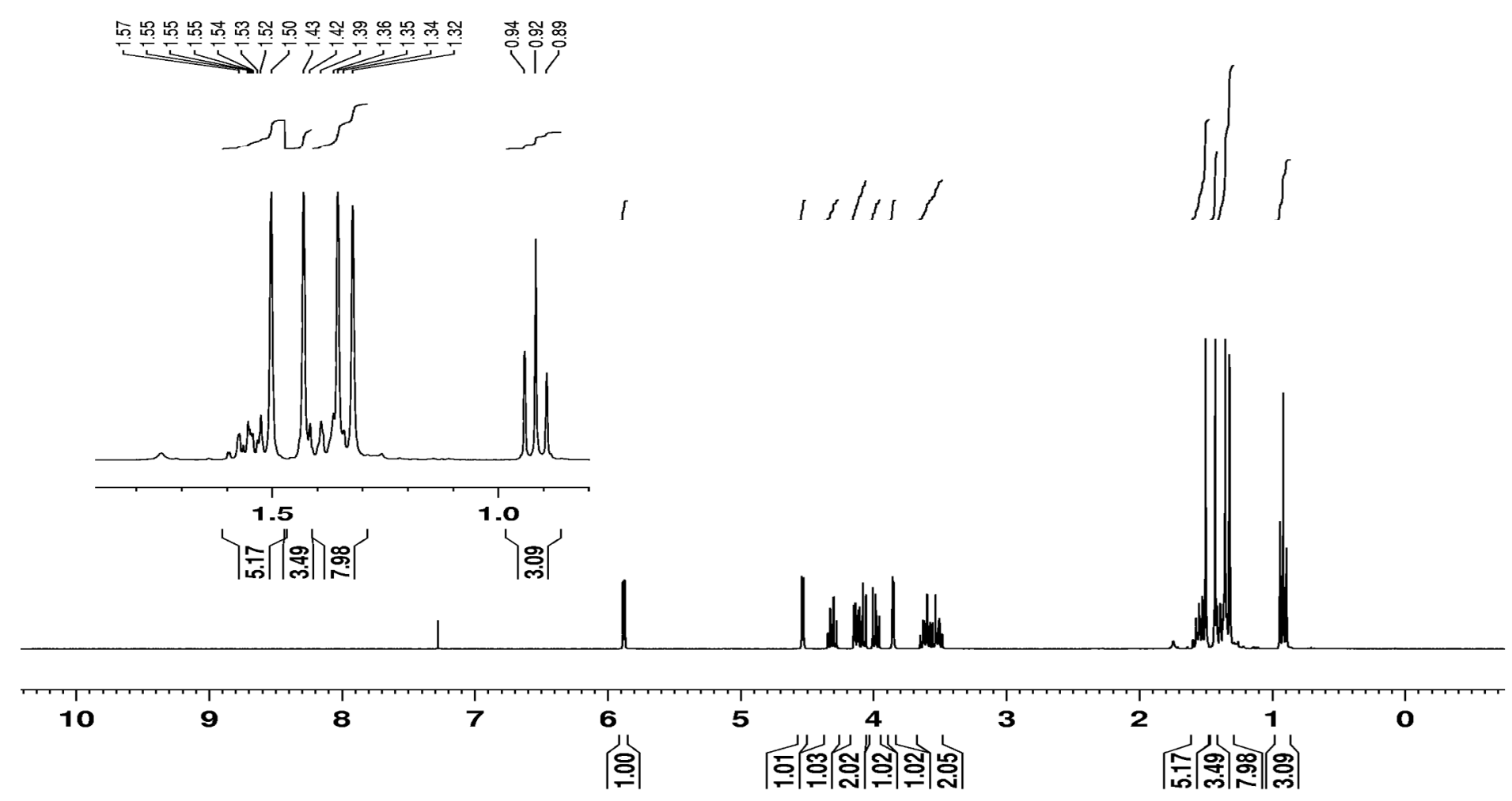



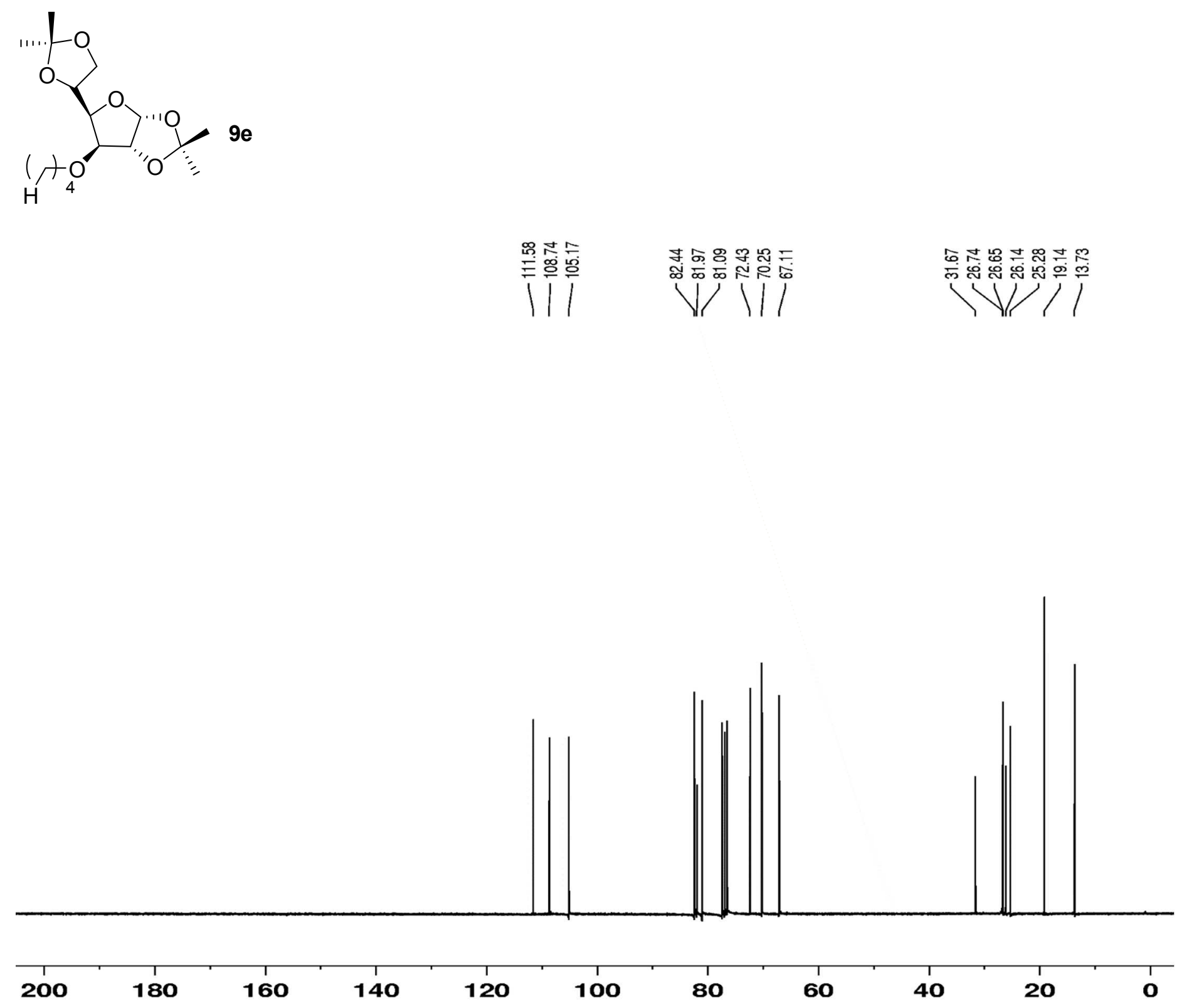

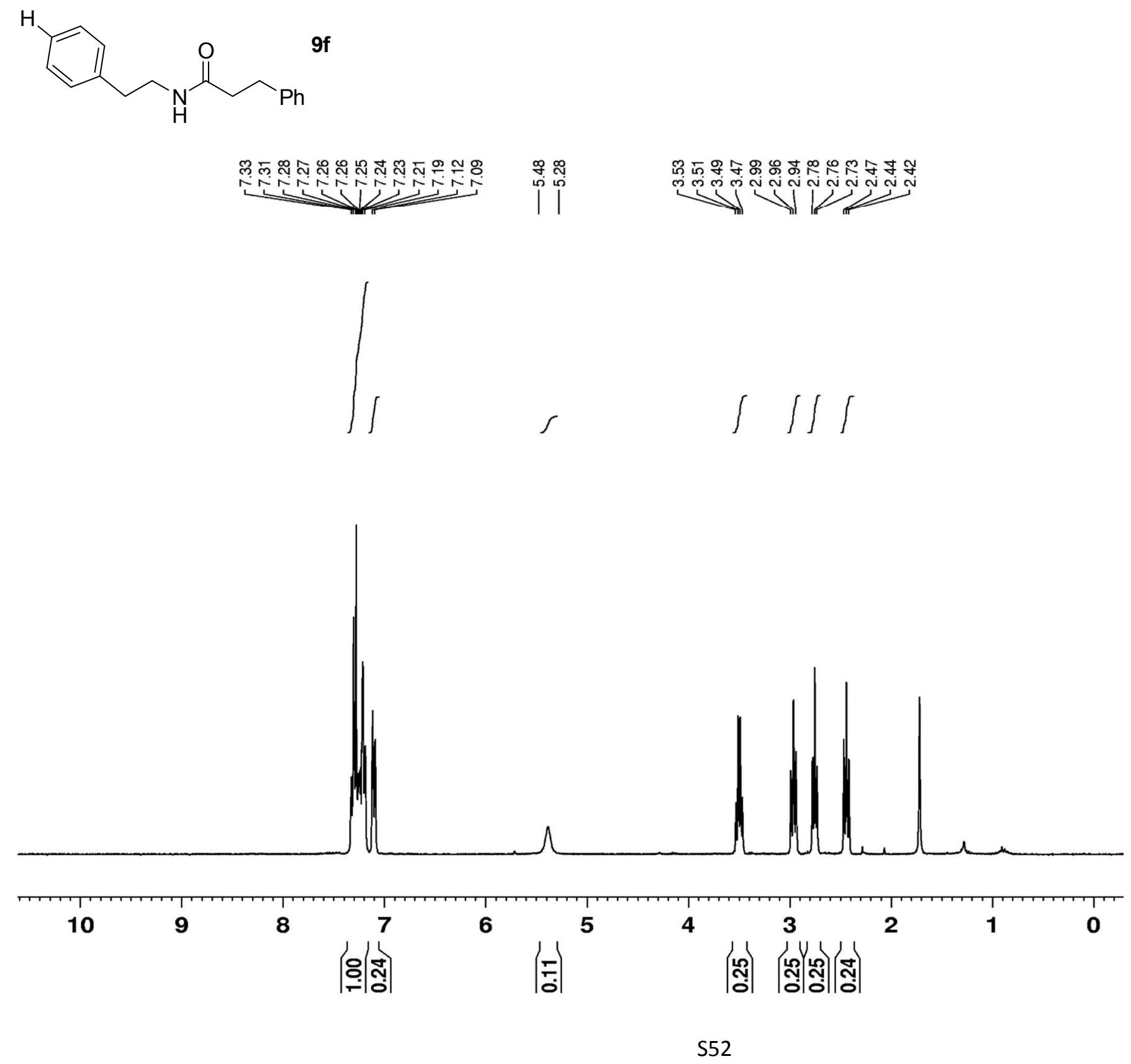

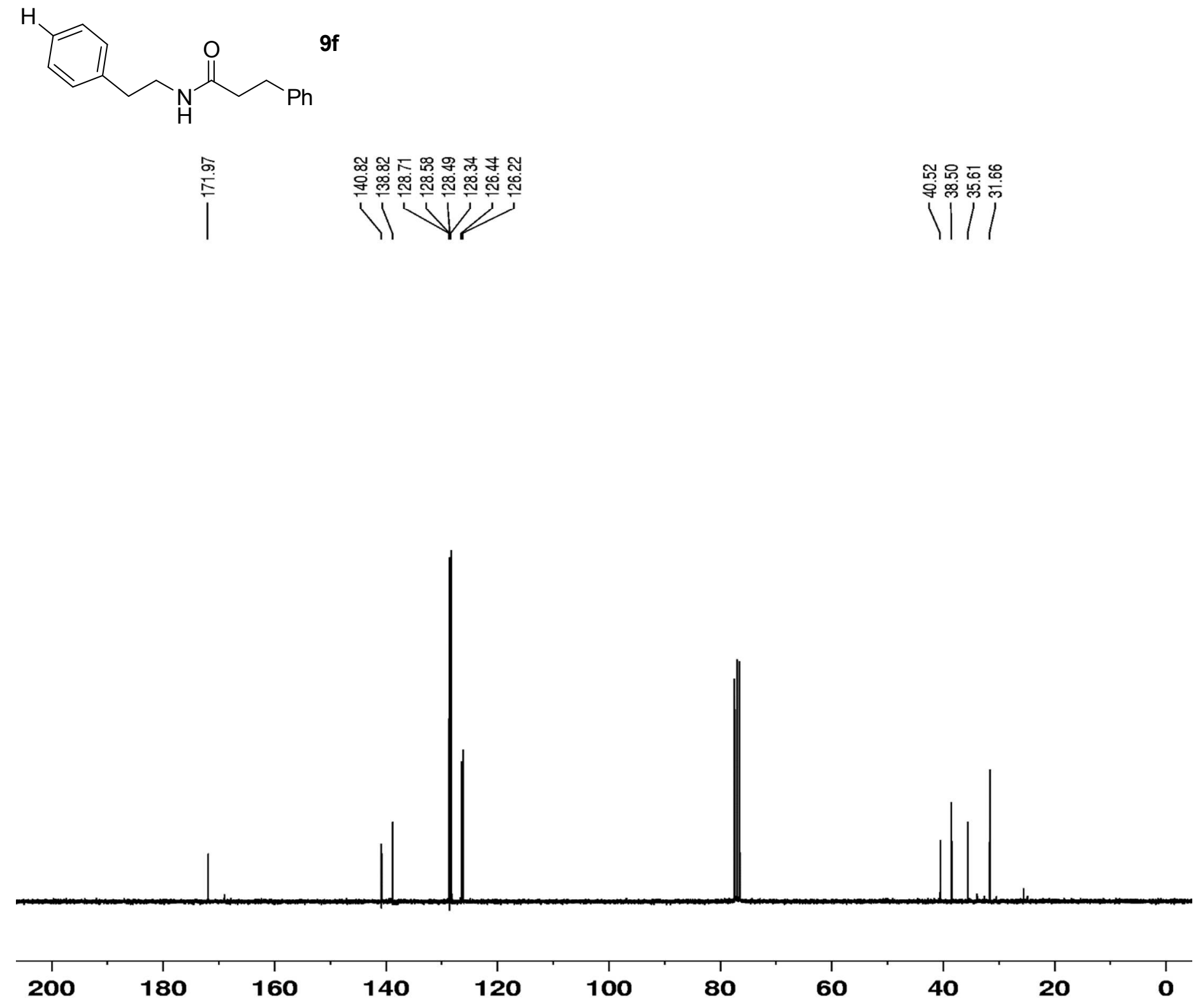
$\mathrm{H}_{3} \mathrm{C}_{4} \mathrm{O}_{5}$

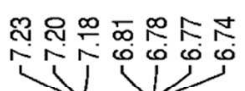

نำ

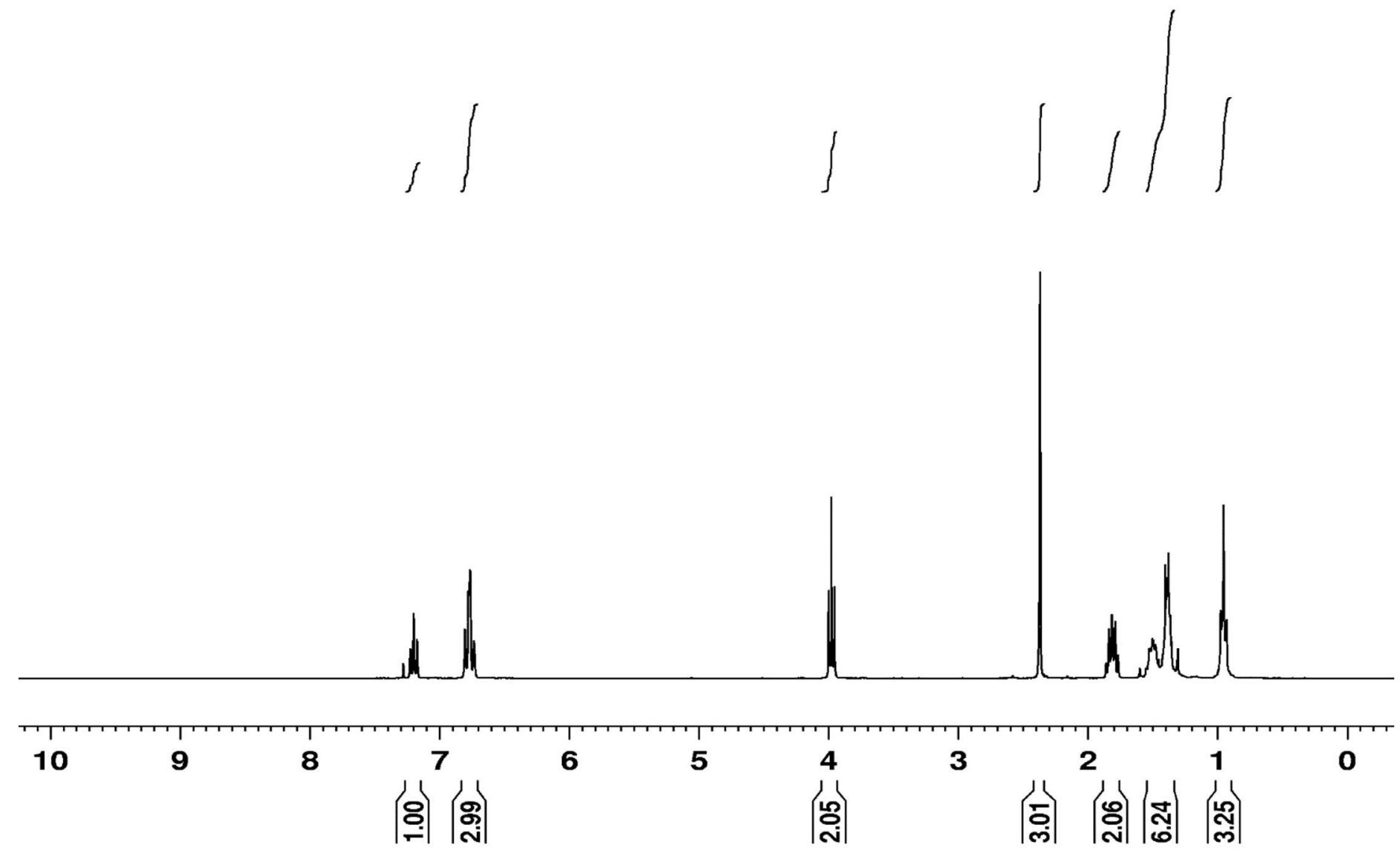


$9 \mathrm{~g}$

$\mid$

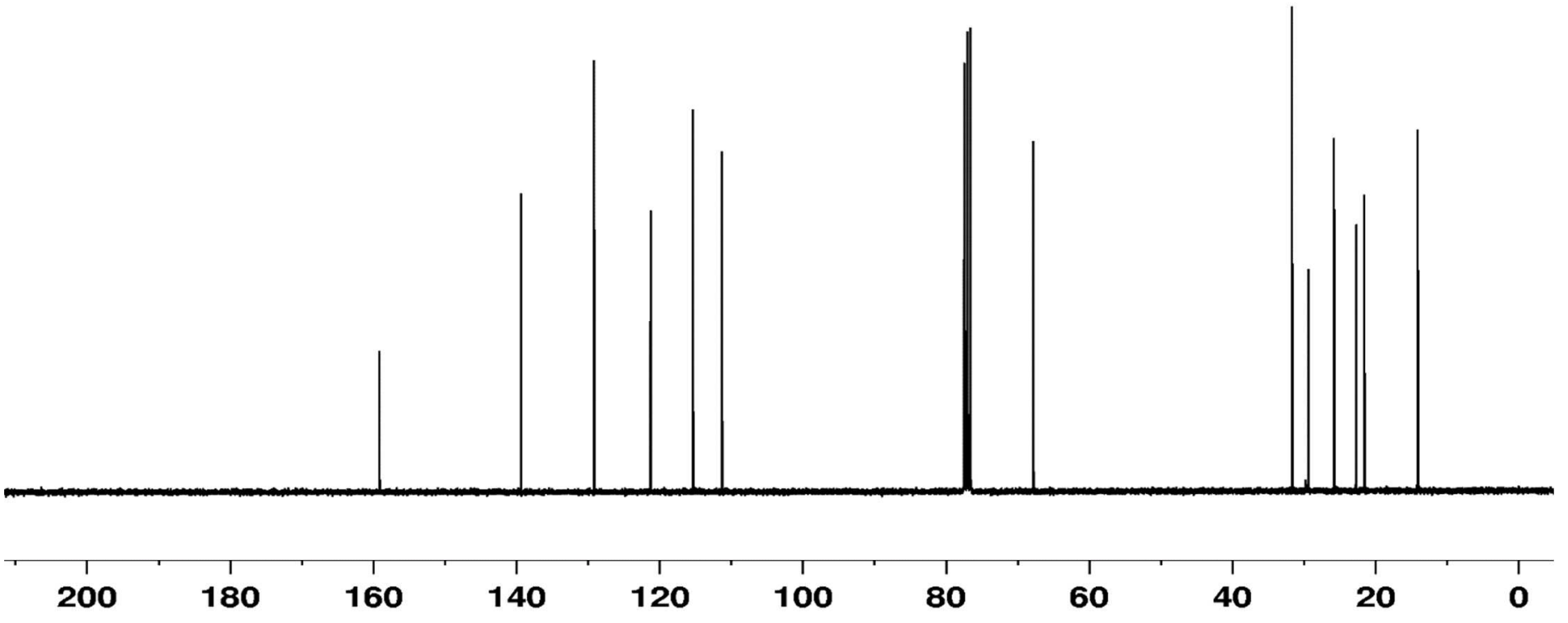



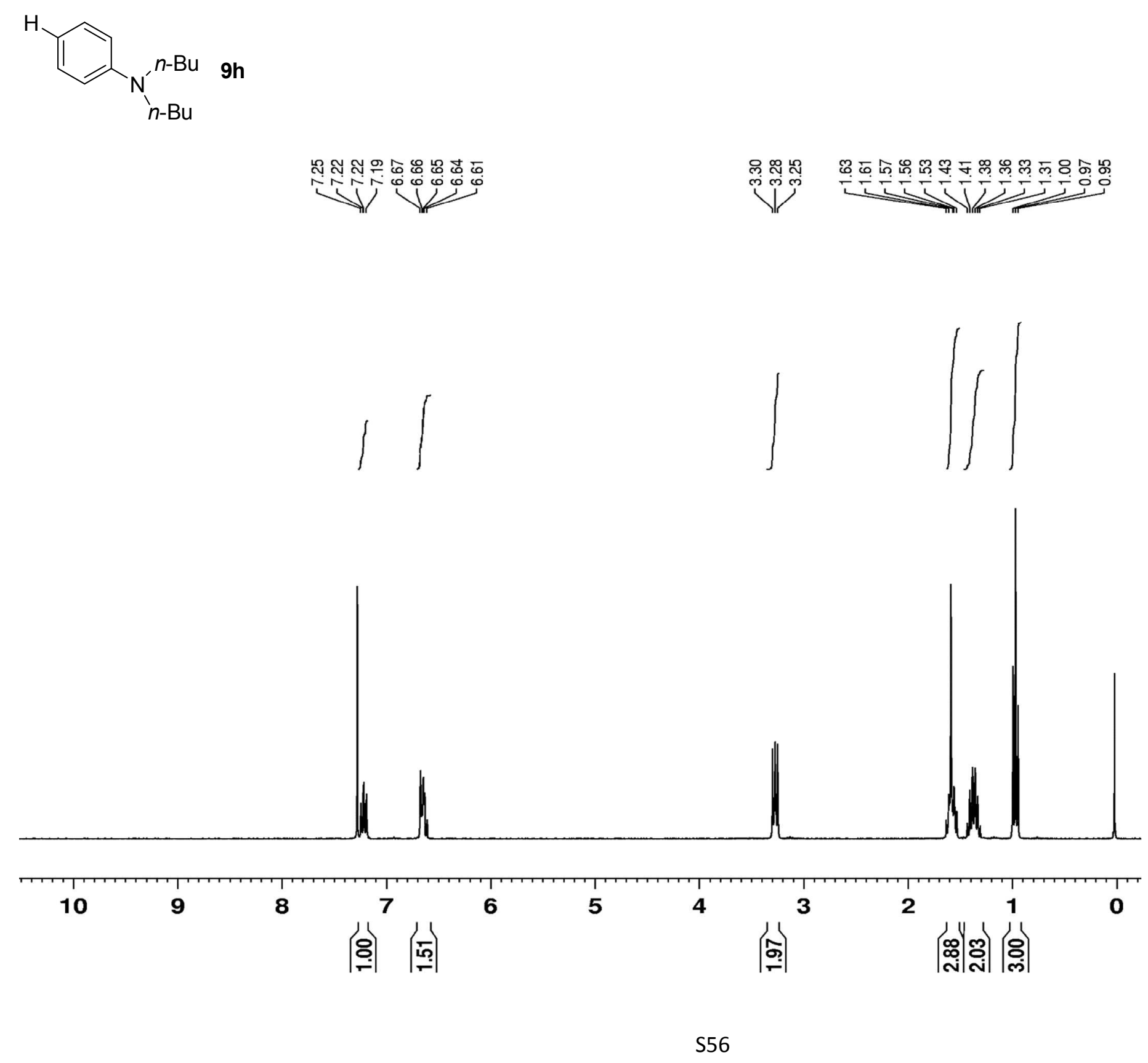
$\underbrace{n-\mathrm{Bu}}_{n-\mathrm{Bu}} 9 \mathrm{~h}$
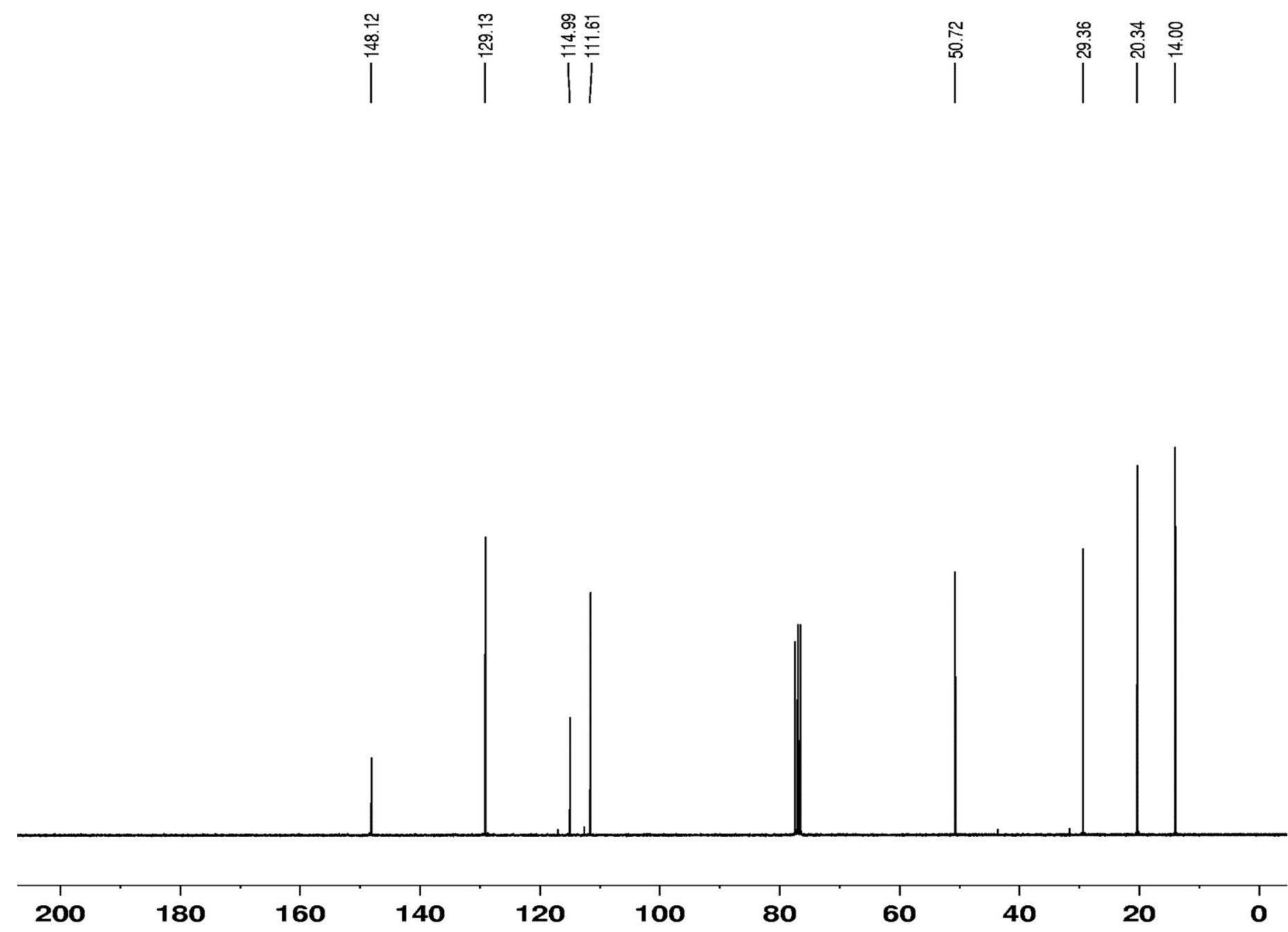


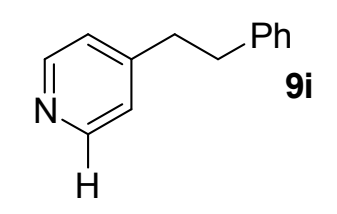

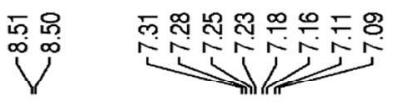

กั่
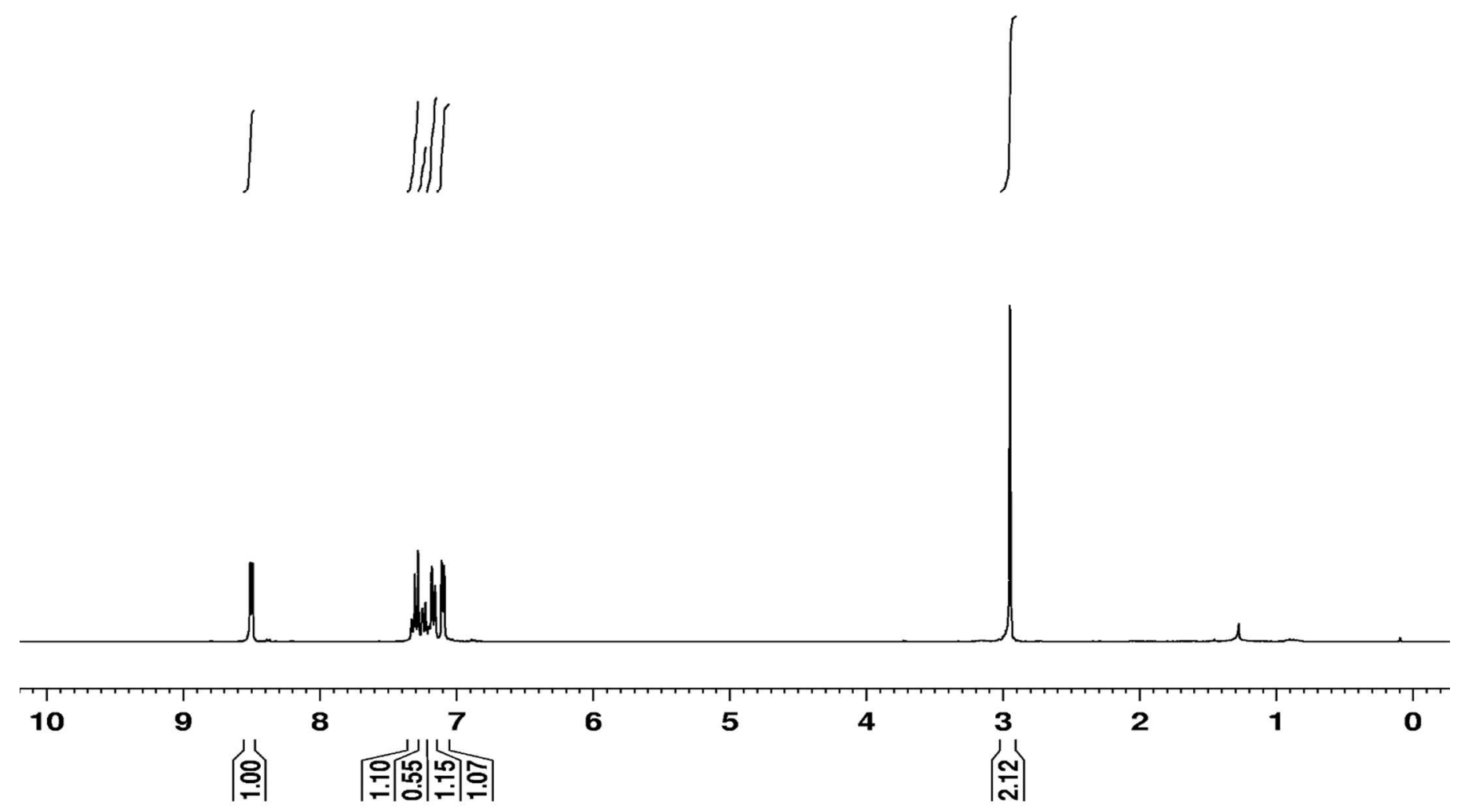


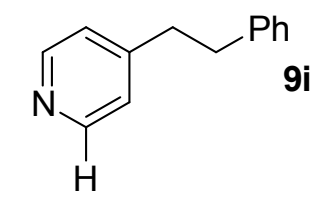

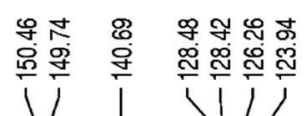

$\int^{\substack{0 \\ \infty}}$

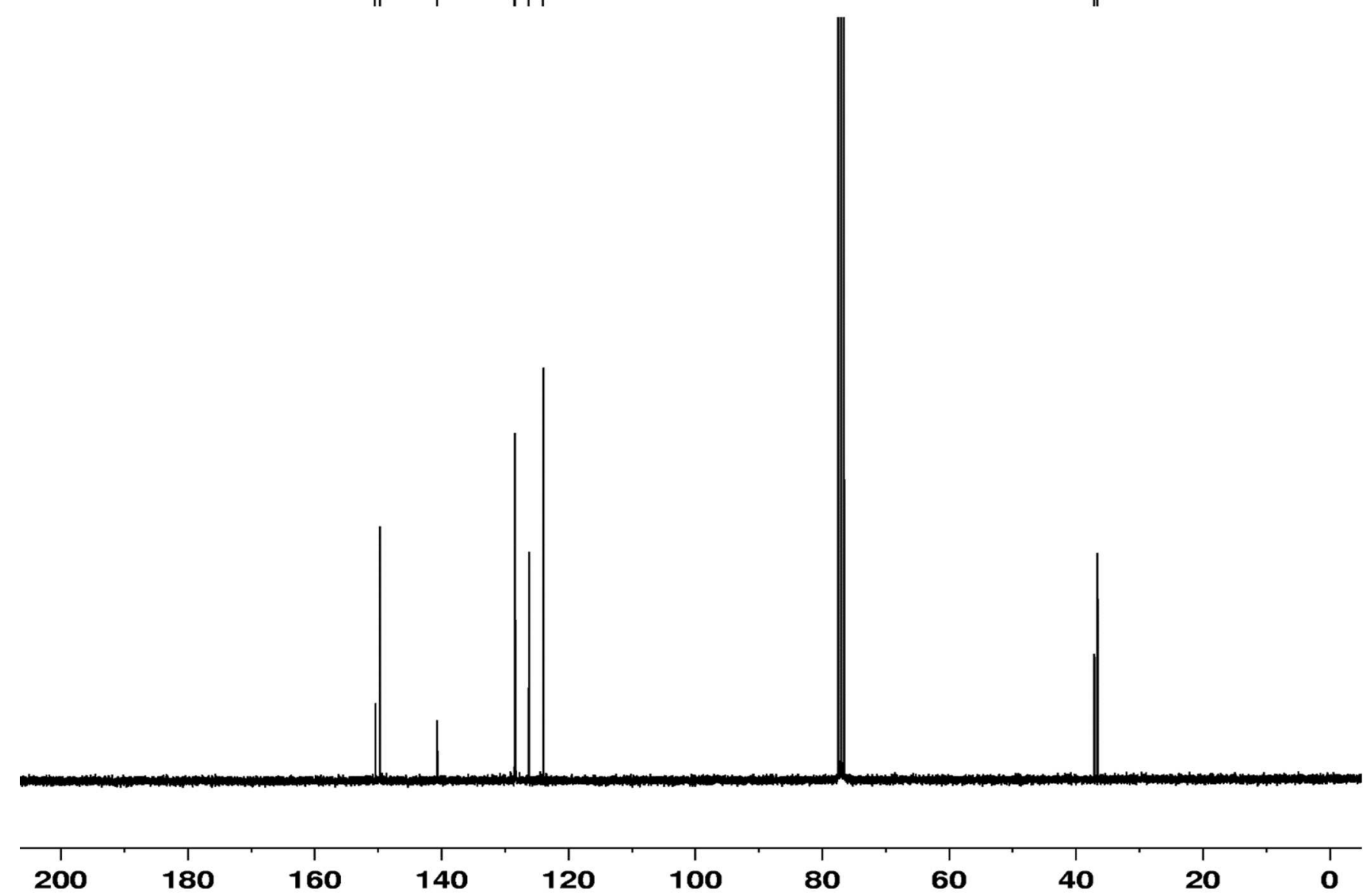

200

180

160

140

20

100

80

60

40

20 


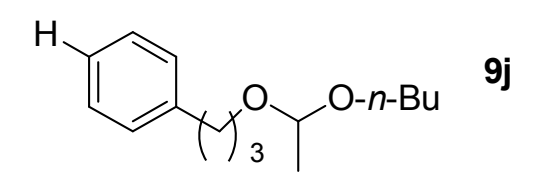

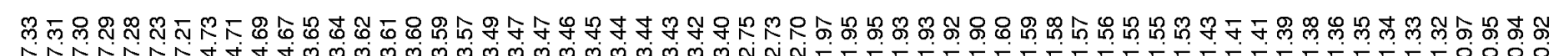
(1)

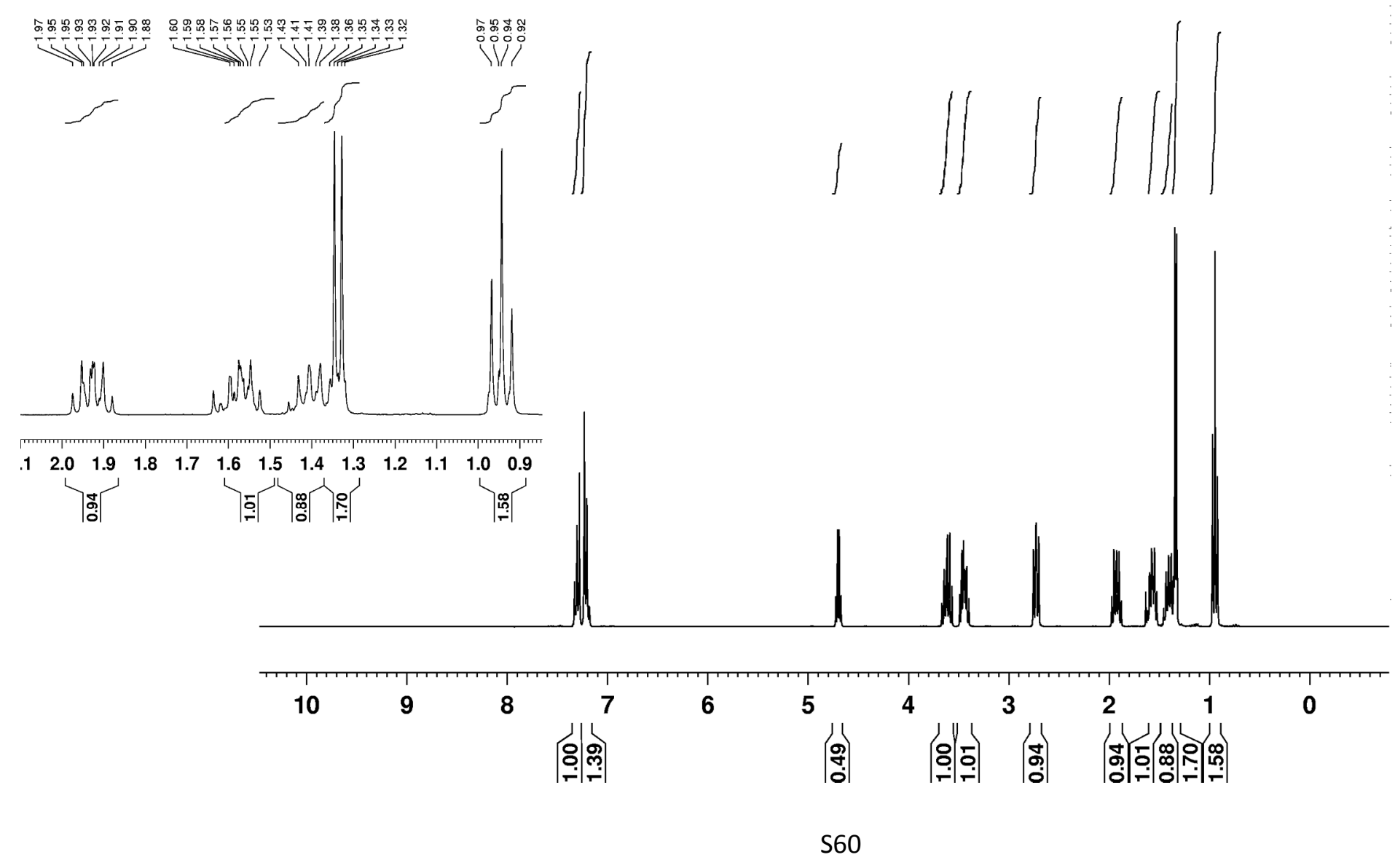



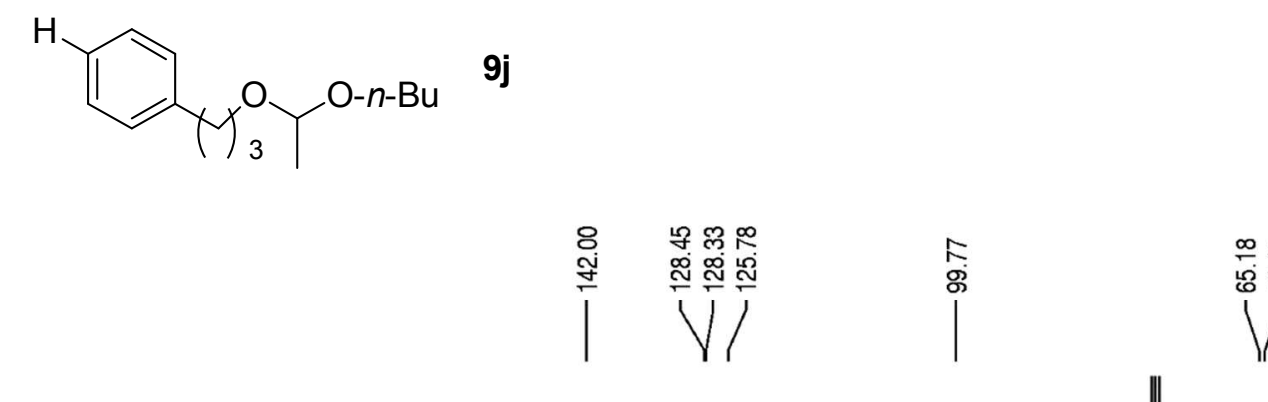

$\infty \stackrel{\infty}{\infty}$

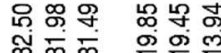

VV

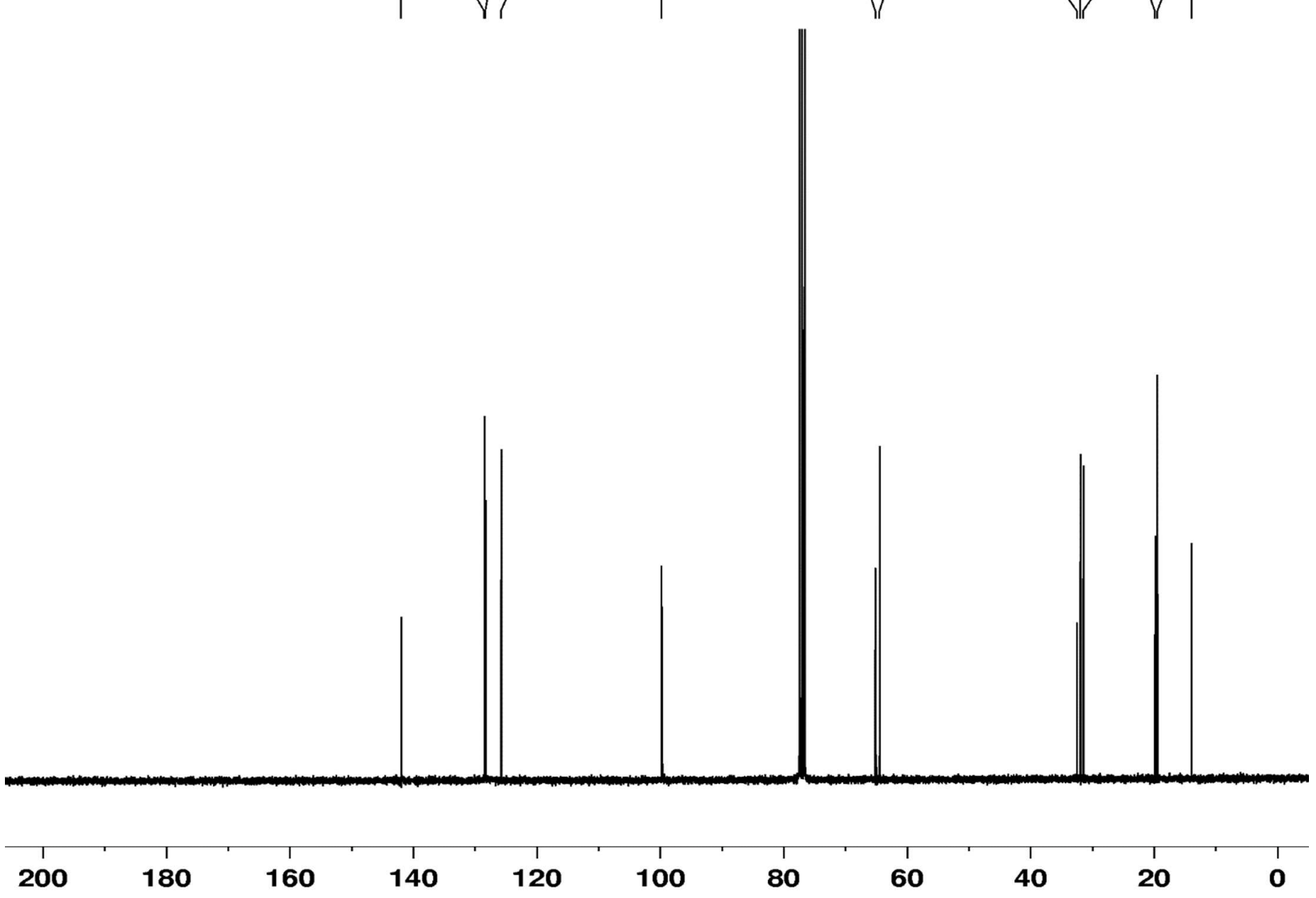


$\mathrm{H}_{3} \mathrm{C} \mathrm{H}_{9} \mathrm{O}_{\mathrm{H}}{ }^{\mathrm{O}}$

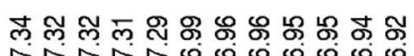

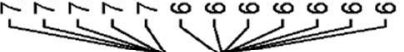

ᄃ요

in

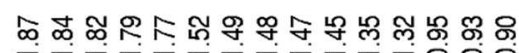
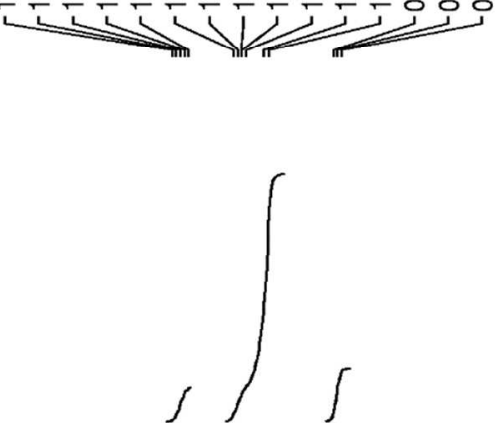

11

f

f

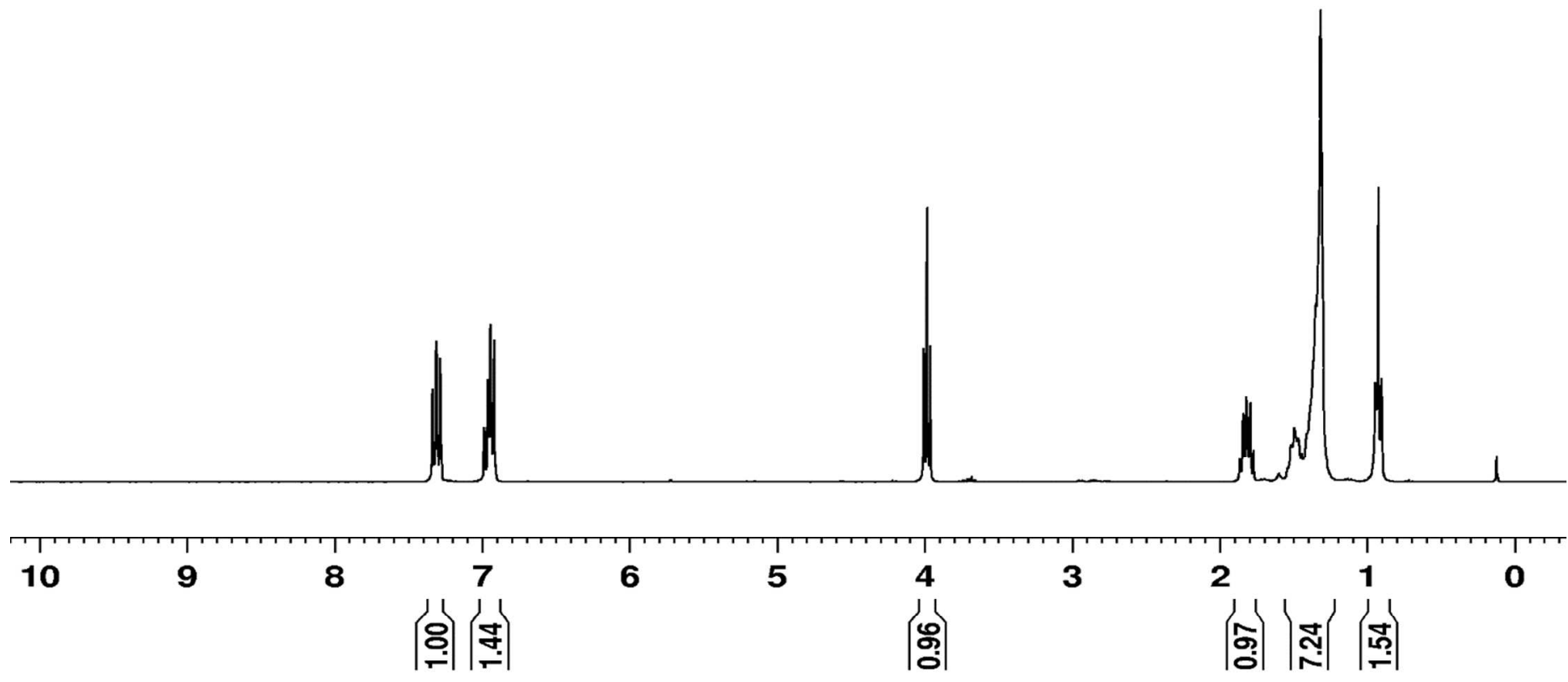




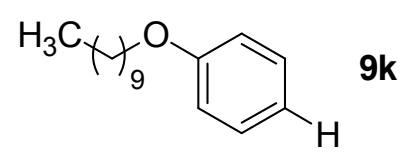
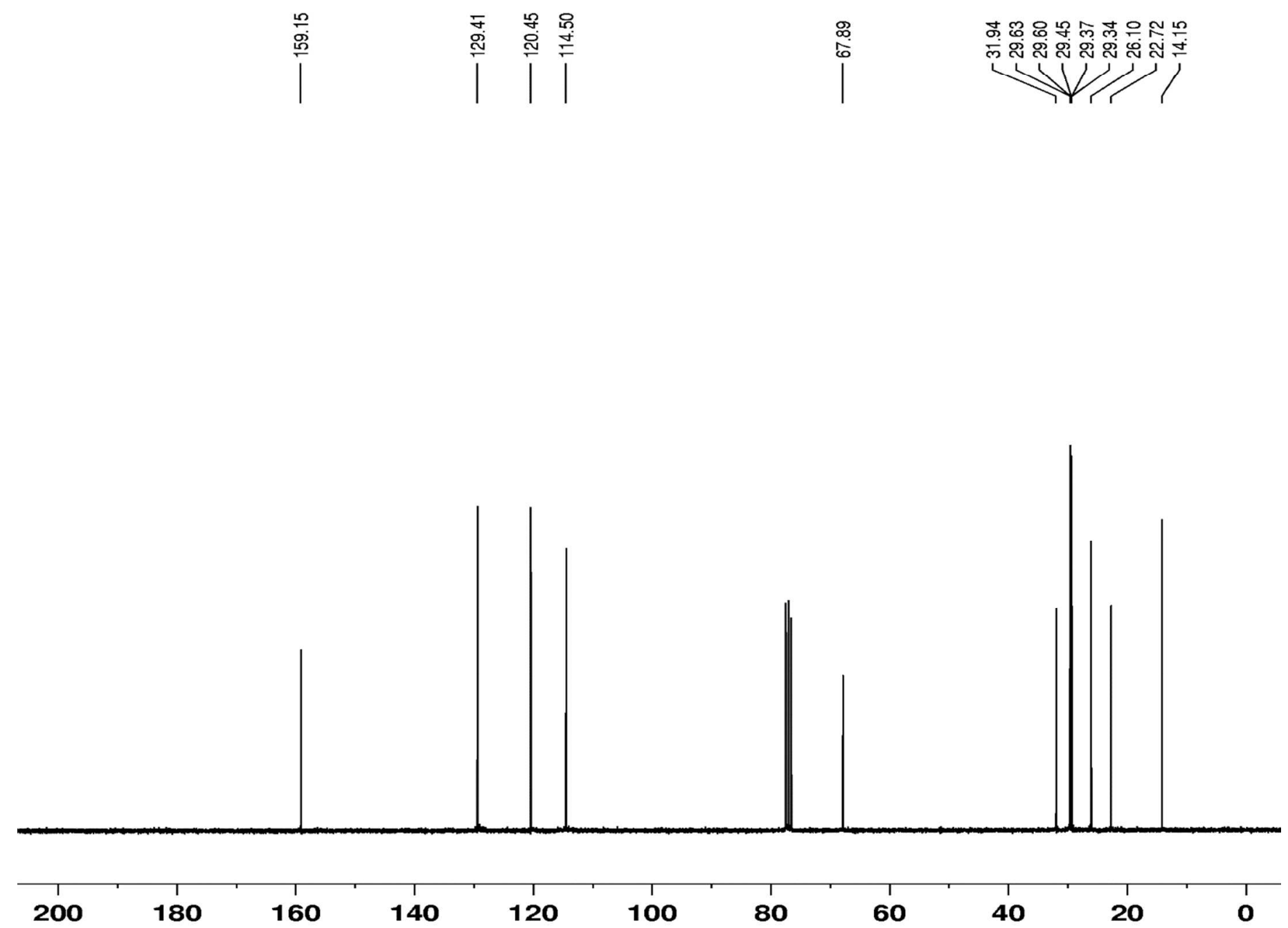

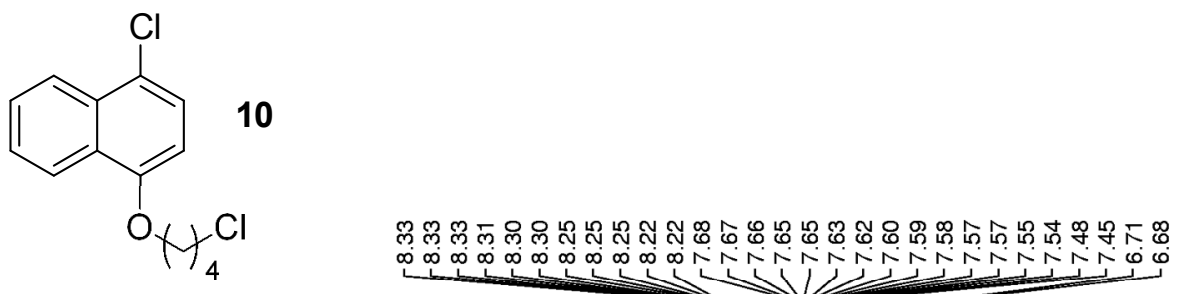

든 Nㅜ다요

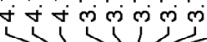

은ㄷㄷ두응ㅇㅇ

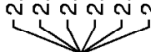

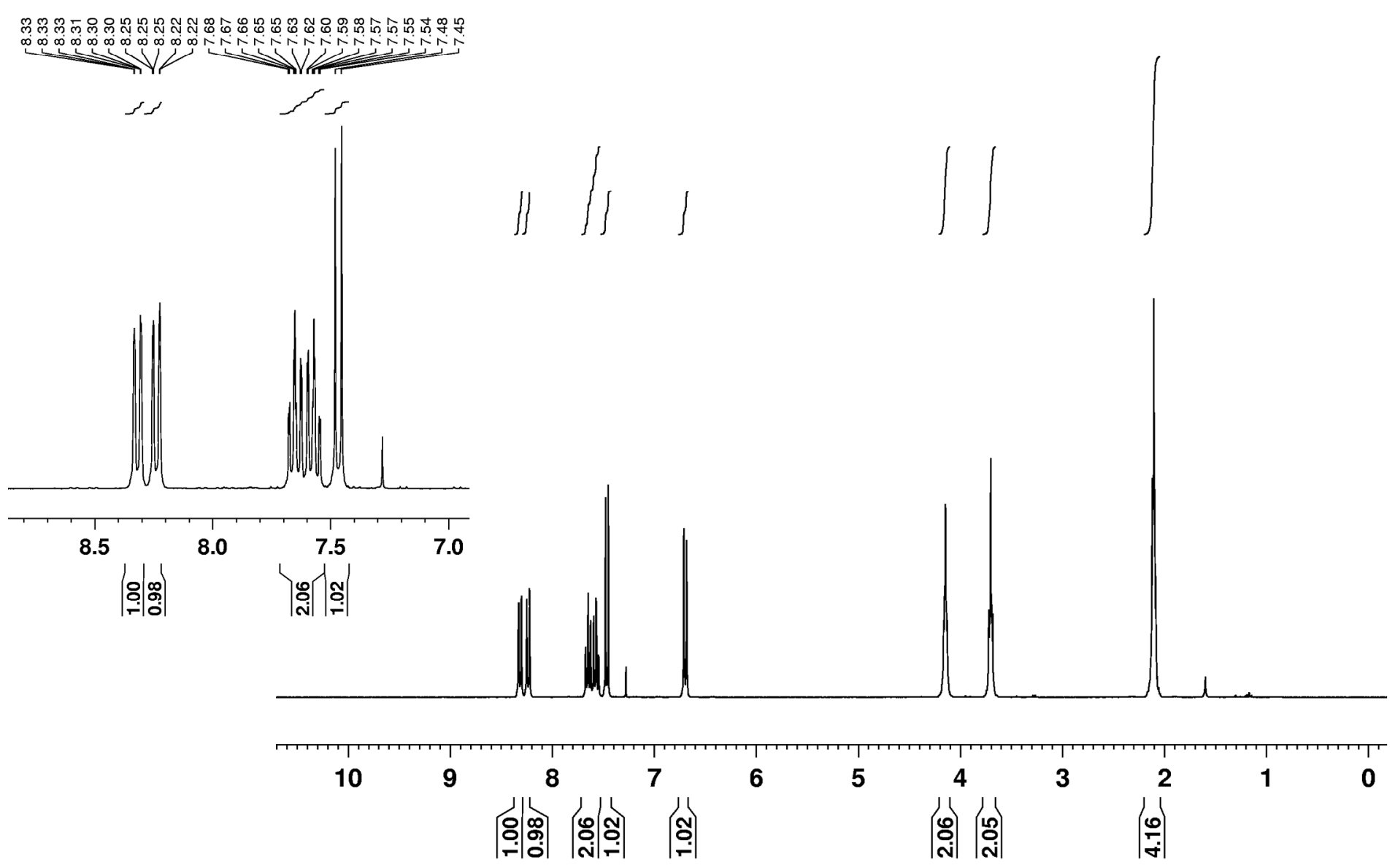




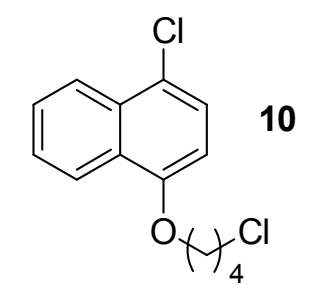

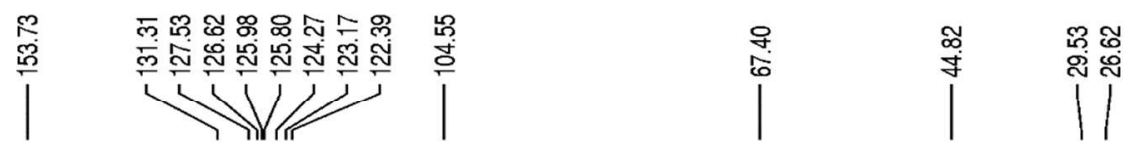

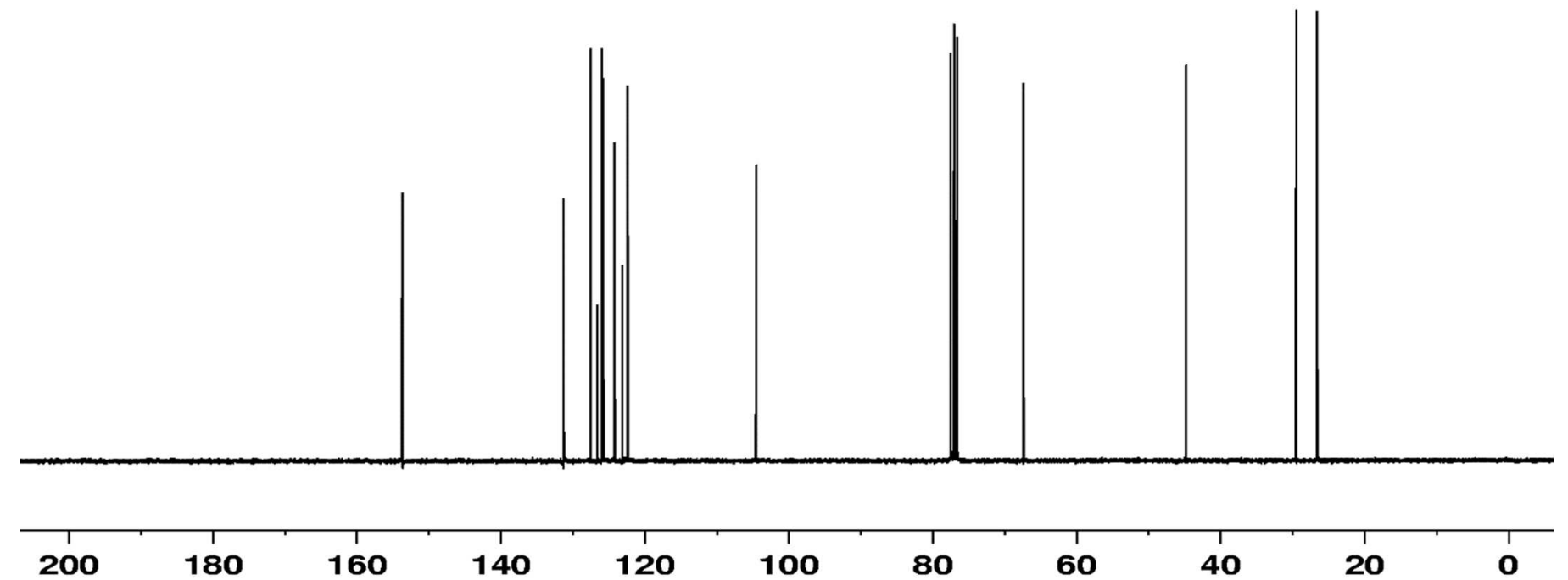


<smiles>CCOc1cccc2ccccc12</smiles>

11

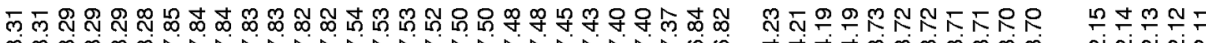

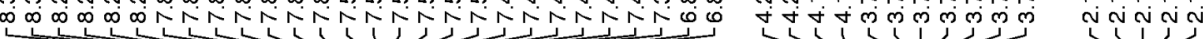
$\gamma_{4}$

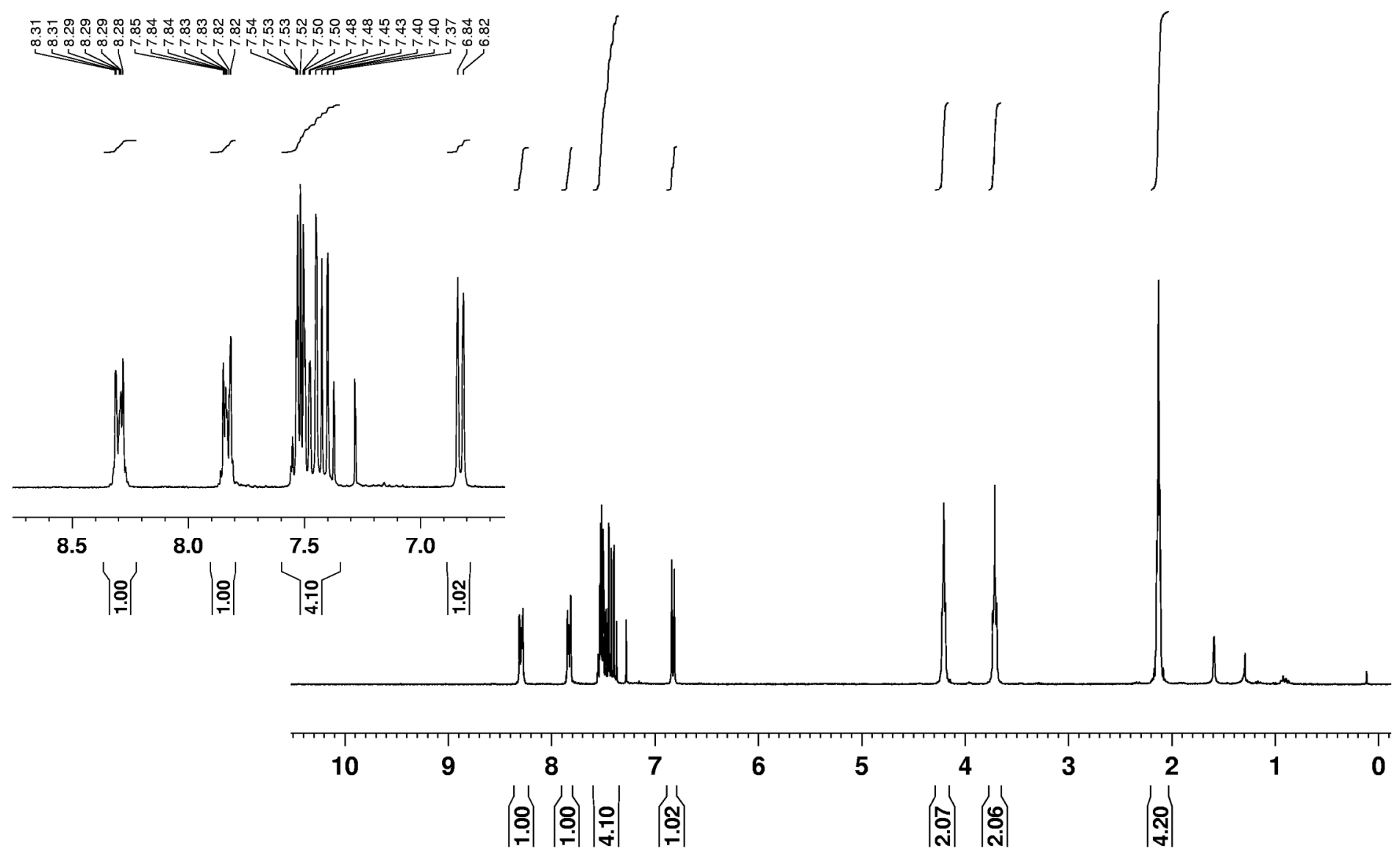



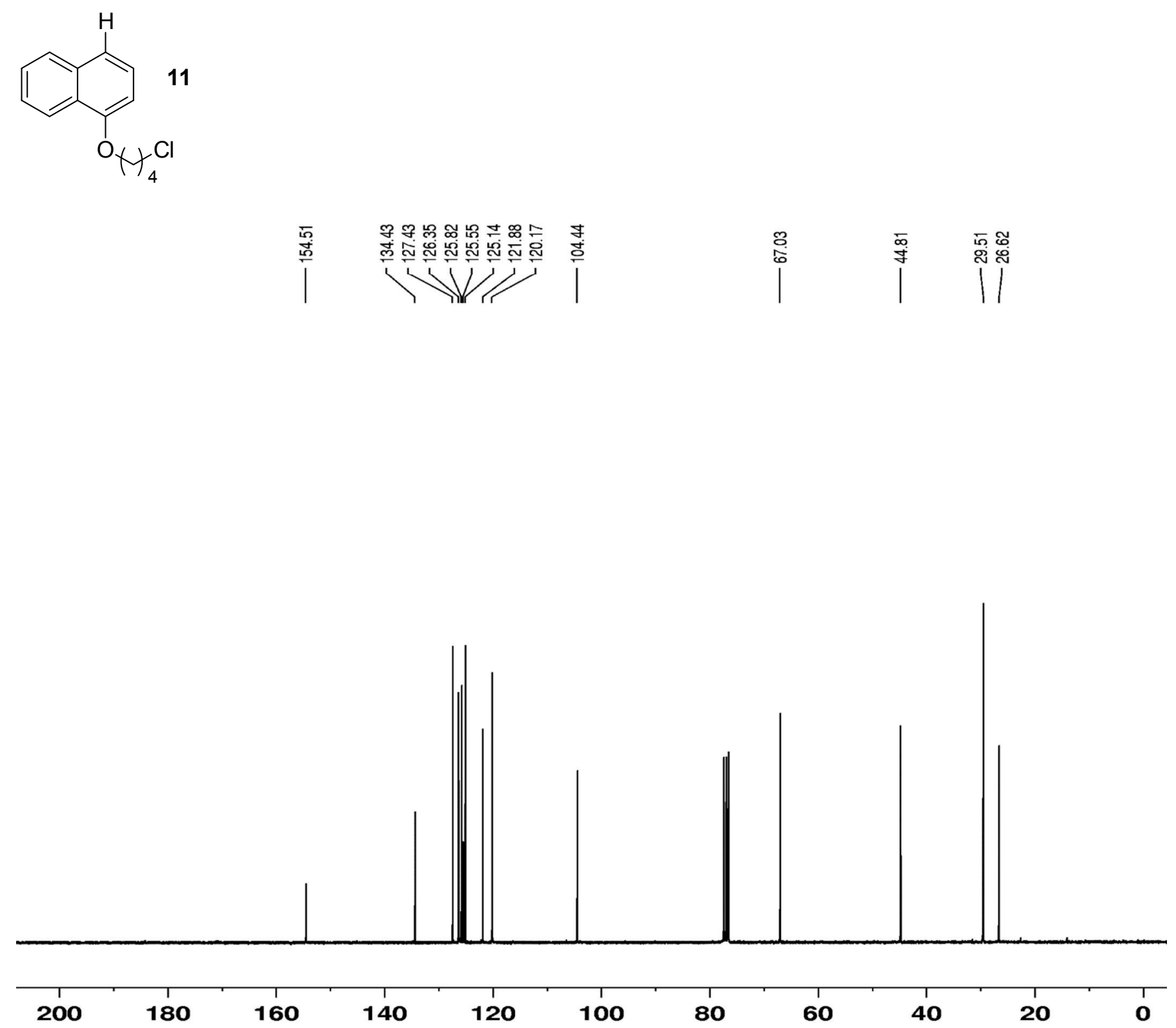

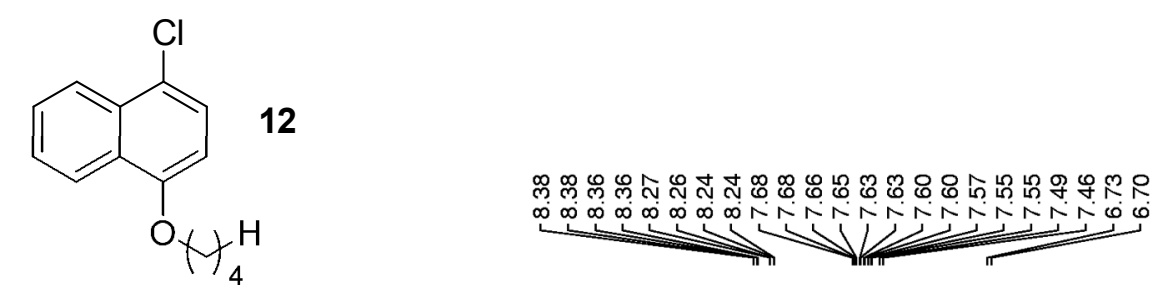

$\underbrace{1}$

$2 e^{2} e^{2}$
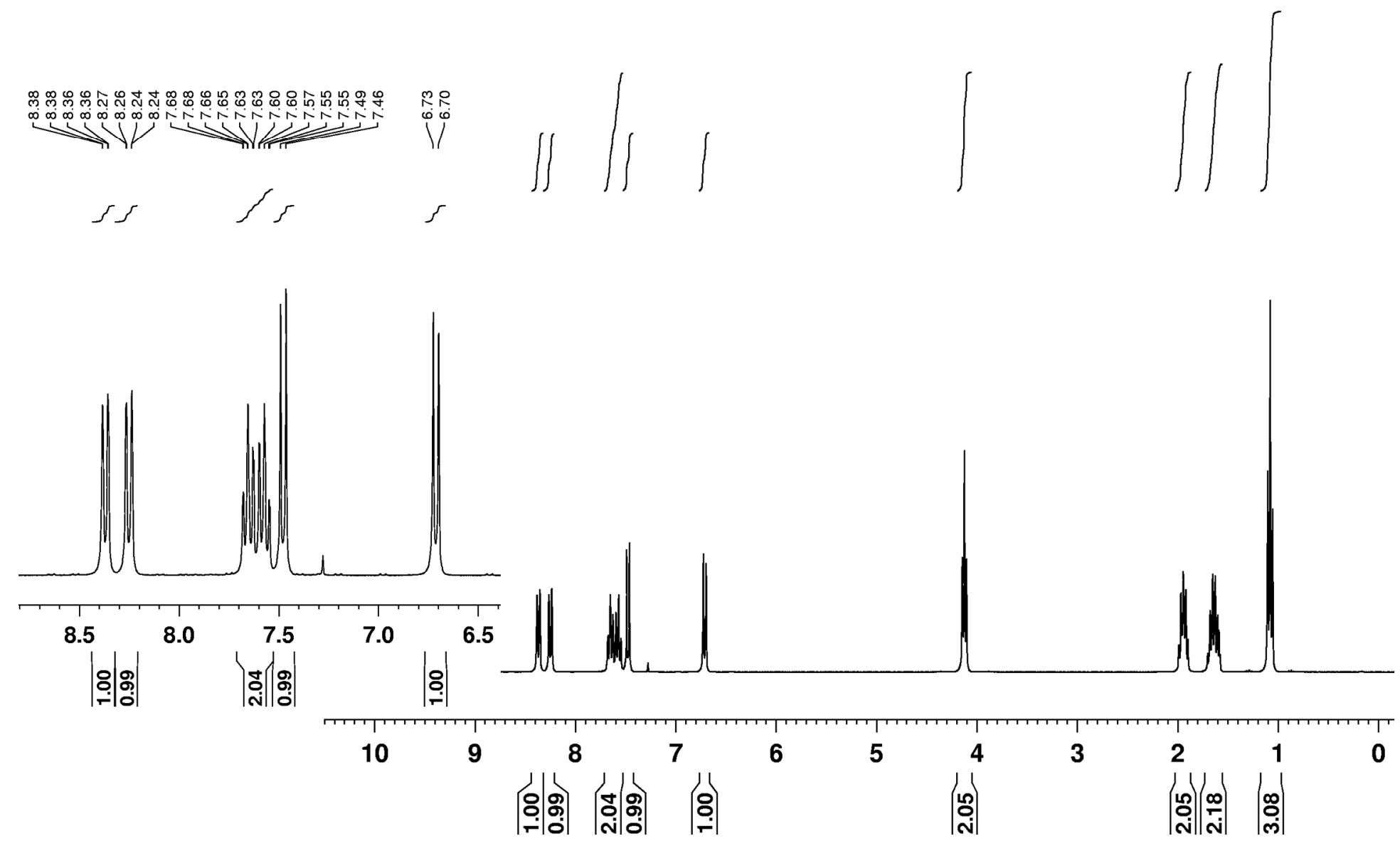

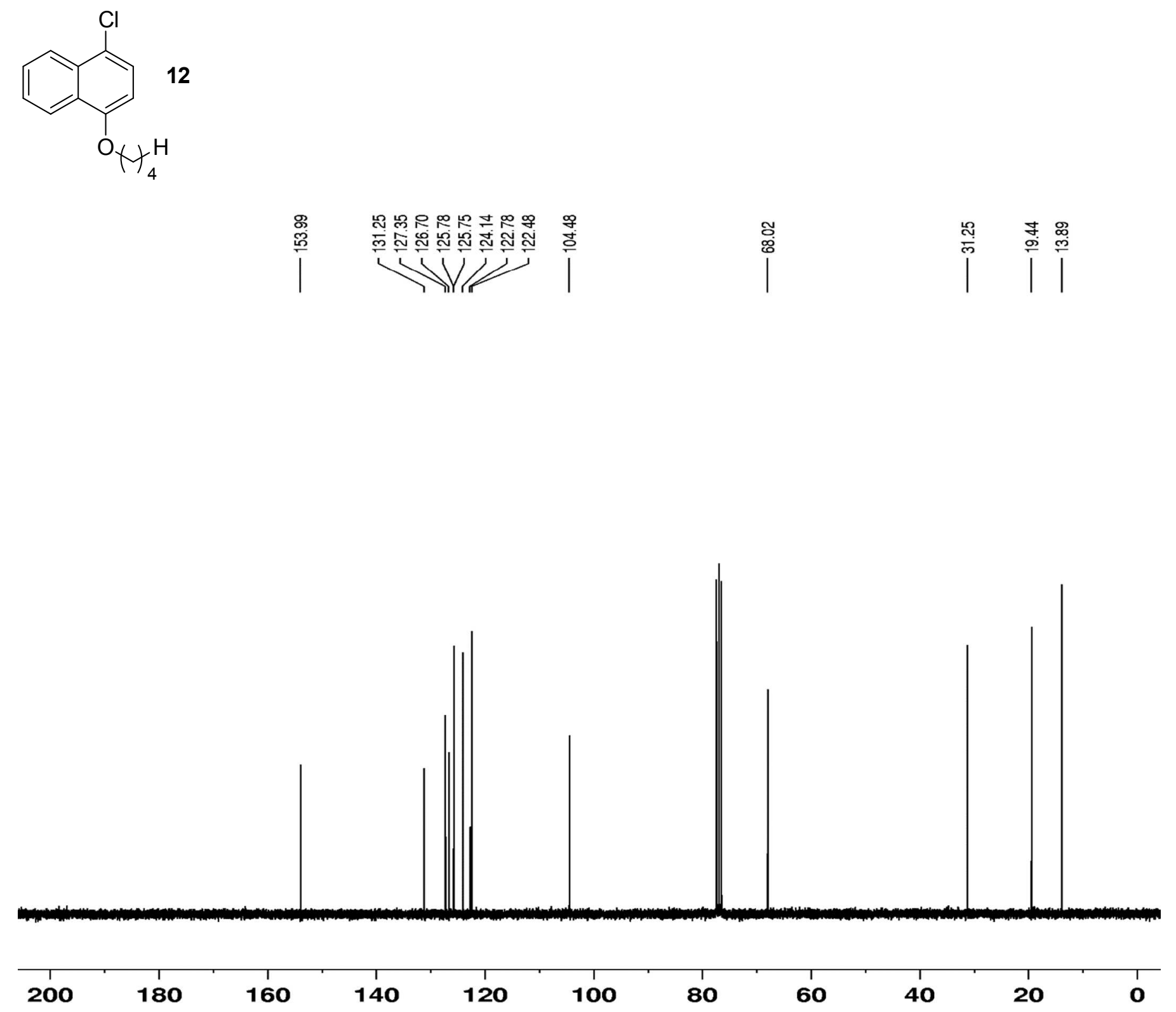


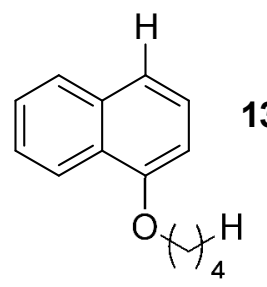

13

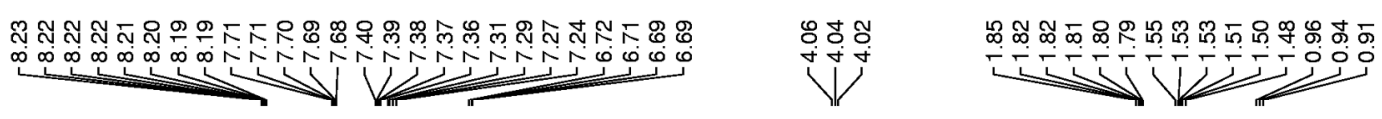

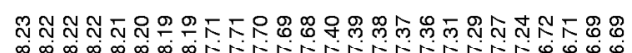

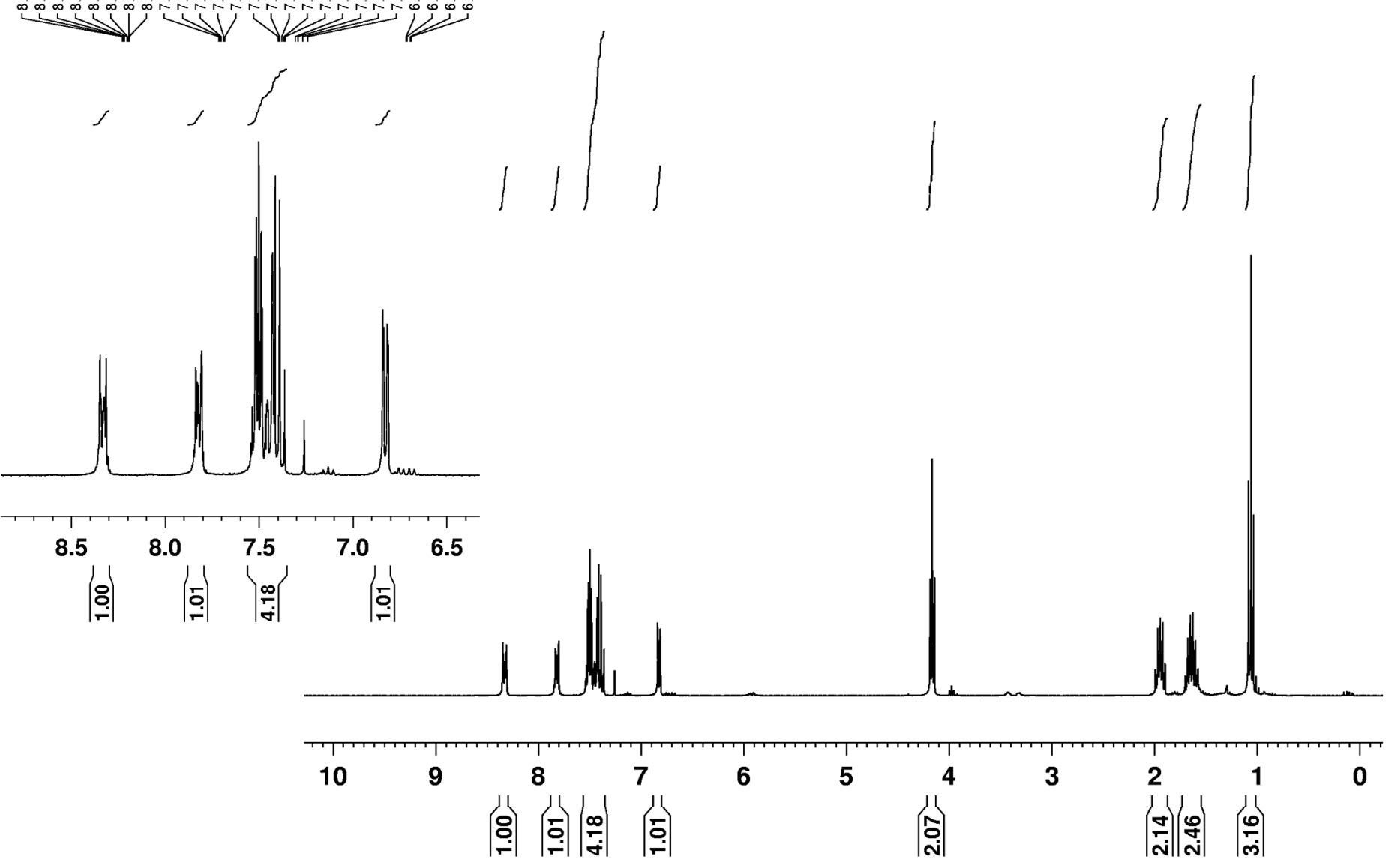



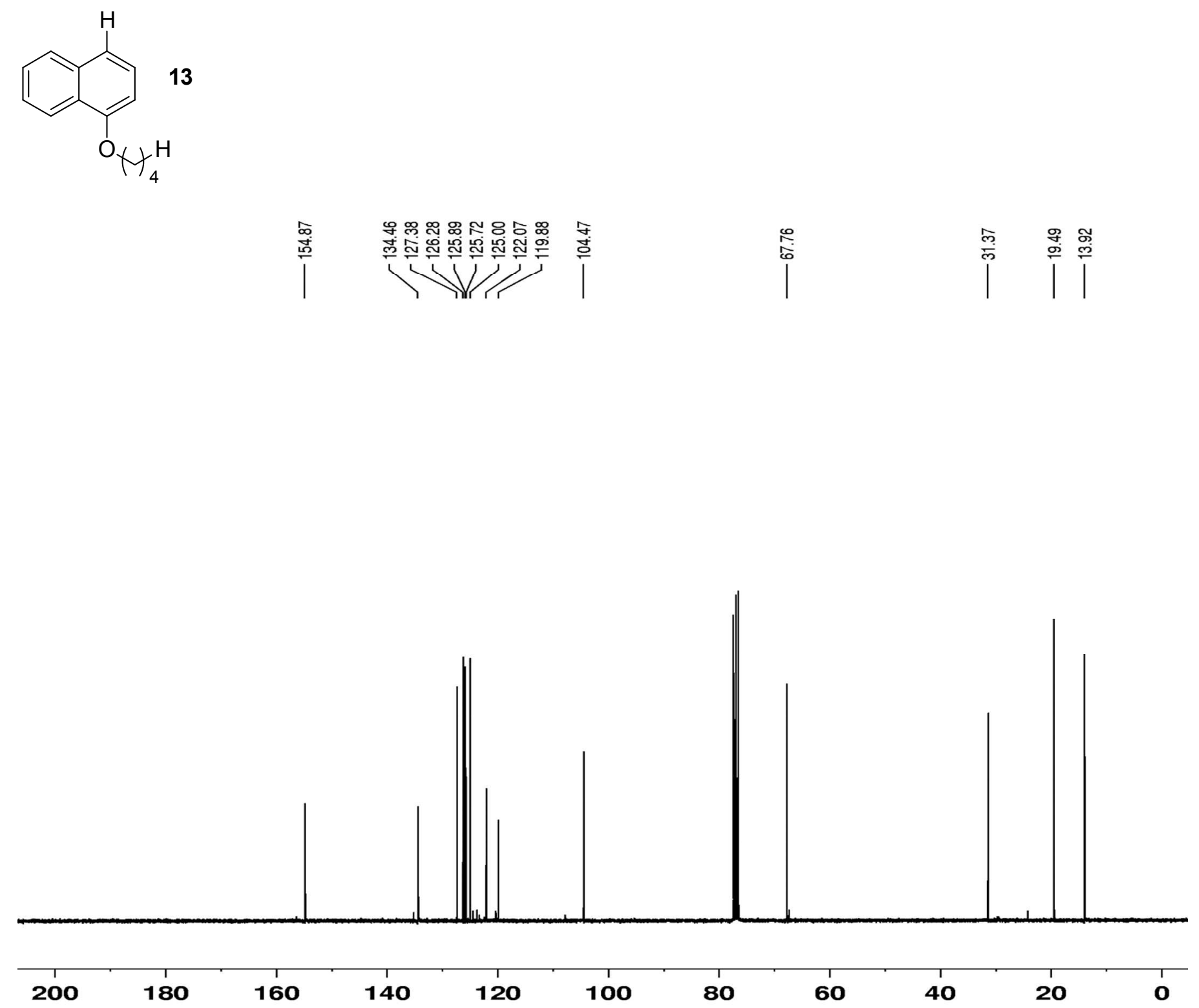